Andrews University

Digital Commons @ Andrews University

\title{
The Relationship Between Financial Incentives and Perceptions of Student Choice at Private Michigan Universities
}

Ndahwa Musa Masanja

Andrews University, ndalahwa@andrews.edu

Follow this and additional works at: https://digitalcommons.andrews.edu/dissertations

Part of the Higher Education Commons

\section{Recommended Citation}

Masanja, Ndahwa Musa, "The Relationship Between Financial Incentives and Perceptions of Student Choice at Private Michigan Universities" (2016). Dissertations. 1603.

https://digitalcommons.andrews.edu/dissertations/1603

https://dx.doi.org/10.32597/dissertations/1603

This Dissertation is brought to you for free and open access by the Graduate Research at Digital Commons @ Andrews University. It has been accepted for inclusion in Dissertations by an authorized administrator of Digital Commons@ Andrews University. For more information, please contact repository@andrews.edu. 


\begin{abstract}
THE RELATIONSHIP BETWEEN FINANCIAL INCENTIVES AND PERCEPTIONS OF STUDENT CHOICE AT PRIVATE MICHIGAN UNIVERSITIES
\end{abstract}

by

Ndalahwa Musa Masanja

Chair: Jay Brand 


\section{ABSTRACT OF GRADUATE STUDENT RESEARCH}

Dissertation

Andrews University

School of Education

\section{Title: THE RELATIONSHIP BETWEEN FINANCIAL INCENTIVES AND PERCEPTIONS OF STUDENT CHOICE AT PRIVATE MICHIGAN UNIVERSITIES}

Name of researcher: Ndalahwa Musa Masanja

Name and degree of faculty chair: Jay Brand, Ph.D.

Date completed: May 2016

\section{Problem}

The rising cost of getting a college or university degree gives millions of students "sticker shock" each year, and paying off student debt has only grown more difficult over time (Liberto, 2012). The College Board, a nonprofit group that runs the SAT exam, indicates that over the past decade, the average annual tuition for community college has risen $40 \%$ to $\$ 3,122$ while the yearly cost at a four-year public university has risen $68 \%$ to $\$ 7,692$. The escalating cost of higher education has inevitably influenced students’ choice of college or university (Felton, 2012). These high tuition costs make a college education unaffordable for some prospective students (Kim, DesJardins, \& McCall, 2009). Escalating tuition and diminishing college affordability pose financial barriers or hardship particularly for the underprivileged student population (Ellwood \& Kane, 2000; 
Kim et al., 2009). In this scenario, students may be looking for colleges with financial incentives in order to minimize student debt. In an effort to understand these trends in the context of private institutions, this study examines the role of financial incentives in students' matriculation choices in selected private Michigan universities.

\section{Method}

This study adopted the correlational approach and the participants were students selected from private universities in Michigan. Simple random sampling was used to choose the universities for the study. These four universities were chosen randomly for the study: Spring Arbor University, Andrews University, University of Detroit—Mercy, and Concordia University-Ann Arbor. The sample consisted of 390 students conveniently selected from the total number of students in those selected institutions. A survey was the main method of data collection. The data gathered was analyzed using SPSS statistics software and tabulated and summarized using appropriate elaborative descriptions.

\section{Results}

The following comprises a summary of the three major findings in this study.

1. In general, mixed results were observed regarding possible relationship between student demographic characteristics and students' perceptions about choice of higher education institutions among students attending selected private universities in Michigan.

2. It was generally observed that there were mixed results about the relationship between personal/family incomes and perceptions of student choice of higher education institution among students at selected private Michigan universities. 
3. It was generally observed that there were mixed results about the relationship between financial incentives (student loans, tuition and fees, scholarships or other financial aid, and grants) and perceptions of student choice of higher education institution among students in selected private Michigan universities.

\section{Conclusions}

Based on the research findings of this study as substantiated by empirical data, the following conclusions were drawn:

1. The first hypothesis was not entirely rejected that there is no significant relationship between student demographic characteristics and Perceptions of Student Choice of higher education institution among students at selected private Michigan universities.

2. The second hypothesis was not entirely rejected that there is no significant relationship between personal/family incomes and Perceptions of Student Choice in higher education institution among students at selected private Michigan universities.

3. The third hypothesis was not entirely rejected that there is no significant relationship between most of the financial incentives (student loans, tuition and fees, and grants) and Perceptions of Student Choice of higher education institution among students in selected private Michigan universities. Specifically, results suggested there may be some relationship between total financial aid and the perceptions of student choice in selected private Michigan universities. 


\author{
Andrews University \\ School of Education
}

\title{
THE RELATIONSHIP BETWEEN FINANCIAL INCENTIVES AND PERCEPTIONS OF STUDENT CHOICE AT PRIVATE MICHIGAN UNIVERSITIES
}

\author{
A Dissertation \\ Presented in Partial Fulfillment \\ of the Requirements for the Degree \\ Doctor of Philosophy
}

by

Ndalahwa M. Masanja

May 2016 
CCopyright by Ndalahwa Musa Masanja 2016 All Rights Reserved 


\title{
THE RELATIONSHIP BETWEEN FINANCIAL INCENTIVES AND PERCEPTIONS OF STUDENT CHOICE AT PRIVATE MICHIGAN UNIVERSITIES
}

\author{
A dissertation \\ presented in partial fulfillment \\ of the requirements for the degree \\ Doctor of Philosophy
}

by

Ndalahwa Musa Masanja

APPROVAL BY THE COMMITTEE:

Chair: Jay Brand

Member: Jimmy Kijai

Member: Sylvia Gonzalez

External: Alexander Odemba

\author{
External: Alexander Odemba
}

Dean, School of Education

Robson Marinho

Date approved 
This dissertation is dedicated to my father Dr. Musa Masanja and my mother Dorcas Masanja who provided moral and financial support toward the completion of my education. 
TABLE OF CONTENTS

LIST OF ILLUSTRATIONS ........................................................................... vi

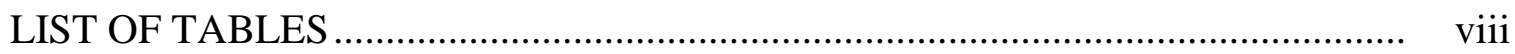

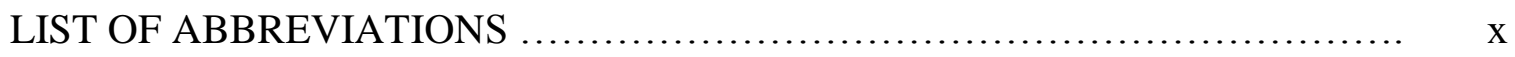

ACKNOWLEDGMENTS ..........................................................................

Chapter

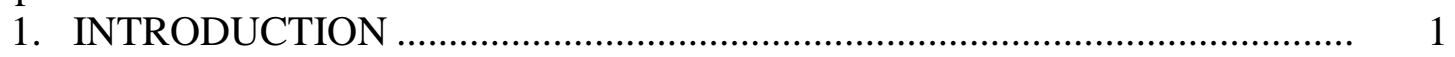

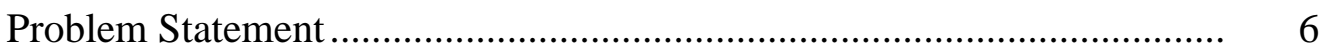

Purpose of the Study ................................................................................ 7

Research Questions ................................................................................ 7

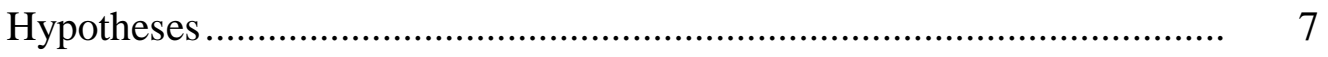

Rationale of the Study ……………………………………………….... 8

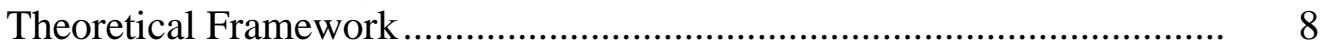

Student Choice in Higher Education.......................................................... 9

Financial Incentive Models for Student Choice in Higher Education ........ 13

Financial Perceptions Model of Student Choice......................................... 17

Significance of the Study ........................................................................ 20

Definition of Terms ........................................................................... 20

Assumption ................................................................................ 21

Limitation of the Study ...................................................................... 22

Delimitation of the Study ..................................................................... 22

Summary …….......................................................................... 22

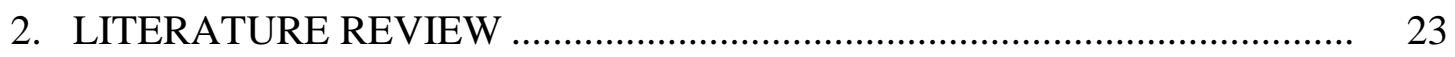

Economic Model ............................................................................. 23

Status Attainment Model ...................................................................... 28

Economic Model Regarding Tuition Cost and Financial Aid ................... $\quad 29$

Information Processing Model.................................................................. $\quad 30$

Traditional Economic Theories on Student Choice ..................................... 31

General Price Theory …………………………………................... 33

Human Capital Theory ...................................................................... 34

Student Choice Models and Financial Incentives in Higher Education ..... 35

Financial Factors Affecting Student Choice in Higher Education.............. 35

Financial Incentives Affecting Student Choice in Higher Education......... 37 
The Impact of Tuition Cost on Student Choice .................................... 38

The Impact of Financial Aid and Scholarships on Student Choice ........... 40

The Impact of Student Loans on Student Choice .................................... 43

The Impact of Government Grants on Student Choice............................ 46

Financial Perceptions Model of Student Choice..................................... 49

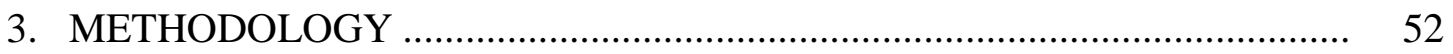

General Introduction ...................................................................... 52

Type of Research .............................................................................. 53

Population and Sample ..................................................................... 55

Definition of Variables ........................................................................ 56

Dependent Variables ................................................................ 56

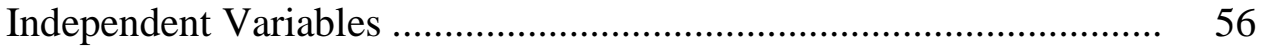

Demographic Variables ................................................................ 56

Personal and Family Income Variables ........................................ 58

Independent Variables ............................................................. 59

Instrumentation ....................................................................... 61

Development of Questionnaire .................................................. 62

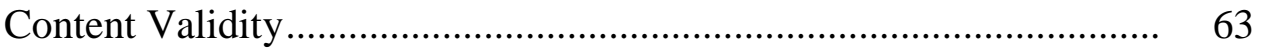

Pilot Study ........................................................................ 64

Reliability Test of the Instrument .............................................. 65

Threats to Internal Validity ........................................................... 65

Factor Analysis ........................................................................ 66

Human Subjects Consideration ........................................................ 67

Procedure ....................................................................... 67

Data Collection ............................................................................... $\quad 70$

Data Entry and Screening ................................................................ 72

Data Analysis .......................................................................... 73

Chapter Summary .................................................................. 74

4. RESEARCH FINDINGS ............................................................... 76

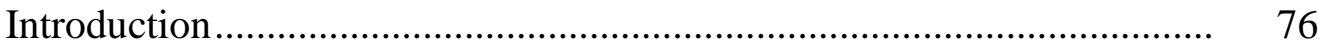

General Findings ................................................................................ 77

Demographic Characteristics of the Participants ............................. 77

Research Question 1 ........................................................................... 79

Research Question 2 .......................................................................... 95

Personal and Family Income on the Perceptions of Expected

Student Choice ............................................................................... 97

Personal and Family Income on the Perceptions of Actual

Student Choice ....................................................................... 100

Research Question 3 ................................................................. 101

Descriptive Statistics of Financial Incentives ................................... 101

Financial Incentives and the Perceptions of Actual Student Choices.. 103

Financial Incentives and the Perceptions of Expected Student

Choice 
Summary of Chapter ………………………………................. 108

5. SUMMARY, DISCUSSION, CONCLUSIONS, AND

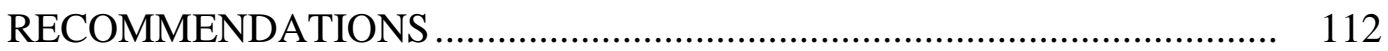

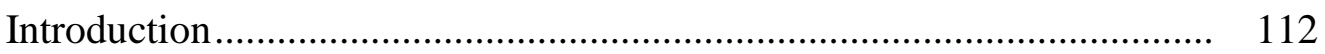

Purpose of the Study ...................................................................... 112

Review of Literature ....................................................................... 113

Research Questions .......................................................................... 114

Summary of Methodology .................................................................. 114

Rationale of Perceptions of Expected and Actual Student Choice ........... 115

General Findings .................................................................................. 117

Key Findings on Question 1 ......................................................... 117

Key Findings on Question 2 ....................................................... 119

Key Findings on Question 3 ...................................................... 119

Discussion .............................................................................. 120

Conclusions ............................................................................... 132

Recommendations for Practice ............................................................ 134

Recommendations for Future Research ................................................ 136

Appendix

A. Recruitment Documents for Students Participants ........................................ 137

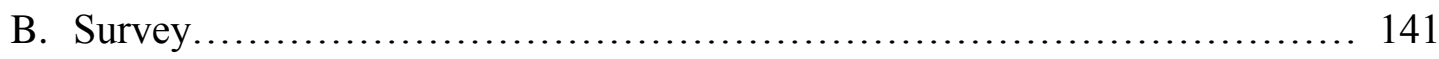

C. IRB Approval Forms ................................................. 147

D. NIH Certificate of Completion............................................. 152

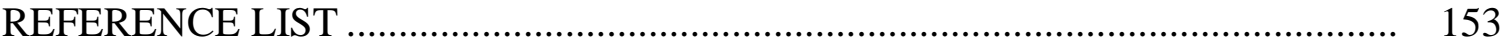

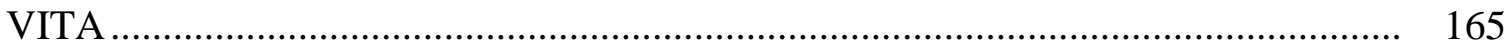




\section{LIST OF ILLUSTRATIONS}

1. Conceptual Framework, the Financial Model for Student Choice ...................... 18

2. Influences on Student College Choice ......................................................... 26

3. The Student Choice Process and Its Important Variables ............................... 33

4. The Financial Perception Model of Student Choice ......................................... 51

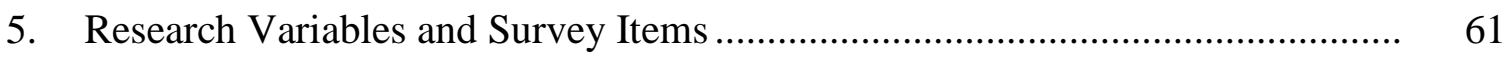

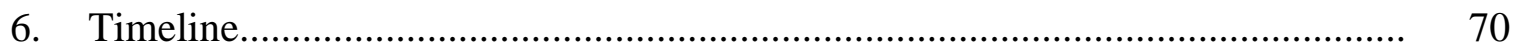




\section{LIST OF TABLES}

1. Prominent College Choice Models ………………............................................ 28

2. Study Participants ................................................................................... 55

3. Kaiser-Meyer-Olkin of Sampling Adequacy and Bartlett's Test of Sphericity.. 66

4. Factor Loading for Principal Component Analysis with Varimax Rotation of Perceptions of Expected and Actual Student Choice.................................... 68

5. Demographic Characteristics of Participants .................................................... 78

6. Relationship Between Age and the Perceptions of Student Choice ................... 81

7. Relationship Between Gender and the Perceptions of Student Choice .............. 83

8. Relationship Between Year of Study and the Perceptions of Student Choice

9. Relationship Between Enrollment Status and the Perceptions of Student Choice

10. Relationship Between Student Origin and the Perceptions of Student Choice ..

11. Relationship Between Degree Major and the Perceptions of Student Choice....

12. Relationship Between Educational Institution and the Perceptions of Student Choice

13. Relationship Between Ethnicity and the Perceptions of Student Choice

14. Descriptive Statistics of Participants' Personal Income and Family Income .....

15. Relationship Between Family Income, Personal Income, Percentage Students, Percentage Parents Pay, and Perceptions of Expected Student Choice........

16. Correlation, Coefficients, P-values, Importance of Family Income, Personal Income, Percentage Students Pay, Percentage Parents Pay, and the Perceptions of Expected Student Choice 
17. Relationship Between Family Income, Personal Income, Percentage Student

Pay, and Percentage Parents Pay Choice …………….................................. 100

18. Correlations, Coefficients, P-values and Importance of Family Income, Personal Income, Percentage Student Pay, Percentage Parents Pay, and the Perceptions of Actual Student Choice

19. Descriptive Statistics of Financial Incentives ................................................. 102

20. Correlations Matrix of Financial Incentives Toward the Perceptions of Actual Student Choice

21. Correlations, Coefficients, P-Values, and Importance of the Financial Incentives Variables and the Perceptions of Actual Student Choice (CATREG)

22. Correlation Matrix of Financial Incentives Toward Perceptions of Expected Student Choice....

23. Correlations, Coefficients, P-Values and Importance of the Financial Incentives and the Perceptions of Expected Student Choice (CATREG) 


\section{LIST OF ABBREVIATIONS}

$\begin{array}{ll}\text { AASCU } & \text { American Association of State Colleges and Universities } \\ \text { ANOVA } & \text { Analysis of Variance } \\ \text { CATREG } & \text { Categorical Regression } \\ \text { CIRP } & \text { Cooperative Institutional Research Program } \\ \text { IRB } & \text { Internal Review Board } \\ \text { MAR } & \text { Missing at Random } \\ \text { MCAR } & \text { Little Missing Completely at Random Test } \\ \text { NABER } & \text { National Bureau of Economic Research } \\ \text { NCES } & \text { National Center for Education Statistics } \\ \text { NIH } & \text { National Institutes of Health } \\ \text { PCA } & \text { Principal Component Analysis } \\ \text { SNK } & \text { Students-New-Keuls }\end{array}$




\section{ACKNOWLEDGEMENTS}

I would like to extend my gratitude to the School of Education at Andrews University for the opportunity to pursue a doctoral degree in higher education. This academic endeavor was intellectually challenging and rewarding with the moral support of a well-qualified teaching staff who provided tireless assistance toward the completion of this degree.

Specifically, I would like to thank Dr. Jay Brand, Chairman of my dissertation committee for offering invaluable advice and guidance; the other committee members, Dr. Sylvia Gonzalez who acted as a content expert and Dr. Jimmy Kijai who was helpful in statistical analysis and interpretation of my dissertation. Moreover, I would like to thank Dr. Jerome Thayer who assisted in statistical analysis.

Finally, I would extend my appreciation to my family for their moral support during the writing of my dissertation. I believe the moral support of my father Dr. Musa Masanja and mother Dorcas Masanja were valuable motivators toward the completion of this study. I cannot repay you fully but may God bless you abundantly. 


\section{CHAPTER 1}

\section{INTRODUCTION}

Leaders and administrators in higher education are naturally concerned about the many important factors influencing where students decide to achieve their undergraduate and graduate degrees (Stark \& Scholder, 2011). Competitive institutions of higher learning understand these factors and how to leverage them, making their recruiting efforts more successful. Understanding the priorities that students and their parents apply to decisions regarding higher education can improve not only the recruiting process but also the efforts of colleges and universities to retain students, particularly students that contribute to diversity and other important institutional strategies (Briggs \& Wilson, 2007; Vossensteyn, 2005).

Understanding the determinants of student choice in higher education has long attracted significant scholarly attention in the West (Cokgezen, 2012). Many investigators have documented the important factors influencing student choice regarding where to earn their undergraduate and graduate degrees (Hearn, 1984; G. Jackson, 1978; Somers et al., 2006; Tierney, 1983). Furthermore, several models to explain student choice in higher education have been developed (Cabrera \& La Nasa, 2000; D. Chapman, 1981; Hanson \& Litton, 1982; G. Jackson, 1978, 1982). All of these models include financial factors such as tuition and fees, student support (grants, loans, family allowance, tax benefits), future earnings, and foregone earnings (Vossensteyn, 2005). However, 
relatively few studies have focused in particular on the financial influences on student choice in higher education at private Michigan institutions.

Several researchers have contributed to the discovery of a broad constellation of factors that influence student choice in higher education. One of the most prominent models was developed by Gregory Jackson $(1978,1982)$ who suggests college choice is a process influenced by preference, exclusion and evaluation. Another study that contributed significantly to student choice in higher education was conducted by D. Chapman. Chapman (1981) described student choice as influenced by student characteristics, external influences, fixed college characteristics and college communication efforts, all of which affect student expectations and choice of colleges. R. Chapman (1984), expounding on student choice research, outlined five stages of presearch activities leading to student choice. Another study by Hanson and Litton (1982) indicated that college choice is influenced by high-school characteristics, student characteristics, personal attributes, public policy, and environment influence on college aspirations. According to Sauder (2008), such pre-choice processes and stage ultimately lead to search and information gathering (affected by media, peers, and college actions), sending applications to colleges depending on college characteristics. Outlining perhaps the most ambitious selection framework, Hossler and Gallagher (1987) proposed that college choice was explained by a complex model featuring the interplay of 10 factors that include saliency of potential institution, cost, parental encouragement, and student aspirations. All these models view student choice as developmental, moving students from a broad conceptual framework of the opportunities in higher education available to them, to enrollment in a single institution, thus these models overlap in a number of 
important ways (Brown, Hernandez, Mitchell \& Turner, 1999; Dixon \& Martin, 1991; Hossler, Braxton, \& Coopersmith, 1989). However, these models do not entirely explain the role of finances or financial incentives in student choice.

In spite of some neglect of the details, researchers have identified finance in general as a significant contributor toward student choice in higher education (Felton, 2012). Relatively early research by D. Chapman (1981) found costs tend to be a factor in students' enrollment decisions. More specifically, Hemelt and Marcotte (2011) estimated an average increase of $\$ 100$ in tuition and fees (in 2006 dollars) would lead to a decline in enrollment of a little more than $0.25 \%$, with larger effects at research universities. These studies confirm the importance of tuition costs, personal or family income, loans, financial aid or available scholarships in student enrollment decisions.

Kim (2012) also confirmed financial aid has a positive impact on enrollment choice. Reflecting the detailed estimates of Hemelt and Marcotte (2011) just cited, Hurwitz (2012) found an additional $\$ 1000$ in institutional grant aid awarded to the typical sampled college increases the probability that the typical accepted student will choose that college by 1.66 percentage points, thus indicating the importance of financial incentives in students' choice of college. A series of evaluations of the HOPE and other state student aid programs suggest that merit-based aid had a disproportionate impact on student choice to attend a state four-year institution, improving the chances of students from white and middle to upper-income families while having little impact on minority and low-income students' college opportunities (Binder \& Ganderton, 2004; Cornwell, Mustard, \& Sridhar, 2006; Dynarski, 2004; Kim, 2012).

Focusing on one form of financial aid—student loans, Mullins (2010) 
demonstrated the impact of students' debt from loans on college choice. Results revealed that students make their enrollment decision based on the potential debt incurred. Callender and Jackson (2008) and Campaigne and Hossler (1998) confirm that the fear of debt represents an important financial constraint, encouraging students to choose colleges based on minimum costs. Similar to the disparate influence of merit-based aid, the impact of student loans on college choice varies depending on students' socio-economic class. Studies show that low-income students perceive educational loans differently than middle and high-income students, because low-income students perceive the cost of higher education as a debt rather than an investment (Callender \& Jackson, 2008).

Additionally, students' (or their family's) income has a significant influence on their college choice decision (Felton, 2012; Perna, 2008). Vossensteyn (2005) describes family income as a "status quo" factor for students, determining whether they evaluate financial incentives in terms of gains or losses. Family income serves as a proxy for family wealth, which partly explains relative sensitivity to the costs and benefits of financial incentives in higher education. Research by Zlomek (2012) supported the notion that prospective students make college choices based on perceived family wealth. When a student perceives his or her family as having higher income, the student is more apt to apply to many different colleges and less likely to ignore any particular school due to its high tuition "sticker price." All these studies provide supporting evidence about the impact of financial factors on student choice.

Despite all the evidence of the impact of finance on student choice, only a few studies have explained the relationship between financial incentives and student choice in higher education. Specifically, no studies have expounded on financial incentives or 
examined the influence of financial incentives on student choice in private Michigan universities. As noted by Gunnes, Kirkebøen and Rønning (2011), most empirical literature on finances in higher education focus on financial aid and the demand side of education (i.e., how financial subsidies can increase enrollment and investment in higher education). This dearth in research points to a need for further study on the subject of financial incentives in higher education.

To further illustrate the limited availability of empirical literature on financial incentives on student choice, most of the studies focused on public universities, while none exist concerning private Michigan universities. For instance, Mullins' (2010) study on debt and decision making, An Evaluation of the Impact of Student Loan Debt on Undergraduate Choice, was conducted in five private and public universities situated in Illinois, Texas, South Carolina, Washington, and Kentucky. In addition, Felton (2012) studied the impact of loans toward student choice with a sample of college students between 19 and 24 years of age at a public university in a Northeast state. Vossensteyn's (2005) descriptive study examined the role of student choice to price responsiveness. None of these studies included Michigan higher education students. Thus, I identified a need to examine the impact of financial incentives on student choice in private Michigan universities to address this deficiency.

In connection with the financial incentives that influence student choice, students have for some time been experiencing difficulties in financing higher education (Kim, DesJardins, \& McCall, 2009). These financial difficulties are due at least in part to the rise in tuition at U.S. higher education institutions. According to Lillis and Tian (2008), the rising cost of obtaining a college education has influenced many students from low- 
and middle-income families to feel that higher education may be priced beyond their means (Vossensteyn, 2005). In turn, student choices have been increasingly influenced by financial incentives or the availability of financial resources (Doyle, 2009), confirming Doolan's (2009) assertion that finances play a crucial role in determining student choice in higher education. To both broaden and refine the relevant knowledge base linking financial considerations to the choice of students and their families regarding higher education, this study investigates how financial incentives influence student choice in private Michigan universities.

\section{Problem Statement}

The rising cost of getting a college or university degree gives millions of students "sticker shock" each year, and paying off student debt has only grown more difficult (Liberto, 2012). The College Board, a nonprofit group that runs the SAT exam, indicates that over the past decade, the average annual tuition for community college has risen $40 \%$ to $\$ 3,122$ while the yearly cost at a four-year public university has risen $68 \%$ to $\$ 7,692$. The escalating cost of higher education has influenced students' choice of college or university (Felton, 2012). These high tuition costs make a college education unaffordable for some prospective students (Kim et al., 2009). Escalating tuition and diminishing college affordability pose financial barriers or hardship particularly for the underprivileged student population (Ellwood \& Kane, 2000; Kim et al., 2009). In this scenario, students may be looking for colleges with financial incentives in order to minimize student debt. In an effort to understand these trends in the context of private institutions, this study examines the role of financial incentives in students' matriculation choices in selected private Michigan universities. 


\section{Purpose of the Study}

The purpose of the study was to investigate the role of financial incentives in the student choice of an undergraduate degree granting higher education institution. In particular, the research investigated the relationship between financial incentives and student choices in selected private universities in Michigan.

\section{Research Questions}

Following are the research questions for this study:

1. What is the relationship between student demographic characteristics and Perceptions of Student Choice of higher education institutions among students at selected private Michigan universities?

2. What is the relationship between personal/family incomes and Perceptions of Student Choice in higher education institutions among students at selected private Michigan universities?

3. Which financial incentives (student loans, tuition and fees, scholarships or financial aid, and grants) are the best predictors of Perceptions of Student Choice of higher education institutions among students at selected private Michigan universities?

\section{Hypotheses}

The research study tested the following hypotheses:

$\mathrm{H}_{01}$ : There is no significant relationship between student demographic characteristics and Perceptions of Student Choice of higher education institutions among students at selected private Michigan universities.

$\mathrm{H}_{02:}$ There is no significant relationship between personal/family incomes and 
Perceptions of Student Choice in higher education institutions among students at selected private Michigan universities.

$\mathrm{H}_{03}$ : There is no significant relationship between financial incentives (student loans, tuition and fees, scholarships or other financial aid, and grants) and Perceptions of Student Choice of higher education institutions among students in selected private Michigan universities.

\section{Rationale of the Study}

The relevance of the study was to identify the relationship between financial incentives and Perceptions of Student Choice in order to inform the institutional policies seeking to increase higher education enrollment at private institutions. Furthermore, the research provides data about students from low- and middle-income families. These data may assist institutions in the development of strategies and plans to make higher education more accessible and affordable to student from all socio-economic classes.

The study provides information for the state and the federal government. The government can use the information to institute financial incentives and tax break programs for students in higher education. In turn, government economic initiatives informed by these results may create financial relief for students and their families.

\section{Theoretical Framework}

This section discusses the impact of financial incentives on perceptions of student choice in higher education, providing a theoretical framework for the study. The first subsection is a general discussion of the models, factors and theories concerning student choice in higher education. The second subsection discusses the financial incentive model 
of student choice in higher education. The third subsection explains the financial perception model and provides a conceptual framework for this study.

\section{Student Choice in Higher Education}

In an effort to understand more of the details about student choice in higher education, D. Chapman (1981) introduced one of the earliest and still most important models relevant to the present investigation. Chapman's model suggests that student choice is influenced by a set of student characteristics in combination with a series of external influences. These external influences can be grouped into three general categories: (a) the influence of significant persons; (b) the fixed characteristics of the institution, and (c) the institution's own efforts to communicate with prospective students. Student characteristics and external influences contribute to and are shaped by students' generalized expectations of college life (D. Chapman, 1981).

Another prominent college choice model extending somewhat beyond the model

elucidated above was developed by Gregory Jackson. According to Jackson $(1978,1982)$, student choice is based on preference, exclusion, and evaluation. Preference involves student aspiration and academic achievement in high school. Exclusion refers to the student's analysis of costs, offerings, admission requirements, and benefits accrued from the institution. The geographical location of the institution and the associated travel expenses are also important factors to be considered according to this model. The last classification component in this model, student evaluation, includes college attributes, potential employment prospects, and the tuition and fees of the institution. Additionally, according to Jackson's model, family background and academic experience play a significant role in the evaluation process. 
In an effort to update these models, Hossler and Gallagher (1987) used later findings from their research as well as other research literature to recognize that student choices to join higher learning institutions are complex, multistage decision-making processes that result in the final decision to attend a particular institution (Hossler, Braxton, \& Coopersmith, 1989; Vossensteyn, 2005). This student choice process involves three broad stages: predisposition, searching and learning about a specific institution and its characteristics, and choosing to join a specific higher learning institution (Vossensteyn, 2005). Although this broad sequence might be crucial to demarcate the overall process, there are other factors, models, and variables to consider in order to fully understand student enrollment choices.

In an attempt to broaden and refine current understanding of available models for predicting student choice, Hossler, Schmit, and Vesper (1999) suggested that student choice models can be grouped into three categories: status attainment models, economic models, and information processing models. Status attainment models, also known as sociological models, refer to a utilitarian decision making process that students undergo in choosing a college, specifically outlining the role of a variety of social and individual factors in the students' occupational and educational aspirations (Chatfield, Lee, \& Chatfield, 2012; G. Jackson, 1982).

The second model category labeled by Hossler et al. (1999) as economic models argues that individuals make college-attendance decisions based on balancing their expected costs and benefits (Yang, 2011). In other words, economic models view college as an investment decision and assume students seek to gain the maximum return on their investment (Hossler \& Palmer, 2008); these models assume that students think rationally 
and make careful cost-benefit analyses when choosing a college (Lee \& Chatfield, 2011). According to Vossensteyn (2005), prospective students make a rational cost-benefit analysis of all financial and non-financial benefits related to institutional choice. Thus, student choice is based on the benefits accrued from the institutions minus their associated costs. As long as the benefits exceed the costs, Vossensteyn posits students will undertake investments in education.

The final category of student choice models established by Hossler et al. (1999), information-processing models, essentially integrate the status-attainment model with the economic model (Chatfield et al., 2012; Hossler et al., 1989). In context, informationprocessing, or combined model incorporates both the rational assumptions from economic models and components of the status attainment models (Lee \& Chatfield, 2011). This combined model assumes that students act according to what they think is expected of them, and they voluntarily or compulsorily adjust to the expectations of others (Vossensteyn, 2005). The model divides the student decision making process into three phases: aspiration development and alternatives evaluation, options consideration and assessment of the remaining options, and final decision (Chatfield et al., 2012; G. Jackson, 1982).

Another theory that addresses student choice of a higher education institution is general price theory. The general price theory assumes that individuals make choices in a way that maximizes utility (Marshall, 1920; Samuelson, 1980). Drawing on the basic principles outlined above, students ought to go to university if they believe that the benefits outweigh the costs and if they have the means to pay for all the associated costs, that is, no liquidity constraint (Vossensteyn, 2005). This theory implies that benefits in 
the form of financial incentives such as loans, financial aid, grants and tax breaks reduce the cost, and therefore these incentives motivate students to choose a particular institution of higher learning.

In connection to this, human capital theory views education as an investment in the productivity of individuals and their environment (Vossensteyn, 2005). This notable and arguably more popular theory known as human capital theory, discusses student choice from a long-run investment perspective, including present and future costs and benefits (Vossensteyn, 2005). According to a general summary of the human capital theory, the attainment of relatively high levels of education (such as associate, bachelor's, master's, professional, and doctoral degrees) or attainment in a particular academic or professional field, plays a crucial role in the overall success of a student (Kaba, 2013). The extended human capital model incorporates the notion that people rely on imperfect information and therefore sometimes seem to make irrational choices (Vossensteyn, 2005). In regard to the knowledge of imperfect information, (potential) students that make decisions based on imperfect information, uncertainty and biased preferences cannot be considered irrational, but rather bounded rational or subjective rational (Menon, 2004).

One might suggest that financial incentives form a common thread linking the student choice models discussed above. However, in order to offer a framework for addressing a number of the complexities surrounding student choice, these models also consider individual differences among applicants in their attempt to explain why students with different background characteristics react differently to financial incentives when making institutional choices (Vossensteyn, 2005). In addition, student choice models 
explore how students' evaluation of the costs and benefits of higher education influence student perceptions of financial incentives related to student choice.

To further integrate these models and their implications for this study, these models provide a theoretical and empirical basis for the role financial incentives play in student choice in higher education. Benefit strategies that involve financial incentive have often been informed by student choice models for higher education. For instance, the economic model has provided theoretical guidance to the development of financial incentive policies for colleges and universities. Institutions and the government have been implementing financial incentive policies so that benefits exceed costs, thus ensuring that students will undertake investments in education (Vossensteyn, 2005).

\section{Financial Incentive Models for Student Choice in Higher Education}

St. John, Asker, and $\mathrm{Hu}$ (2001) reviewed the theory and research about the role of finances in student choice and suggested that relevant research literature reveals that finances are one of the key factors determining student choice in higher education, yet the precise role and methods of influence of finances on student choice has been the subject of much debate. Examining the recent evidence on the effects of students' choices on their prospect of succeeding in college supports the importance of finances in higher education. King (2002) reiterates the need to elucidate just how finances influence student choice; this need rests on the fact that finances may represent the most significant impact on student choice in higher education. Several arguments support this notion.

For one thing, studies have been conducted on student responsiveness to price changes in higher education. These studies found that differences in student responsiveness to prices depend on gender, race, ethnicity, age, family background, and 
other demographic characteristics. For instance, McPherson and Schapiro (1991)

examined the effectiveness of federal and state financial aid to students; St. John (1991) identified factors that can promote minority attendance among high school and college students; and St. John and Starkey (1995) explored the influence tuition charges and the amount of grants, loans, work awarded on within-year persistence by adult undergraduate students (over 22 years of age) enrolled in public and private four-year colleges. These studies show low-income students are more responsive to increased prices than middleor upper-income students (St. John et al., 2001). In another study, Kaltenbaugh, St. John, and Starkey (1999) evaluate the effects of tuition and student aid on persistence by European, American and African American college students. The study presents results that African Americans may be more sensitive to tuition cost increases even when income is controlled.

Initially, according to St John et al. (2001), review of theory and research about the role of finances in student choice, student price responsiveness was measured using a single indicator known as price (tuition or net price). However, this indicator has evolved through the years. Most recent studies reveal other price factors that have a significant influence on student responsiveness to costs in higher education. Studies conducted by DesJardins, Ahlburg, and McCall (1999) examined the temporal dimensions of student departure from a large research university; Paulsen and St. John (1997) assessed the connection between student aid, college choice, and persistence on a sample of students in both public and private universities; and St. John (1991) used two sets of logistic regressions to identify the factors that can promote minority attendance. All these studies suggest that students actually respond differently to various kinds of prices (i.e., tuition 
and fees, room, and board) and subsidies (grants, loans, and work) in their enrollment decisions (Hicks, 2013; St. John et al., 2001). Together, these results suggest that the various constituent elements contributing to the "price" or "cost" of higher education may have differential effects on students' choices regarding where they earn their college or university degree.

Research indicates that student choice is determined by the student's income and his or her family's socio-economic status (Felton, 2012; Kim et al., 2009). As stated by Perna (2008) who used data from descriptive case studies of 15 high schools to examine high school students' willingness to borrow to pay for a college education, the financial/income level of the student or student's family has a sizeable impact on their decision to select a college. Furthermore, the conceptual framework in Figure 1 identifies the significance of loans in student choice. A study conducted by Mullins (2010) examines the extent to which traditional-age undergraduates' student loan debt influences their choices of majors, vocation, and post-college choice. Mullins found a significant positive association between student loans and student choice. Other studies found that students' decisions regarding their choice of college were significantly influenced by concerns over future debts (Felton, 2012; Mullins, 2010).

In connection to financial incentives, fixed college financial characteristics like tuition and fees, scholarships, and financial aid influence student choice in higher education (Felton, 2012; King, 2002). Hemelt and Marcotte (2011) used data on all U.S. public four-year colleges and universities from 1991 to 2006 to assess the impact of tuition increases on enrollment at colleges and universities. The study revealed that a $\$ 100$ increase in tuition and fees causes a decline in enrollment of about $0.25 \%$ with a 
larger effect at research universities. Doyle (2012) examined the politics of public colleges and state financial aid supports the notion that tuition and fees, scholarships, or financial aid are paramount in choice of higher education among prospective students and their families. These studies are a clear indication of the impact of financial characteristics like tuition and fees, scholarships, and financial aid in student choice.

McDonough, Calderone, and Purdy (2007) adding to the discussion of financial incentives, examined grant-aid programs in 11 states and their effects on students' college choices. The research suggests government support in terms of grants and tax breaks plays a crucial role in student choice in higher education. Substantial empirical evidence exists to suggest that grants are largely responsible for massive enrollment growth in higher education, particularly the large increase in the enrollment of low income and other under-represented students. Hurwitz (2012) used admission and financial aid data to access student plans to attend college in the fall of 2009 from 30 anonymous post-secondary institutions. The study revealed that the dissolution of government grants such as the Pell grant would increase the likelihood that students would decline admission offers from colleges they would have preferred if finances were a non-issue. Furthermore, research evidence suggests grants increase the probability that students will choose the aid-granting college over his or her first choice by as much as three percentage points.

In conclusion, over two academic years (2003/04 and 2004/05), Briggs and Wilson (2007) studied 1,400 students enrolled in two undergraduate disciplines to explore the influence college information and the cost of attendance on undergraduate choice at six universities in Scotland. Briggs and Wilson identified financial incentives as 
affecting student choice. Furthermore, Yang (2011), evaluating the impact of financial aid on learning, career decisions, and employment among Chinese college students, found that financial incentives influence student choice. Kim (2012) undertook a study between the 1992 and 2000, that explored how state aid policies differentially affected students' post-secondary enrollment choices factoring in their family income and race/ethnicity. Kim demonstrates that there is a clear and consistent gap in college choice for students who are from different income and race/ethnic groups. Similarly, a report by Kinzie et al. (2004) analyzed how student and family characteristics, institutional admissions policies and practices, and public policies have influenced the manner and timing of students' college-choice decisions. The report also agrees that financial incentive factors have a significant influence over student choice in higher education.

\section{Financial Perceptions Model of Student Choice}

In order to develop a strong theoretical and conceptual framework that can be applied to this study, the study by Vossensteyn (2005) provides a strong theoretical and conceptual background by examining the perception of student price-responsiveness. This was a study that examined a behavioral economic exploration of the relationship between socio-economic status, perceptions of financial incentives, and student choice. Vossensteyn (2005) developed an empirical model that captures information on student background characteristics (independent variables), students' perceptions of financial incentives (intermediary variables) and students' observed study-related choices (dependent variables). Figure 1 provides a conceptual frame work of a simple financial perceptions model of student choice in higher education. 


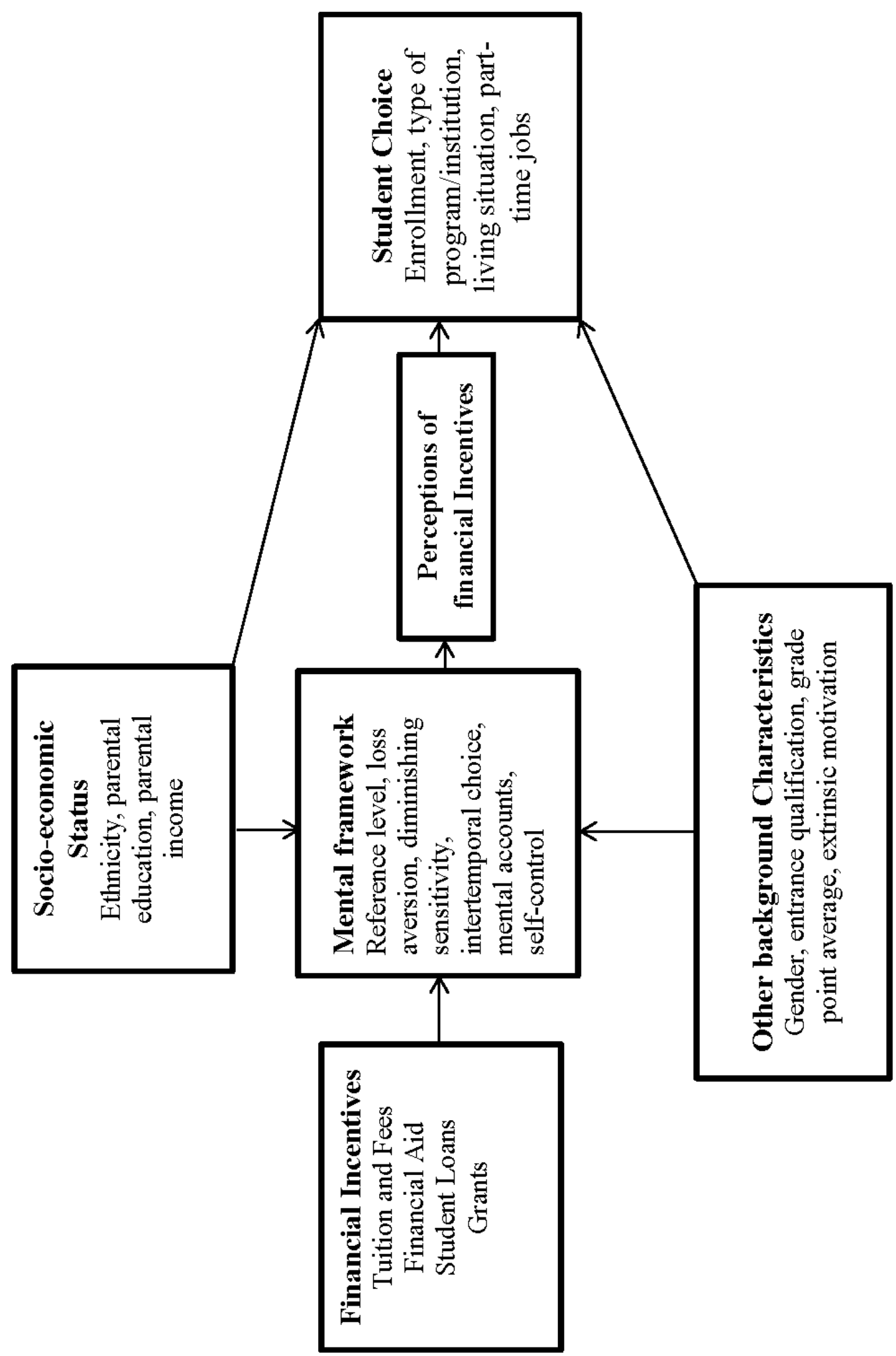

Figure 1. Conceptual framework, the financial model for student choice. Developed by Vossensteyn (2005, p. 182). 
As portrayed in Figure 1, the background characteristics, perceptions, and observed choices are operationalized into variables that are then quantified by information in a (survey) database with information on individual students. According to Vossensteyn (2005) the empirical model is tested with statistical methods that address the relationship between the specified independent, intermediary, and dependent variables. This test is carried out on the basis of an integrated model incorporating the above variables. Bivariate statistical tests were performed and multiple regression analysis was used, as well as structural equation modeling (Vossensteyn, 2005).

Three specific predictions for this study can be derived from Vossensteyn's (2005) financial perception model on student choice. First, there should be significant relationship between student demographic characteristics and perceptions of student choice of higher education institution among students at selected private Michigan universities. Second, there should be significant relationship between personal/family incomes and perceptions of student choice in higher education institution among students at selected private Michigan universities. With regard to potential interactions between parental income or parents' education and ethnicity, the theoretical framework suggests that foreign or out-of-state students are more sensitive to financial incentives than in-state students but, due to the reference level effects, thought to be less for in-state students with higher educated or higher income parents.

A final prediction is that there will be a significant relationship between financial incentives (student loans, tuition and fees, scholarships or other financial aid, grants, and tax breaks) and perceptions of student choice of higher education institution among students in selected private Michigan universities. These predictions are based on 
extensive studies that suggest that financial incentives directly or indirectly influence student choice (Hemelt and Marcotte, 2011; Hicks, 2013; Sahin, 2004). The following additional implication will also be tested: the behavioral economic perspective suggests that students from lower socio-economic backgrounds are likely to value financial incentives/consequences related to student choice differently than students from higher socio-economic backgrounds (Texeira, Johnson, Rose, \& Vossensteyn, 2006).

\section{Significance of the Study}

The results of this study can inform student recruitment strategies and enrollment efforts in higher education. In particular, the study highlights which financial incentives have the most influence on students' decisions to enroll at colleges or universities. Additionally, university administrators can use the findings to increase accessibility and affordability of higher education for students. Administrators may derive approaches to formulating financial policy from these data that provide financial incentives to all students.

This research contributes to the body of knowledge in that scholars and other researchers may be able to identify the financial incentives that influence student choice in higher education. Researchers may be prompted to further investigate financial incentives and their detailed effects on student enrollment in higher education.

\section{Definition of Terms}

Financial incentives: Financial factors or arrangements that directly influence student behavior often administered through governmental or institutional arrangements. These include tuition and fees, student support (grants, loans, family allowances, and tax benefits), but also future earnings and foregone earnings (Vossensteyn, 2005). 
Financial aid: Any scholarship or financial assistance given to a student to pay tuition and fees at a higher learning institution.

Grants: Any financial assistance that students receive that may not be repaid and provided by various sources such as federal and state agencies.

Private Michigan universities: Higher learning institutions where funding comes from tuition, investments, and private donors and not from the taxpayers even though the students may be entitled to tax breaks, public and private student loans, financial aid and grants.

Student choice: This refers to all choices students make related to studying, including whether or not to enroll, what institution and program to choose, whether to stay in college or drop out, whether to live with their parents or independently, whether to obtain student loans, or whether to secure a part-time job. Until recently, student choice was limited to only the first three of these variables (Vossensteyn, 2005). For this study, student choice refers to all college choices students make related to what institution to choose.

Student loans: Money lent to students by a money-lending institution or agency to pay as tuition or fees and repaid back to the lender with interest in an agreed future date.

Tuition and fees: The price students have to pay for enrollment in a particular program in a given higher learning institution where by the tuition and fees are related to the cost of instruction or even more like study material (Vossensteyn, 2005). 


\section{Assumption}

The main assumption of this study is that students are able to identify the financial incentives that affect their choice in higher education.

\section{Limitation of the Study}

It may be difficult for students to be open about their finances; therefore, the limitation of the study may be the reluctance of students to be honest in their responses on the questionnaires. The students might not disclose all the information about financial incentives provided by the institution, state, or federal government.

\section{Delimitation of the Study}

The study was delimited to undergraduate students enrolled at five selected private Michigan universities. These students were entitled to all financial incentives provided by their colleges or universities.

\section{Summary}

A number of studies discuss the factors influencing student choice in higher education. However, relatively few studies have investigated the role of financial incentives in student choice. Furthermore, escalating tuition and diminishing college affordability pose financial barriers or hardship to the student population (Kim et al., 2009). In this scenario, students may be looking for colleges with financial incentives in order to minimize their resultant student debt. This study examines the role of financial incentives in students' matriculation choices at five selected private Michigan universities. 


\section{CHAPTER 2}

\section{LITERATURE REVIEW}

Because students comprise one of the primary constituencies at any institution of higher education, their choices related to whether to attend college or university, where to attend, how to finance their education, whether to attend full or part-time, whether to pursue a part-time job, and many related issues continue to represent important topics in higher education. In fact, student choice about where to attend college or university has been investigated and discussed over several decades for several reasons. First, institutions want to know what drives students to apply for admission and to complete the enrollment process at their choice of schools (Stark \& Scholder, 2011). Furthermore, the study of student choice assists institutions in recruiting and retaining students. Second, the study of student choice helps students and parents determine the best choice for higher education by revealing the dominant reasons influencing such choices. For these reasons, understanding student choice can benefit institutions of higher learning, students, parents, and the community at large.

Several studies of student choice in higher education (Cabrera \& La Nasa, 2000;

D. Chapman, 1981; Galotti \& Mark, 1994) have modeled the factors and determinants of student choices in higher education in terms of their precursors, influences occurring before and immediately prior to a student's decision to attend one institution over alternatives. Other studies have analyzed student choices as a function of academic 
discipline (Burns, 2006; Curtis, 2012; Mehboob, Shah, \& Bhutto, 2012).

Many such models have been developed and investigated to determine the primary influences on student choice in higher education and how these factors interrelate (Mehboob et al., 2012). The first significant college-choice model was developed by Gregory Jackson. According to Jackson $(1978,1982)$, student choice is based on preference, exclusion, and evaluation. A student's preference takes into account the aspiration and academic achievement of the student in high school. Exclusion refers to the student's analysis of costs, offerings, admission requirements, and benefits accrued from the institution. The geographical location and travel expenses are important factors to be considered. The last stage is student evaluation. The student evaluates the merits of the college, potential future employment, and tuition cost of the institution (Jackson, 1982). Additionally, family background and academic experience play a significant role in the evaluation process.

A second important model for organizing the salient variables involved in student choice in higher education has been outlined by D. Chapman (1981). Chapman's model suggests that student choice is influenced by a set of student characteristics in combination with a series of external influences. These external influences can be grouped into three general categories: (a) the influence of significant persons, (b the fixed characteristics of the institution, and (c) the institution's own efforts to communicate with prospective students.

According to the general categories of D. Chapman's model (1981), student characteristics and external influences contribute to and are shaped by students' generalized expectations of college life. Chapman describes student characteristics as 
socioeconomic status, aptitude, high school performance, and level of education aspirations or the degree expectations of students.

The external influences include significant persons, fixed college characteristics, and college efforts to communicate with students (D. Chapman, 1981). The significant persons are the important people in the student's life: friends, parents, and high school personnel.

According to D. Chapman's model (1981), the remaining external influences on student choice in higher education are fixed college characteristics, including cost (financial aid), location, and availability of the program. College efforts to communicate with students involve written information, campus visits, admissions or recruitment efforts. All these factors have a significant impact on student choice of college or university. Figure 2 provides a comprehensive illustration of the model of student choice.

Hanson and Litton (1982) provide a third student choice model. This model focuses on high school characteristics, student characteristics, personal attributes, public policy, and environmental influences on college aspiration (Sauder, 2008). Students search and gather information from the media, parents, peers, and college action, which eventually lead to them sending in an application as a result of perceived college characteristics.

A fourth model of student choice in higher education, the three-stage model of student choice, was introduced by Hossler and Gallagher in 1987. In the first, or predisposition phase, students determine whether they would like to continue their education beyond the secondary level or not (Tatar \& Oktay, 2006). During the second, or search phase, students gather information about institutions of higher education and 


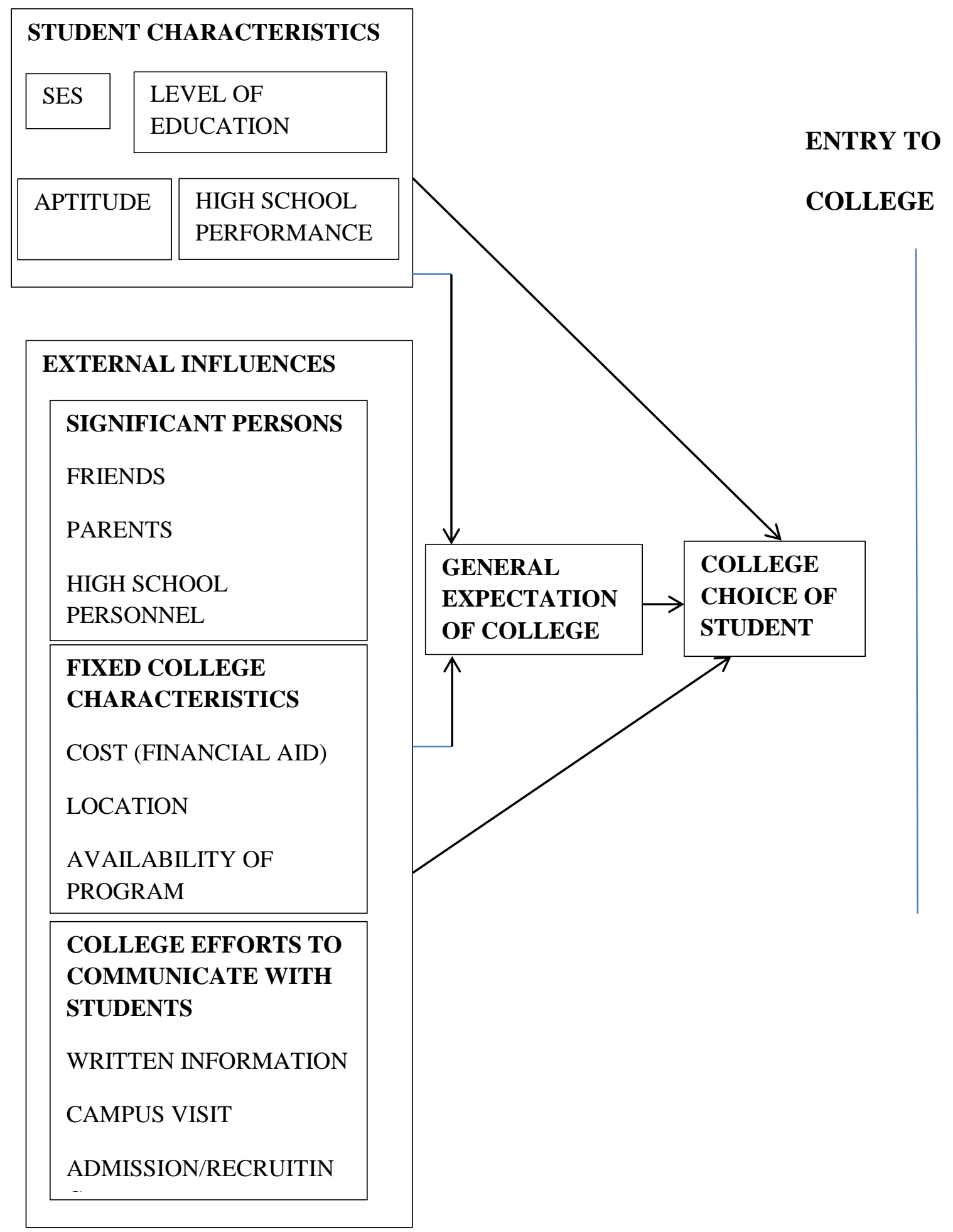

Figure 2. Influences on student college choice. Adapted from D. Chapman (1981, p. 15) and used with permission. 
establish their 'choice set' or the group of institutions to which students would actually apply (Tatar \& Oktay, 2006). The third or choice stage involves choosing which college or university a student would actually attend. Based on the pros and cons of each institution, the student selects an institution, which best suits his or her needs, available resources, and aspiration for higher education.

Cabrera and La Nasa (2000) provide a fifth model with ten factors influencing student choice in higher education. According to Sauder (2008), these factors include saliency of potential institution, costs, parental encouragement, and student aspirations. Additionally, some studies have identified the impact of financial incentives as a significant factor on student choice. For instance, DesJardins, Ahlburg, and McCall (2006) propose a model that includes financial aid as an important factor in college choice. Table 1 provides a summary of the entire student choice model discussed in this section. This summary has been adopted from Sauder (2008).

Other researchers have identified economic and social theoretical frameworks to examine factors influencing college choice (Hearn, 1984; G. Jackson, 1978; Somers et al., 2006; Tierney, 1983). According to Lee and Chatfield (2011), these studies have resulted in three theoretical or conceptual approaches to modeling college choice: (a) economic models (b) status-attainment models, and (c) combined or information processing models. 
Table 1

Prominent College Choice Models

\begin{tabular}{|c|c|c|}
\hline Author & Date & Model Features \\
\hline G. Jackson & 1978,1982 & $\begin{array}{l}\text { College choice is a process of preference, } \\
\text { exclusion, and evaluation }\end{array}$ \\
\hline D. Chapman & 1981 & $\begin{array}{l}\text { Student characteristics, external influences, fixed } \\
\text { college characteristics, and college } \\
\text { communication efforts affect student } \\
\text { expectations and contribute to choice of } \\
\text { colleges }\end{array}$ \\
\hline Hanson \& Litton & 1982 & $\begin{array}{l}\text { High-school characteristics, student } \\
\text { characteristics, personal attributes, public } \\
\text { policy, and environment influence college } \\
\text { aspirations, which lead to search and } \\
\text { information gathering (affected by media, } \\
\text { parents, peers, college actions), which leads to } \\
\text { sending an application (affected by college } \\
\text { characteristics) }\end{array}$ \\
\hline R. Chapman & 1984 & $\begin{array}{l}\text { Five stages of pre-search activities lead to } \\
\text { enrollment }\end{array}$ \\
\hline Hossler \& Gallagher & 1987 & $\begin{array}{l}\text { A three-stage model: predisposition leads to } \\
\text { search, which leads to choice }\end{array}$ \\
\hline Cabrera \& La Nasa & 2000 & $\begin{array}{l}\text { Complex model with interplay of } 10 \text { factors, } \\
\text { including saliency of potential institution, cost, } \\
\text { parental encouragement, and student's } \\
\text { aspirations }\end{array}$ \\
\hline $\begin{array}{l}\text { DesJardins, Ahlburg, \& } \\
\text { McCall }\end{array}$ & 2006 & $\begin{array}{l}\text { The financial aid offered is a significant part of } \\
\text { college choice }\end{array}$ \\
\hline
\end{tabular}

Note. Adapted from Sauder (2008, p. 319).

\section{Economic Model}

Economic models view college as an investment decision and assume students seek to gain the maximum return on their investment (Hossler \& Palmer, 2008); these models assume that students think rationally and make careful cost-benefit analyses when choosing a college (Lee \& Chatfield, 2011). To be more specific, economic college models advocate that student choice of higher education or selecting a specific institution is based cost and benefit analysis. This means students choose an institution if and only if 
the perceived benefits of that choice outweigh the perceived benefits of the alternative or opportunity cost (Vossensteyn, 2005). Furthermore, the economic choice model refers to how students with certain characteristics (gender, financial ability, and parental socioeconomic status) differ in the extent to which financial variables are deemed important in choosing an institution of higher learning (Vossensteyn, 2005).

The economic model is based on financial incentives and therefore concentrates on the monetary costs and benefits of higher education (Vossensteyn, 2005). Hossler et al., 1989) provides the following major variables used in the economic model:

1. Monetary costs: It composes of tuition fees, net tuition fees (tuition fees minus financial support), with other study costs as stationary, living expenses, and forgone earnings as opportunity cost.

2. Monetary benefits expected or future earnings, grants, or scholarships.

3. Student demographic characteristics as family background characteristics which include parents' income, education, and occupation.

From this perspective, broad, objective issues like price, tuition cost, financial aid, and market forces influence student decision-making (Hossler \& Palmer, 2008).

\section{Status Attainment Model}

The status attainment model, on the other hand, assumes that students go through a utilitarian decision making process in selecting a college (G. Jackson, 1982). Accordingly, this model has also been termed the sociological model of student choice. This framework involves a specific variety of social and individual factors leading to career and academic aspirations.

Status-attainment models focus on the interactive process between broad social 
environment variables and students' individual characteristics in relation to students' college choices (Hossler et al., 1999). This model deals with the socialization processes that shape the possibilities and ambitions of students since they were born, including family conditions, peers interactions, and school environment (Vossensteyn, 2005). There are several variables that have interactive impact at different stages in the college choice process and the influence of such variables may change over time (2005). According to Vossensteyn (2005) the sociological models generally leave financial factors out of the analysis and instead utilize the following groups of independent variables to explain student choice:

1. Behavioral variables: students' academic performance, students' aspirations, spending of leisure time, motivation;

2. Background variables: family background characteristics (parental encouragement, parents' income, education, and occupation), gender, ethnicity, and influence of peers (e.g., teachers, friends).

\section{Economic Model Regarding Tuition Cost and Financial Aid}

Several studies have noted the relationship between the economic model with tuition cost and financial aid. According to Samuelson (1976), the economist describes two types of price inflation: cost-push and demand-pull inflation. Cost push inflation is when the underlying prices of goods rise and there is no suitable substitute goods or services, while demand-pull inflation exists when there is an excess and supply remains largely inelastic, or unresponsive, to the increase in demand (Heller 2013).

The implication of economic theory is that the increase in college and university 
prices is a result of cost-push inflationary pressures, could not have been sustained without an increase demand for higher education (Heller, 2013). This is the reason that the higher education industry in the U.S. has increased in prices more quickly than enrollments and therefore the rise in prices makes higher education expensive for prospective students. In turn, financial aid subsidizes the cost of education, and thus education is an economic viable investment for future students in higher education.

According to the study by the U.S. Department of Education to answer to what extent has federal aid been used to offset increases in institutional aid (Cunningham et al., 2001, p. 3). According to Heller (2013), the study found no relationship between either federal or state grant aid, or loans, and tuition price increases:

Regarding the relation [sic] between financial aid and tuition, the regression models found no associations between most of the aid packaging variables (federal grants, state grants, and loans) and changes in tuition in either the public or private not-forprofit sectors. (Cunningham et al., 2001, p. 133)

The only relationship found between financial aid and price increases was for public and private comprehensive institutions, where there was a positive relationship between spending on institutional grants and tuition price increases (Heller, 2013). These findings indicate there is a relationship between the economic model and how students perceive financial incentives in higher education.

\section{Information Processing Model}

Finally, the information processing or combined model incorporates both the rational assumptions from economic models and components of the status attainment models (Lee \& Chatfield, 2011). The combined model categorizes the decision-making process into three phases: aspirations development and alternative evaluation; options 
consideration; and evaluation of the remaining options and final decision (G. Jackson, 1982).

The information-processing model provides a comprehensive explanation of student choice in higher education. Since information processing combines the economic model and status attainment model, the model therefore minimizes the shortcoming of the other models. According to Wyer (2006), information processing occurs in several stages: the first, the comprehension stage is fully automatic, making use of concepts that happen to be relevant and accessible in memory. If information cannot be comprehended on the basis of the automatic mechanisms that occur at this initial stage, more deliberative processes are activated and used (Wyer, 2006). This combined model has also been developed to better explain the effects of institutional recruitment efforts and policy interventions (Hanson \& Litten, 1982). According to Hossler et al. (1989), the model underlines researchers' and policy makers' interest in knowing what variables can be controlled for when influencing college choice. These include constraints (e.g., infrastructure, location, and the types of students admitted) and auxiliary policy actions like pricing, programming, and recruitment efforts (Vossensteyn, 2005).

Information processing or combined models is the most comprehensive student choice framework, including various choice stages and an extensive research of explanatory variables that are deemed important in the various stages of the student college decision-making process (Vossensteyn, 2005). Figure 3 illustrates the student choice process and its most important variables. 


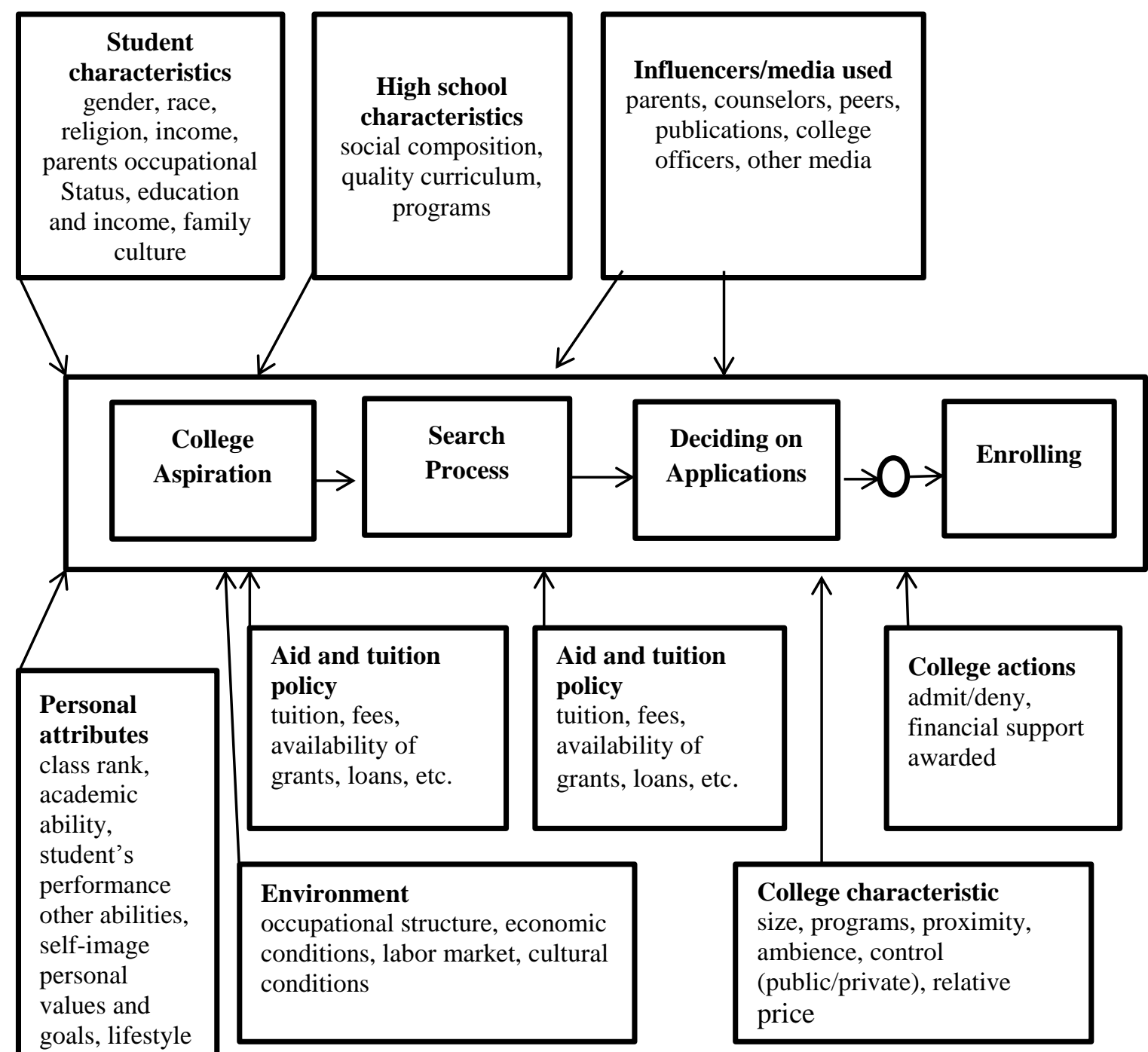

Figure 3. The student choice process and its important variables (adapted from Vossensteyn, 2005). This framework is a slightly modified version of Hanson's and Litten's 1982 model.

\section{Traditional Economic Theories on Student Choice}

There are several model involved in student choice in higher education. These models provide different perceptions and opinions of student choice. These models 
provide a comprehensive theoretical framework for student choice in higher education.

One of the theories is the general price theory and the second is human capital theory.

\section{General Price Theory}

One of the theories supporting student is general price theory. The general price theory assumes that individuals make choices in a way that maximizes utility (Marshall, 1920; Samuelson, 1980). Drawing on the basic principles set out above, students ought to attend university if they believe that the benefits outweigh the costs and if they have the means to pay for all the associated costs, that is, no liquidity constraint (Vossensteyn, 2005). This theory implies that the benefits through financial incentives as loans, financial aid, grants, and tax breaks reduce the cost; therefore, these motivating students to choose a particular institution of higher learning.

\section{Human Capital Theory}

The human capital theory has concepts that acknowledge education as an investment. The human capital theory believes education is an investment in the productivity of individuals and their environment (Vossensteyn, 2005). Though Theodore Schultz (1961) was among the first to acknowledge that education could be regarded as an investment in human capital, the central thesis goes back to Adam Smith in his book The Wealth of Nations (1776). "[A] man educated at the expense of much labor and time ... may be compared to one of those expensive machines."

The human capital theory has several implications to student choice in higher education. The extended human capital model incorporates the notion that people rely on imperfect information and therefore sometimes seem to make irrational choices (Vossensteyn, 2005). In regard to the knowledge of imperfect information (potential), 
students that make decisions based on imperfect information, uncertainty, and biased preferences cannot be considered irrational, but rather bounded rational or subjective rational (Menon, 2004).

\section{Student Choice Models and Financial Incentives In Higher Education}

The student choice models provide a basis for financial incentives in higher education. Vossensteyn's (2005) study, conducted among higher education students in the Netherlands, revealed that student choice models offer a framework for addressing a number of the complexities surrounding student choice; thus, student choice models assist in explaining why students with different background characteristics react differently to financial incentives when making institutional choices. Moreover, the student choice models discussed here have influenced the government's and institutions' implementation of financial incentives for students. Therefore, it is appropriate to conclude that student choice models and financial incentives should be intertwined.

To be more specific, institutions realize that the economic model identifies factors that impact student choice. Thus, institutions create financial incentives like financial aid to attract students to their institutions (Vossensteyn, 2005). In addition to this, higher learning institutions formulate financial incentive policies to promote student enrollment choices. Hence, this dual strategy represents a vivid example of how student choice models are related to financial incentives in higher education.

\section{Financial Factors Affecting Student Choice in Higher Education}

According to Felton (2012), in a study of students' ages 19 to 24 at New York College, research revealed financial factors played a significant role in student choice. 
Chapman (1981) found that costs tend to be a factor in the decision to enroll in college rather than the sole influence on where to apply. This is a clear indication of the importance of financial incentive factors on college choice. For instance, Kim (2012) found financial aid has a positive impact on enrollment choice.

Applying such financial factors to this research, the study of financial incentives is important due to the rise in tuition costs in higher education. Researchers for the National Center for Education published a report in 2011 highlighting tuition increases for racial groups. During a period of time, the tuition costs for White students rose from $\$ 16,000$ in $1999-2000$ to $\$ 18,700$ in $2007-2008$ (National Center for Education Statistics [NCES], 2011). Black, Hispanic, Asian, Pacific Islander, and students with two or more races encounter similar or even greater increases in some cases with $\$ 2,600, \$ 2,600$, $\$ 3,100, \$ 5,000$, and $\$ 3,100$ net price increases respectively. These statistics clearly indicate the rise of tuition costs. At the same time, they signal the necessity to study financial incentives as a basis for student choice in higher education.

The well-documented role of financial factors in student choice in higher education suggests that financial incentives affect students' choice of college. A survey by the Cooperative Institutional Research Program (CIRP) concluded that:

Students were more likely than ever before to weigh financial incentives in choosing a college: 41.6 percent of students reported that the cost of their school was a very important reason for choosing it, the highest number since the survey asked the question. And 44.7 percent said that an offer of financial aid from the school was a very important reason for attending, up from 34.4 percent in 2007. (Zernike, 2010, p. A25)

The CIRP survey's results comprise one of many outcomes providing clear evidence of the importance of financial incentives for students' choice. 
With all the studies supporting the notion that financial incentives have an impact on student choice in higher education, there are some studies that contradict this notion. Indeed, these studies tend to disagree that financial incentives influence student choice of university or college. For instance, Slavin (2009), in an article reviewing international experiments, argued that financial incentives raise thorny philosophical, political, and social questions regarding "paying people to do what they should be doing anyway." Additionally, Slavin's study found no significant influence or impact of financial incentives on student choice. Specifically, this study revealed evidence that just as with more traditional financial incentives, unconditional cash transfers have few effects on student choice or enrollment.

\section{Financial Incentives Affecting Student Choice in Higher Education}

Financial incentives are obviously a topic of great concern within higher education in the United States today. The relevant literature indicates that U.S. institutions have developed their own recruitment policies in which tuition and student aid play significant roles (Vossensteyn, 2005). Many studies also acknowledge that one socio-economic factor, namely parental income, is the strongest predictor of whether or not students pursue higher education, as well as of what type of institution and program they join. However, the academic research literature evaluating the effect of financial incentives on higher education remains limited. This study attempts to fill specific lacunae about the impact of financial incentives on students' choices in higher education. In particular, the degree to which students are responsive to financial incentives are discussed, following an exploration of personal and family income; then the focus shifts 
to tuition and fees, grants, scholarships, loans, and other financial aid as major financial incentives influencing student choice in higher education.

\section{The Impact of Tuition Cost on Student Choice}

Several studies have tracked the increase in tuition and its impact on student participation in higher education. These studies have generally found a relationship between tuition cost and student choice (Hemelt \& Marcotte, 2011; Vossensteyn, 2005). In the 1970s and 1980s, Leslie and Brinkman (1987) found that students were price responsive and that ceteris paribus, a $\$ 100$ increase in tuition and fees reduced students' participation rate (in higher education) by $0.7 \%$. Another study by Heller (1997) found an inverse but moderate relationship between tuition and enrollment rates across most studies, ranging from $-0.5 \%$ to $-120 \%$ for each $\$ 100$ tuition increase (Vossensteyn, 2005). A more recent study by Hemelt and Marcotte (2011), using data gathered between 1991 and 2006 from all U.S. public 4-year colleges and universities, illustrates that tuition increased dramatically beginning in the early part of this decade. The study found that a $\$ 100$ increase in tuition and fees could cause a decline in enrollment of about $0.25 \%$ with possibly larger effects at research universities. These statistics indicate that student choice clearly varies depending on the tuition and fees imposed by institutions.

Other research indicates the relationship between tuition and student choice changes based on the socio-economic background of a student. For instance, a study by Heller (1997) on student price response in U.S. higher education revealed low-income students are sensitive to changes in tuition, while higher income students are price inelastic. Additionally, Hispanic and African American students are more sensitive to price changes than White students, highlighting important differences between racial 
groups (Vossensteyn, 2005). Vossensteyn states the reason for these findings might be due to substitution effects of income and price changes among students from different socio-economic groups.

In order to gain a deeper understanding of the effects of tuition prices on student choice, some studies have managed to assess tuition price responsiveness between students from public and private institutions. Research conducted by Cokgezen (2012) examined the determinants of university choice among Turkish students using school level data. The data indicated that public university students are more price sensitive than private university students, while private university students care more about academic performance, as might be anticipated from the typical income differences between the two groups. These differences in price sensitivity are caused by certain characteristics that differ widely and which may cause differing demand structures. Cokgezen suggests that students attending public universities typically come from lower income families than their counterparts at private universities. However, overall, students in both public and private universities are influenced by the tuition costs of higher education.

To summarize, the price of tuition is negatively related to student choice. That is, an increase in tuition and fees results in a decrease in students' participation in higher education, therefore impacting student choice. However, Callender and Jackson (2005), who studied 2,000 prospective students in England, state that although the cost of tuition may not necessarily be the main reason that potential entrants decide on a particular university, costs and financial incentives still comprise the key influences among a range of cultural, institutional, and dispositional factors affecting students' choice to participate in higher education. 


\section{The Impact of Financial Aid and Scholarships on Student Choice}

Financial aid, another factor of interest in higher education, has been shown to have a positive impact on student choice in higher education (Vossensteyn, 2005).

Literature published in the U.S. indicates financial aid increases college access (Dynarski, 2003; Kane, 2004), enhances college persistence and retention (Yang, 2011), improves college learning experiences (Starter, 2009), and contributes toward postgraduate choice (Field, 2007; Zhang, 2010). These are some of the benefits of financial aid for students in higher education.

In order to further establish the impact of financial aid and scholarship on student choice, Hurwitz (2012) used admission and financial aid data from 30 anonymous postsecondary institutions on students planning to attend college in the fall of 2009 . The study showed a strong correlation between student choice and financial aid, revealing that an additional \$1,000 in financial aid awarded by an institution to a prospective student increased the probability by $1.66 \%$ that the student would choose that institution. The National Bureau of Economic Research (NBER), a private research organization, published a study on financial aid (Robinson \& Cheston, 2012), concluding that lowering the annual price of higher education by $\$ 1,000$, either through tuition reductions or nonpayable aid, lead to a $3 \%$ to $5 \%$ influence on post-secondary choice. In other words, the effect of spending $\$ 100,000$ in financial aid to 100 students would result in three to five students who would not have chosen to go to college, but changing their minds because of the availability of financial aid.

Students from different socio-economic backgrounds show a varied response to the availability of financial aid. Hurwitz (2012) observed low-income students were 
nearly three times more sensitive to institutional financial aid than high-income students. Another study conducted by Robinson and Cheston (2012) used the NCES to evaluate the impact of Pell grants among students in U.S. higher education. The study found the effect of $\$ 1,000$ given in aid per student had a five times greater draw for students whose families earn $\$ 25,000$ annually than on students of families earning $\$ 75,000$. These studies are a clear indication of the effect of financial aid on student choice in higher education.

The impact of financial aid also varies by the racial and ethnic backgrounds of the prospective students. St. John, Paulsen, and Carter (2005) used the Nexus model, sequential sets of logical regression analyses, to examine the influence of variables related to student background, college choice, college experience, current aspiration, and financial support on persistence. The research revealed differences in the way financial aid influences African American students and White students. The study posits that a larger percentage of African Americans selected higher learning institutions based on financial aid packages. Additionally, the study discerned that a lower percentage of White students choose their college based on financial aid while a higher percentage choose colleges or universities based on loan availability.

Other studies have contrasted the impact of financial aid versus loans in relation to student choice. As noted by Long (2008) in a paper that discusses the research literature on the effectiveness of financial aid with special focus to its implications for policy, grants have been an effective way to influence student choice. Long further reveals that students would choose an institution based on financial aid available rather than opt for a loan to fund their education. Long (2008) also suggests students prefer 
financial aid since loans raise concerns about student debt burden and on academic and employment decisions.

While several studies provide further evidence about the impact of financial aid in college choice, these studies provide a partial perspective on financial aid. This is due to the fact that such studies are based on cross-sectional data that explore fixed differences between places in tuition levels. It is difficult to distinguish the impact of tuition from other characteristics of the different locations that have remained constant over a period of time (Long, 2008). According to Long, other omitted factors may be correlated with enrollment, subsidy, and tuition prices and, therefore, cloud the true effect of financial aid and student choice.

Other challenges about cross-sectional financial aid studies are the level of aggregation in numerous studies (Long, 2008). Long argues that while many studies use state averages to measure the costs student face, this could cover the vast heterogeneity in college price, quality and subsidies, and their impact on student choice. Long continues to urge that tuition levels do vary greatly among different levels of schools by sector and sensitivity. Thus, using a state means as proxy for tuition price may not truly portray the tuition costs students face in deciding the institutions to join. Long acknowledges the tuition price and student choice may depend on the characteristics of the student (i.e., residence, ability level, and family income).

Long (2008) states that the best studies have used "natural experiment" to assess the impact of financial aid on student choices in higher education. As summarized by Dynarski (2002) in a review of the literature using quasi-experimental methods, the 
natural experiment method underscores that subsidies increase college attendance rates and influence student choice in higher education.

\section{The Impact of Student Loans on Student Choice}

The recent financial crisis of 2008 resulted in decreased funding for higher education from government grants and institutional financial aid. In turn, students have had to rely more on loans to pay for their education; hence, the rise of student loans in higher education funding in recent years.

Studies differ in their perception of the impact of loans on student choice in higher education. Some studies have argued, with concern, the large debts students accumulate impact negatively on potential student choice in pursuing a college education (Baum \& O’Malley, 2003; Cunningham \& Santiago, 2008; King \& Bannon, 2002; King \& Frishberg, 2001; Price, 2004). Other studies claim that the aversion to debt limits access to higher education among low-income students, therefore, limiting their college choices (Burdman 2005, 2006; Cunningham \& Santiago, 2008; ECMC Group Foundation, 2003; Gertner, 2006; Jaschik 2008; Monaghan, 2001).

Vossensteyn (2005), investigating the relationship of loans and student choice in empirical analysis that explored perception of student price-responsiveness in the Netherlands, concluded that loans have a relatively low influence on higher education choice; however, loans have a greater impact on college destinations. In addition, for five years Bouse and Hossler's (1991) studied the various choices students make at each grade level in high school toward a decision as to which college or university to attend. They found that student loans had a negligible impact on post-secondary education 
aspiration because financial motives are only taken into consideration in the later stages of student decision making process.

To further understand the impact of loans on undergraduate and graduate programs, Zhang (2010) examined how college educational loans affected student choices of bachelor's degree. Zhang used a base-year survey that included a national sample of about 11,000 students who received their bachelor's degrees between July 1992 and June 1993. Data revealed that for public college graduates, college loans had a negative and significant effect on graduate school attendance. The negative effect was focused on more expensive programs associated with an MBA, first professional degrees, and doctoral programs; however, the study also revealed that loans had no effects on the choice of a Master's degree. On the other hand, for private colleges, loans do not have an effect on the overall graduate school attendance, but this absence effect conceals the differential effects of loans on different graduate programs. In addition, the study shows loans have a positive and significant effect on the choice of an MBA or first professional program and zero effect on other programs. The study indicates mixed effects on loans on student choice in higher education.

In an effort to understand the impact of loans and student choice, some studies have established the relationship between student loans and choice of higher education. For example, Heller (2001) examined the relationship between the amount of loan students accumulate during their undergraduate years and their decisions about career and enrollment in graduate school. Conducted for the U.S. Department of Education, the study used data from baccalaureate education in the 1992-1993 academic year. The study revealed students in the most expensive institutions borrowed for college at a rate of only 
$6 \%$ greater than those in least expensive institutions (Heller, 2001). At the same time, students who hoped to earn a professional or doctoral degree had higher average loan levels.

Some studies have found a relationship between undergraduate borrowing and the students enrolling for graduate school. For instance, Heller (2001) found that the increase in borrowing as an undergraduate was related to only a $0.2 \%$ increase in the likelihood of enrolling in graduate school. This statistic indicates that undergraduate borrowing appears to have an insignificant effect on whether students attend graduate school. However, Millet (2003), using data from baccalaureate and graduate study (1993-1994), examined the influence of student background characteristics, collegiate performance, and financial indebtedness on the decisions by recent bachelor's degree recipients to enroll in graduate or first professional school. The study found that students with undergraduate debt were less likely to apply to graduate school than those students with no undergraduate debt. The study revealed students with a debt of $\$ 5,000$ or more are significantly more likely to apply to a graduate school or a first professional institution than their peers who did not have educational debt. Therefore, there are mixed results about the impact of student loans on undergraduate students attending graduate school.

Students from different social economic groups and their perception of student loans has been observed by several researchers, among them Perna (2008) whose study, using data from descriptive case studies of 15 high schools to examine high school students' willingness to borrow to pay college prices, suggests a major difference in how students from low-, middle-, and high-income families perceive loans for higher education. The study revealed students from high and middle income families had a more 
extensive knowledge about the merits of college education and were more willing to take loans to pay for their studies. On the other hand, the study found low-income students were skeptical about loans for funding their educational pursuits and lower their educational aspirations by attending community college or forego college in order to avoid future debt (Perna, 2008). Moore, McNeil, and Halliday (2011) explored the understanding young people had on how increases in tuition and fees affected their decisions to pursue higher education. The paper drew on research with young learners in three large United Kingdom urban areas in Greater Manchester, Greater Merseyside, and West Yorkshire. The research supports the notion that students from lower socioeconomic groups are less likely to perceive a college degree as worth the future debt. Additionally, Callender and Jackson (2005) examined the relationship between prospective higher education students' attitudes to debt and their decisions about whether or not to enter higher education. The data was derived from a survey of approximately 2,000 prospective students. The research found among low-income students, debt was an important factor for picking a university, competing with a lower cost of living, proximity to home, and prospects of long-term employment. Thus, these studies reveal the reluctance of low-income students and their families taking loans as they plan to choose a college or university.

\section{The Impact of Government Grants on Student Choice}

Since the 2008 financial crisis, the federal government has been reducing their funding for higher education. In an article on academic bankruptcy, Taylor (2010) examined the challenge of financing higher education and suggested that financial aid and grants are drying up and federal government support is not keeping pace with the 
rising cost of college. The cutbacks in grants are an obvious indication that the federal government is reducing its funding of higher education. This decline in available grants has significant repercussions to the state, the institution, and the student, in that a greater proportion of the costs for higher education are ultimately shifted to the state, the institution, and the student.

The federal government has a role in higher education affordability, as has every state. The state role has been changing over the years, according to AASCU (2012) policy statements,

In 1985, tuition income represented 23 percent of public higher institutions' operating revenues, with the balance of 77 percent covered by state and local appropriations. By fiscal year 2010, the tuition share of revenues had climbed to 40 percent while the state appropriations share had declined to 60 percent. The state-to-student cost shift in who pays for college is especially evident at public master's universities, where in 2009 tuition revenues accounted for 48.7 percent of Education and Related (E\&R) spending, with the state funding share down to 51.3 percent. (p. 16)

There is a significant shift of funding responsibility from the state to the student, the student having to bear more of the costs of higher education, inevitably creating a greater financial burden on the student pursuing higher education. As a matter of fact, this reduced funding restricts accessibility to higher education among low-income students.

Though the government is reducing its contribution to funding higher education, the government is still offering financial assistance to students. One of the most dominant forms of government financial aid is Pell grants. Pell grants are need-based grants offered to millions of undergraduate students every year, in amounts ranging from $\$ 555$ to $\$ 5,550$ per student (Robinson \& Cheston, 2012). These grants have a significant impact on student choice and college participation. According to their study, Pell grants have been relatively effective in getting low-income students into college; however, they are 
not effective in helping students to graduate. This implies Pell grants have a significant influence on student choice in higher education making them more likely to enroll for higher education.

Studies have tracked the relationship between government grants and student choice in higher education. McDonough et al. (2007) examined the impact of 11 selected state financial aid programs on students' choices. They offer compelling evidence to suggest that financial aid in large part mediates the final destination choices of students from lower-income and working-class families and that those choices are often made in response to pricing and financial grant availability. This is a vivid illustration of the role government grants play in student choice in higher education.

Other studies have explored the relationship between grants and subsidies in college selection among students. Fiorini (2012) builds a dynamic structural model of educational choices in which cognitive skills shape decision by using cohort data where individuals are observed from birth to the middle of their working life. The paper revealed that grants foster enrollment at the lowest cost, but the parental income subsidy generates more welfare, as measured by a class of social welfare functions. In another study, Usher (2006) summarizes the literature that focus on grants and their impact on access to education. Usher acknowledged that grants increase the benefit-to-cost ratio for education by offsetting educational costs such as tuition and foregone future income. The study further reveals grants increase student purchasing power in the short-term, thus reducing the out of pocket (i.e., the amount students pay from current income) which in turn impacts student choice in higher education.

On the issue of subsidies and their impact on higher education, Sahin (2004) 
explained the incentive effect of education subsidies on student effort by utilizing a game-theory model to analyze the disincentive effect of low tuition policies on student effort. According to Sahin, education subsidies make college education more accessible by increasing families' ability to pay for college and thus subsidies have a greater impact on student choice. Furthermore, Sahin states that subsidies provided directly to students are more effective in encouraging human capital accumulation as compared to the operating subsidies provided to postsecondary institutions.

While grants have been compared to subsidies, it is also appropriate to assess the impact of grants versus loans or tax credits. According to Long (2008), research suggests that grants have a stronger impact on student choice than loans. Long continues to explain that tax credits are also not as effective in influencing student choice in comparison to grants, because the main beneficiaries of tax credit are unlikely to be students who can barely afford to attend college. In addition to this, students do not receive the tax benefit at the time tuition payments are due; therefore, the effects of the tax credit on student choice is at best limited. Perhaps for these reasons, Long suggests that the Federal Higher Education Tax credit have not have an effect on student choice. Thus, grants serve as the best predictor for student choice in higher education.

Providing grant monies to increase college opportunities for students historically marginalized and underrepresented within the nation's colleges and universities, federal financial aid offers the promise of supporting a more accessible and egalitarian system of higher education (McDonough et al., 2007).

\section{Financial Perceptions Model of Student Choice}

Because the literature has covered a wide range of models, theories, and 
arguments on student choice in higher education, it is important to review the new models of student choice. The study by Vossensteyn (2005) provides a strong theoretical and conceptual background by examining the perception of student price-responsive. This was a study that explored a behavioral economic exploration of the relationship between socio-economic status, perceptions of financial incentives and student choice. Vossenteyn (2005) developed an empirical model that captures information on student background characteristics (independent variables), students' perceptions of financial incentives (intermediary variables) and students' observed study-related choices (dependent variables).

To summarize, the model depicts financial incentives exerts impact on student choice through a mental framework of students which results into the perceptions students have these financial incentives (Teixeira, Johnson, Rosa, \& Vossenteijn, 2006). Furthermore, the background characteristics are probable to influence the mental framework, and hence the perceptions of students (2006). In addition, the model differentiates between two distinct relationships, the first being the process in which perceptions are formed about the financial incentives, and second being the relationship between the perceptions of students and financial incentives and their actual study related choices (2006). In general, the model provides an explanation how psychological mechanism can influence the perceptions of prospective students and hence these decision influence student choice in higher education.

Figure 4 is a model developed by Vossensteyn (2005) showing the theoretical argument that students' background characteristics are processed through individual frameworks and lead to perceptions of financial incentives that result in student choice. 


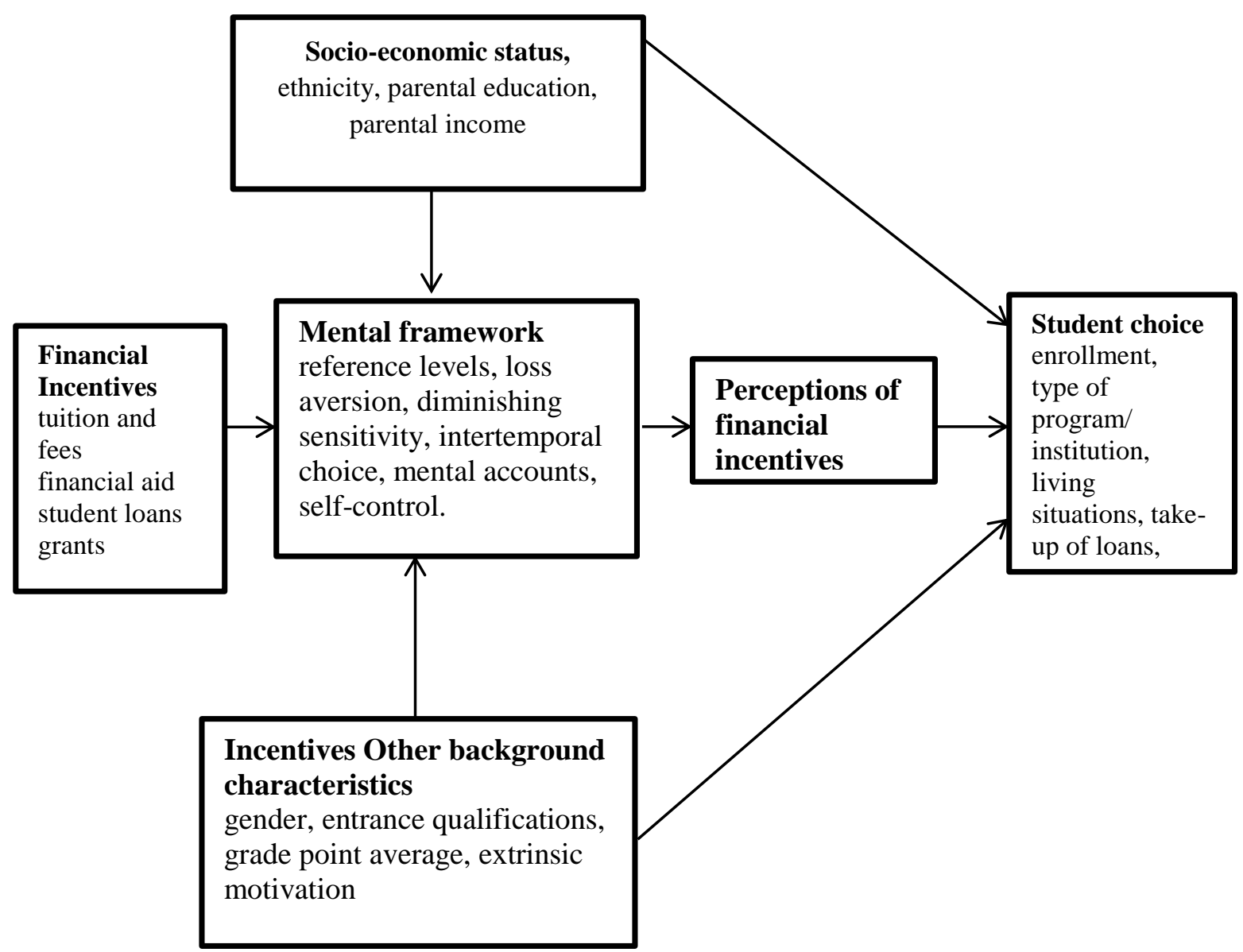

Figure 4. The financial perception model of student choice. Adapted from Vossensteyn, (2005, p. 182).

To summarize the literature discussed in this section, the literature has provided a comprehensive and thorough explanation about the role of financial incentives on student choices in higher education. This means financial aid, tuition costs, loans and government grants have an influence on student choice in higher education. In other words, financial incentives are an important subject of concern, beneficial to prospective students, university or college administrators, and higher learning institutions at large. 


\section{CHAPTER 3}

\section{METHODOLOGY}

\section{General Introduction}

The study used a quantitative research approach. Quantitative research is a method used for describing trends and explaining the relationship among variables (Creswell, 2008). I formulated narrow questions, located or developed instruments to collect data to answer the questions, and then analyzed numbers from the instruments using statistics. I analyzed the data to provide a formal report of the findings with possible recommendations.

\section{Type of Research}

Fundamentally, this study adopted the correlational method, a non-experimental method that describes the relationship between two measured variables (S. Jackson, 2011). According to Thomas (2003), this method determines to what extent one variable changes as another variable is altered. The method can describe relationships between variables ranging in precision from very general verbal observations to highly specific statistical measures.

Several reasons for the intention to use the correlational research approach could be given. First, the correlational approach provides substantial information or evidence about the relationship between variables (Thomas, 2003). I gathered substantial evidence about the relationship between financial incentives which affect student choices in higher 
education. Thus, this approach was suitable for the study. Furthermore, the correlational method allows the researcher to make predictions from one variable to another (S. Jackson, 2011). This study aimed to test predictions regarding whether financial incentives affect students' choices of higher education institution.

\section{Population and Sample}

The participants were students in selected private universities in Michigan. The reason for choosing private universities is due to the fact that most studies were conducted in public universities (Fitch, 2009; Mullins, 2010; Vossentlyssn, 2005). Thus, there is a need to study the impact of financial incentives in private universities. Of the 16 private universities in Michigan (Features, 2014), five are private liberal arts universities and two are private for profits.

Simple random sampling was used to choose the universities for the research. This sampling selects participants (or units, such as universities) for the sample so that any institution has an equal probability of being selected from the population (Creswell, 2008). This method ensures the sample is representative of the population and enables the researcher to make generalizations applicable to other similar populations. Five universities were chosen randomly for the study. The selected institutions were: Spring Arbor University, Andrews University, University of Detroit Mercy, Clearly University, and Concordia University. These institutions represent the private liberal arts universities and private universities in Michigan.

However, due to the fact that Clearly University did not provide an Internal Board Review approval for the researcher to conduct this study at their institution, the study was conducted in four institutions which were Andrews University, Concordia University, 
Spring Arbor University and University of Detroit-Mercy. Therefore the sample size and survey was administered among four universities was recomputed.

Specifically, convenience sampling was used to select the participants of the study. In a convenience sample, the researcher simply uses as participants those individuals who are easy to get; thus, respondents are selected on the basis of their availability and willingness to respond (Gravetter \& Forzano, 2012).

The sample was generated from the total number of students in those selected institutions. The total enrollment for the four private selected institutions was approximately 14,120 students (Features, 2014). A sampling formula was applied to determine the sample of the study. In this instance the Yamane (1967) sampling formula was used to calculate the sample size of the study (Wilson, 2010).

$$
\begin{aligned}
& n=N /\left[1+N e^{2}\right] \\
& \text { where } n=\text { sample size } \\
& N=\text { number of population } \\
& E=\text { significant error } \\
& n=14,120 /\left[1+14,120\left(0.05^{2}\right)\right. \\
& n=388.98 \text { (approximately } 389 \text { students) }
\end{aligned}
$$

According to Beri (2007), stratification ensures that the sampling fraction is proportionate to the population in each stratum. The stratified sampling formula has been adopted from Srivastava, Shenoy, and Sharma (1989).

$$
n=(N 1 / N 2) N 3
$$

Where $n=$ stratified sample size

$$
N 1=\text { Institutional population }
$$


$N 2=$ Total population of all institutions

$N 3=$ Sample size

Table 2 provides a clear description of participants in the study.

I administered 780 questionnaires to the respondents. The additional distributed questionnaire to $200 \%$ of the desired sample size increased the retrieval rate. As

Table 2

Study Participants

\begin{tabular}{llc}
\hline Institution & $\begin{array}{l}\text { Computation } \\
n=(N 1 / N 2) N 3\end{array}$ & $\begin{array}{l}\text { Research } \\
\text { Participants }\end{array}$ \\
\hline Andrews University & $(3,589 / 1,4120) 389=98.87$ & 99 students \\
Concordia University, Ann Arbor & $(700 / 14,120) 389=19.28$ & 19 students \\
Spring Arbor University & $(4,231 / 14,120) 389=116.56$ & 117 students \\
University of Detroit-Mercy & $(5,600 / 14,120) 389=154.27$ & 154 students \\
\hline Total & & 389 Students \\
\hline
\end{tabular}

Note. The number of surveys administered to participants was doubled to 780 students to ensure an adequate sample size for estimating population parameters pertinent to the statistical analysis.

supported by Agresti (2013), the number of questionnaires administered should exceed the desired sample size by at least $20 \%$ to allow for various contingencies like low retrieval rate of questionnaires distributed to respondents. In connection to this, stratified sampling was used to determine the student sample size for each of the four institutions.

\section{Definition of Variables}

In examining the perceptions of student choice in selected private Michigan universities (the main purpose of this study), two key dependent variables were used to design the questionnaire items that comprised the research instrument. These variables constitute the two main components of the student choice model. 


\section{Dependent Variables}

For this study, perceptions of expected student choice refer to the anticipated or expected financial incentives that would cause a student to choose an institution. To be more specific, the perceptions of expected student choice represented what participants assumed or presumed to be the financial incentives that would influence student choice in selected private Michigan universities. In summary, four items (question 24, 25, 26, and 27) in the research instrument were used to gather the perceptions of expected student choice.

Alternatively, the perceptions of actual student choice refer to the confirmed or definite financial incentives which influenced student choice. Specifically, the goal of this variable was to determine the attested financial incentives that influenced student choice in selected private Michigan Universities. For this variable, six items (question 23, $29,30,31,32$, and 33) were used to gather the perceptions of actual student choice in the research survey.

\section{Independent Variables}

The independent variables in this study included three variables (demographic variables, personal and family income, and financial incentives) influencing the perceptions of expected and actual student choice in selected private Michigan universities. The following outline provides descriptions of the independent variables.

\section{Demographic Variables}

Demographic variables refer to the statistical data about the characteristics or attributes of the research participants. Specifically, the nine demographic items on the research instruments were: age, gender, year of study, enrollment status, student origin, 
degree program, student major, institution attended, and ethnicity. The demographic variables and their designation in the research survey were as follows:

Age: All research participants were asked to identify their age group. These age groups were as follows: under 19 years, 19 to 24 years, 25 to 35 years, 35 to 50 years, and over 50 years. In this study, one item (question 1) provided information about the participants age.

Gender: All participants were asked to provide information about their gender. Three options were available which included female, male, or transgender. One item (question 2) gave information about the gender of the research participants.

Year of study: All respondents were asked to indicate their academic class standing at their institution. The participant had the following response options: first year, second year, third year, fourth year, and others. One item (question 3) provided information about the year of study.

Enrollment status: This information was provided by student participants who selected from two options: either part-time or full-time. One item (question 4) provided information about the enrollment status of the participants in this study.

Student origin: All respondents were asked to provide information about their home residency by responding to the following options: in-state, out-of-state, or an international student. One item (question 5) provided information about the home residency of the research participant.

Degree program: All respondents were asked to provide information about their academic degrees using the following options: certificate, associate, bachelors, and others. One item (question 6) asked about the academic degrees of the study participants. 
Major: All participants were asked to select one academic major that represented the general category of their degree program. The general categorical majors included arts and humanities, biological sciences, business, education, engineering, physical sciences, professional, social sciences, technical, undeclared or no major, and other majors. One item (question 7) asked about the students majors.

Institution attended: The participating students were asked to indicate one of the four institutions: Andrews University, Clearly University, Concordia University, Spring Arbor University, and University of Detroit-Mercy. One item (question 8) asked which institution they attended.

Ethnicity: All respondents were asked to select their ethnic groups. The following were the ethnic options: African American, Caucasian, Asians, Latino, and others. One item (question 9) provided the ethnic group of the research participants.

\section{Personal and Family Income Variables}

Personal and family income variables compose of four items (4 questions) which determines the student and family financial or economic back ground. The main purpose of this variable is to examine the relationship between personal and family income and the perceptions of student choice. The personal and family income variables were divided into four variables as follows:

Personal Income: All participants were asked to indicate the best estimate of the average annual income. The respondents had the following response options: Less than $\$ 10,000 ; \$ 10,000-\$ 14,999 ; \$ 15,000-\$ 19,999 ; \$ 20,000-\$ 29,999 ; \$ 30,000-\$ 39,999$; $\$ 40,000-49,999 ; \$ 50,000-\$ 59,999 ; \$ 60,000-\$ 69,999 ; \$ 70,000-79,999 ; \$ 80,000-89,999$; 
$\$ 90,000-99,999$; or $\$ 100,000$ or more. One item (question 10) provided the participants average annual income

Family Income: All research respondents were asked to estimate their family's annual household income. For this section, the participants had the following response options: Under $\$ 30,000$, between $\$ 30,000$ and $\$ 60,000$; between 60,001 and $\$ 90,000$; and 90,001 or above. One item (question 12) provided the family annual income.

Percentage Student Pay: All participants were asked to provide the best estimate of the percentage of college cost that they pay out of pocket (i.e., money a student pays directly to their institution not from loans, grants, financial aid, or scholarships). Students had the following response options: 0 or I don't have any out of pocket college costs, $1-20 \%, 21-40 \%, 41-60 \%, 61-80 \%$, and $81-100 \%$. One item (question 11) provided information about percentage student pay for tuition and fees.

Percentage parents pay: All respondents were asked to estimate the percentage of college cost that their parents currently pay out of pocket. The following were the response options: I don't have any out of pocket, $1-20 \%, 21-40 \%, 41-60 \%, 61-80 \%$, and 81-100\%. One item (question 14) provided information about the percentage parents pay.

\section{Independent Variables}

The independent variables in this study were financial incentives influencing the perceptions of expected and actual student choice in selected private Michigan universities. The following are the financial incentives used in this study.

The first financial incentive examined was student loans. Student loans refer to money lent to students by a lending institution or agency to pay as tuition or fees and repaid back to the lender with interest in an agreed time. For this study, one item 
(question 15) was used to measure the total loan or debt a student would expect to accumulate by the time of graduation.

Another financial incentive was tuition and fees. Tuition and fees includes the price students have to pay for enrollment in a particular program in a given higher learning institution whereby the tuition and fees relate to the cost of instruction (Vossensteyn, 2005). In the questionnaire, two items (question 16 and 17) were used to determine the amount of the tuition and fees incurred at a given university. In particular, question 16 measured the annual tuition and fees incurred and question 17 measured the total tuition and fees for the entire academic program.

Financial aid is one the financial incentives and refers to any scholarship or financial aid given to a student as part of tuition and fees for education at a higher learning institution. In the survey, two items (question 18 and 19) were used to determine the amount of student financial aid. Specifically, question 18 measured the annual financial aid received at an institution and question 19 measured the total financial aid received for the entire academic program.

The last financial incentive involved grants. In this study, grants are any financial assistance offered to students by various sources such as federal and state agencies which do not need to be repaid. In the survey, two items (question 20 and 21) determined the amount of grants offered to students. Specifically, question 21 measured the annual federal and state grants given to a student and question 22 measured the total federal and state grants expected to be received by the time of graduation.

Figure 5 provides an overview of the research questions, independent variables and dependent variables used in this study. 


\begin{tabular}{|c|c|c|}
\hline Research Question & Independent Variables & Dependent Variables \\
\hline $\begin{array}{l}\text { Relationship between demographic } \\
\text { variables and the perceptions of } \\
\text { student choice in selected private } \\
\text { Michigan universities }\end{array}$ & $\begin{array}{l}\text { Demographic Variables } \\
\text { Age (Question 1) } \\
\text { Gender (Question 2) } \\
\text { Year of Study (Question 3) } \\
\text { Enrollment Status (Question } \\
\quad \text { 4) } \\
\text { Student Origin (Question 5) } \\
\text { Degree Program (Question 6) } \\
\text { Major (Question 7) } \\
\text { Institution (Question 8) } \\
\text { Ethnicity (Question 9) }\end{array}$ & $\begin{array}{l}\text { Perceptions of Actual } \\
\text { Student Choice } \\
\text { (Question 23,29, 30, 31, } 32 \& \\
\text { 33) }\end{array}$ \\
\hline Relationship between personal and & $\begin{array}{l}\text { Personal Income (Question } \\
\text { 10) }\end{array}$ & Perceptions of Expected \\
\hline $\begin{array}{l}\text { family income and the perceptions } \\
\text { of student choice in selected } \\
\text { private }\end{array}$ & $\begin{array}{l}\text { Family Income (Question 12) } \\
\text { Percentage Students Pay }\end{array}$ & $\begin{array}{l}\text { Student Choice } \\
\text { (Question 24, 25, 26, \&27) }\end{array}$ \\
\hline Michigan universities & $\begin{array}{l}\text { (Question 11) } \\
\text { Percentage Parents Pay } \\
\text { (Question 14) }\end{array}$ & $\begin{array}{l}\text { Perceptions of Actual } \\
\text { Student Choice } \\
\text { (Question 23, 29, 30, 31, 32, } \\
\quad \text { \& 33) }\end{array}$ \\
\hline $\begin{array}{l}\text { Relationship between financial } \\
\text { incentives and the perceptions of } \\
\text { student choice in selected private } \\
\text { Michigan universities }\end{array}$ & $\begin{array}{l}\text { Student loans (Question 15) } \\
\text { Annual Tuition and Fees } \\
\text { (Question 16) } \\
\text { Total Tuition and Fees } \\
\text { (Question 17) } \\
\text { Annual Financial Aid } \\
\text { Total Financial Aid } \\
\text { Annual Grants } \\
\text { Total Grants }\end{array}$ & $\begin{array}{l}\text { Perceptions of Expected } \\
\text { Student Choice } \\
\text { (Question 24, 25, 26 \& 27) } \\
\text { Perceptions of Actual } \\
\text { Student Choice } \\
\text { (Question 23, 29, 30, 31, } 32 \\
\text { \& } \\
\text { 33) }\end{array}$ \\
\hline
\end{tabular}

Figure 5. Research variables and survey items.

\section{Instrumentation}

A questionnaire, the main method of data collection, was distributed to a sample of students from a population of students. The questionnaire consisted of three parts. The first part collected the demographic information of the participants (students). The second part was the student-selection questionnaire. These questions inquire about the financial incentives affecting students' choice in higher education. Furthermore, the questions 
provide information about the independent variables investigated in the study. The participants provided their opinions, views, and perspectives concerning financial incentives in their institutional choice in higher education.

\section{Development of Questionnaire}

The questionnaire was adapted from Felton (2012) and Mullins (2010); however, the questionnaire was modified to capture all the necessary information relating to the research questions. Modifying the research instruments refers to locating an existing instrument, obtaining permission to change it, and making any necessary changes to address the research questions of this study (Creswell, 2008).

Since the research instrumentation is adapted from Felton (2012) and Mullins (2010), the validity and reliability has been tested previously. As described by Felton, he conducted a pilot study via electronic mail, which was completed through the Zoomerang online tool. The pilot study provided an estimated response rate to the survey. Furthermore, the pilot testing also assisted in adapting and improving questions, improving format, and adapting scales as required (Creswell, 2009; Felton, 2012).

Mullins (2010) designed his research instrument using Sanford's (1966) conceptual framework of challenge and support. Mullins then submitted an initial version of the survey for review by several faculty members in the Department of Educational Leadership and Policies at University of South Carolina (USC) and piloted the research instrument with four graduate assistants September 2009 at USC. Once Mullins included the pilot study feedback, he was able to test the survey online and provide changes over the course of several weeks before administration. 


\section{Content Validity}

Content validity is one of most important and necessary elements of a research instrument. According to Krishnaswamy, Sivakumar, and Mathirajan (2006) content validity has been defined as the representativeness of the content of a measuring instrument, and if the instrument contains a representative sample of the universe of the subject matter of interest, then content validity is good. In this study, the researcher took two major steps to ensure content validity.

First, a literature review of numerous sources, including Felton (2009) and Mullins (2010), resulted in the generation of 33 items for the survey. The review of literature ensured that the researcher covered all necessary demographic characteristics items, socio-economic background items, and financial incentives pertinent to the study. To be more specific, this implies student loans, tuition and fees, financial aid, and grants were adequately presented in the survey items. In addition, the researcher ensured that there were questions related to the perceptions of expected and actual student choice.

Second, content validity was determined using a panel of persons to judge how well the instrument meets the standards. The researcher submitted an initial draft of the questionnaire for review by several faculty members in the School of Education at Andrews University: Dr. Jay Brand, Professor of Leadership and Higher Education; Dr. Jimmy Kijai, Professor of Research and Statistical Methodology; and Dr. Sylvia Gonzalez, Professor Emeritus of the Leadership Department. The reviewers' feedback suggested a decrease the number of questions in order to decrease the possibility for survey fatigue of participants. Moreover, the reviewers recommended grammatical and 
structural changes and alterations in the sentences of the survey items. Furthermore, the researcher removed all survey items which were irrelevant and ambiguous so as to minimize confusion for the prospective participants.

In connection to instrument content validity, Mr. Mordecai Ongo, Research Integrity and Compliance Officer at Andrews University, suggested revising the survey to make questions more clear and easy for students to answer. At the same time, he suggested that I should not put my name on the survey. All the suggestions were incorporated in the final survey administered to the research participants.

\section{Pilot Study}

Specifically for this study, a pilot study was conducted to assess the feasibility of the main study in order to correct any problems or weakness in the research instrument and therefore ensures the study design is adequate (Taylor, Kermode \& Roberts, 2006). In addition, the pilot study ensured that a questionnaire can be administered without variability in participants' understanding of the questions (Creswell, 2009). Thirty students participated in the pilot study at Andrews University.

The pilot study provided constructive feedback to improve the research instruments. In particular, the pilot study gave an estimate of 5 to 10 minutes to compete the survey. Moreover, the pilot test provided feedback on questions to alter or change to ensure the respondents would understand and answer the questions accurately.

In this respect, the pilot study was used to evaluate the feasibility of recruitment, retention, assessment procedures, and implementation of the research process thus ensuring hypothesis testing in the study (Leon, Davis, \& Kraemer, 2010). Furthermore, 
the pilot study enabled the researcher to minimize the risk of research problems such as question ambiguity and the participant recruitment process.

\section{Reliability Test of the Instrument}

According to Muijs (2010) reliability in statistics refers to the extent to which test scores are free of measurement errors. This means that a test of reliability indicates how free a scale is from random errors and tests the internal consistency, which is the degree to which the items that make up the scale are all measuring the same underlying attribute (Pallant, 2013).

For the main purpose of the reliability testing, 30 students participated in a pilot study from Andrews University. Specifically, I used the most common test, Cronbach's coefficient alpha to assess the reliability and internal consistency of the research instrument. This test was applicable for the Likert-scale questions. In this case, the expected and actual perception was rated on a 5-point Likert scale which ranged from 1 to 5: 1 indicated strongly disagree, 2 represented disagree, 3 indicated neutral, 4 indicated agree and 5 indicated strongly agree. The pilot results indicated that the Cronbach's coefficient alpha was 0.931 for perceptions for expected student choice while the Cronbach's coefficient alpha was 0.734 for the perceptions for actual student choice. The high Cronbach coefficient alpha ensured internal consistency and therefore it was deemed appropriate to proceed with the study.

\section{Threats to Internal Validity}

Internal validity was also addressed by the researcher. Internal validity is the process where the researcher revises the study plan to ensure that the results of the study are free from the influences of extraneous variables, flaws in the study design, or 
researcher bias (Blakenship, 2009). In other words, greater internal validity implies a greater likelihood that the observed (or unobserved) relationship between the independent and dependent variable is genuine; this allows a researcher to be more confident that any changes in the dependent variable are related to the independent variable (Schwester, 2015).

The researcher used strategies described by Blakenship (2009) to control and minimize the threats to internal validity. First, the researcher used standardized questions that are scored in the same way to ensure adequate time to score data consistently.

Second, the researcher was the only person collecting the data, allowing easy standardization of the data collection process.

\section{Factor Analysis}

The researcher used factor analysis to assess the construct validity of the research instrument. Specifically for this study, the factorability of the 12 items (questions 22 to 33) describing the perceptions of student choice in selected private Michigan universities was initially determined. In Table 3, the Kaiser-Meyer-Olkin measures of sampling adequacy for the factors were: Perceptions of expected student choice (0.789) and Perceptions of actual student choice (0.708), both exceeded the recommended value of 0.5 (Field, 2005). In addition, the Bartlett's test for sphericity for all dependent variables were significant at $\mathrm{p}<0.00$.

Table 3

Kaiser-Meyer-Olkin of Sampling Adequacy and Bartlett's Test of Sphericity 


\begin{tabular}{lcccc}
\hline Dimensions & KMO & $\begin{array}{c}\text { Approx Chi } \\
\text { Square }\end{array}$ & $\begin{array}{c}\text { Bartlett's Test } \\
\text { of Sphericity } \\
(\mathrm{df})\end{array}$ & Sig \\
\hline Expected Choice & 0.789 & $1,214.037$ & 6 & 0.00 \\
Actual Choice & 0.708 & 826.282 & 10 & 0.00 \\
\hline
\end{tabular}

Table 4 illustrates that 10 items were factor analyzed using the principal component analysis (PCA) with varimax (orthogonal) rotation. In this case, the choice of PCA was based on the assumption that the variables were not independent. Therefore, the two variables (perceptions of expected and actual student choice) with rotation reveal that the subscales of the research instruments measure what they intend to measure (See Table 4). Furthermore, there were no items removed in the factor analysis. However, several items were reworded and some items which were accidentally redundant were eliminated.

\section{Human Subjects Consideration}

In order to conduct this study with students in the selected private Michigan universities, the researcher successfully completed the National Institutes of Health (NIH) Web-based training course about "Protecting Human Research Participants" (see Appendix D). In addition, the rights of respondents participating in this study were secured through the provision of consent forms.

\section{Procedure}

The participant recruitment process involved contacting the administrator, especially the Institutional Review Board (IRB) of the five institutions at the beginning of November 2014 to arrange access to a random sample of 780 undergraduate e-mail 
addresses to recruit participants for the survey. However, the IRB did not provide e-mail addresses of student participants due to confidentiality reasons.

Table 4

Factor Loading for Principal Components Analysis with Varimax Rotation of Perceptions of Expected and Actual Student Choice

\begin{tabular}{|c|c|c|c|c|}
\hline \multirow[t]{2}{*}{ Dimensions/Factors } & \multirow[t]{2}{*}{ No. } & \multirow[t]{2}{*}{ Item } & \multicolumn{2}{|c|}{ Components } \\
\hline & & & 1 & 2 \\
\hline \multirow[t]{4}{*}{ Expected Choice } & 24 & $\begin{array}{l}\text { If money were not a concern, I } \\
\text { would have chosen another } \\
\text { college or university. }\end{array}$ & 0.873 & 0.142 \\
\hline & 25 & $\begin{array}{l}\text { If financial aid and/or } \\
\text { scholarship were not a } \\
\text { concern, I would have chosen } \\
\text { another college or university }\end{array}$ & 0.857 & 0.229 \\
\hline & 26 & $\begin{array}{l}\text { If State and Federal grants } \\
\text { were not a concern, I would } \\
\text { have chosen another college or } \\
\text { university }\end{array}$ & 0.894 & 0.302 \\
\hline & 27 & $\begin{array}{l}\text { If state and federal Tax breaks } \\
\text { were not a concern, I would } \\
\text { have chosen another college or } \\
\text { university }\end{array}$ & 0.848 & 0.351 \\
\hline \multirow[t]{4}{*}{ Actual Choice } & 23 & $\begin{array}{l}\text { Concerns regarding the future } \\
\text { debt associated with the } \\
\text { college I chose influenced the } \\
\text { college or university I selected }\end{array}$ & 0.115 & -0.013 \\
\hline & 29 & $\begin{array}{l}\text { The availability of loans } \\
\text { influenced the school I chose }\end{array}$ & 0.143 & 0.558 \\
\hline & 30 & $\begin{array}{l}\text { The primary reason I chose } \\
\text { my current college or } \\
\text { university was cost }\end{array}$ & 0.356 & 0.655 \\
\hline & 31 & $\begin{array}{l}\text { Financial aid or scholarship } \\
\text { offered by institutions have } \\
\text { influenced the school of } \\
\text { choice }\end{array}$ & 0.100 & 0.739 \\
\hline
\end{tabular}


32 State and federal grants offered by my institution have influenced the school I chose to attend

$33 \quad$ State and federal tax breaks offered by my institution have influenced the school I chose to attend

At the same time, four out of five institutions granted the IRB approval. These institutions were Andrews University, Spring Arbor University, University of DetroitMercy, and Concordia University-Ann Arbor. Cleary University did not provide IRB approval even though I was persistent in attempts to contact the IRB Board including a personal visit to the institution requesting IRB approval.

For those institutions that granted IRB approval, I distributed invitation letters to recruit participants for the survey. At the same time, I posted research flyers in each institution as a continuous effort to recruit additional research participants. The recruitment documents provided my phone number and e-mail address so that those students who were willing to participate would let me know. The process of participant invitation occurred from December 1 to December 14.

Subsequently, I administered a survey to a sample of 780 conveniently selected undergraduates. In order to ensure maximum retrieval rate of the survey, I personally administered a copy of the consent forms and survey to research participants in some classrooms and other designated areas assigned by these institutions. However for the students who were not able to respond immediately to the questionnaire in the classrooms or other designated areas, the participants were asked to complete the informed consent form and the survey in one week. 
Figure 6 provides a comprehensive description about participant recruitment, the necessary activities, and the timeline of the whole process.

\begin{tabular}{|c|c|c|}
\hline Dates & Event & Activity \\
\hline October $15-$ & IRB & Contact IRB committees of every \\
\hline \multirow[t]{3}{*}{ November 15, 2014} & Application & $\begin{array}{l}\text { institution expected to participate in the } \\
\text { study. }\end{array}$ \\
\hline & & $\begin{array}{l}\text { 2. Prepare necessary documents for IRB } \\
\text { application. }\end{array}$ \\
\hline & & $\begin{array}{l}\text { 3. Request access to a random sample } \\
\text { of undergraduate email addresses. }\end{array}$ \\
\hline \multirow[t]{2}{*}{ November 20, 2014} & IRB Approval & $\begin{array}{l}\text { 1. Received the letter of IRB approval } \\
\text { from four institutions. }\end{array}$ \\
\hline & & $\begin{array}{l}\text { 2. Did not receive access to a random } \\
\text { sample of undergraduate email } \\
\text { addresses. }\end{array}$ \\
\hline \multirow[t]{3}{*}{ December 4, 2014} & Participants & 1. Visited the institutions and requested \\
\hline & Recruitment & $\begin{array}{l}\text { access to participants to participate in } \\
\text { the study }\end{array}$ \\
\hline & & $\begin{array}{l}\text { 2. Post recruitment flyers in each } \\
\text { institution. }\end{array}$ \\
\hline \multirow[t]{2}{*}{ January $15-24,2014$} & Survey & 1. Visited the institutions and requested \\
\hline & Administering & $\begin{array}{l}\text { access to participants to survey } \\
\text { 2. Administer personally the informed } \\
\text { consent forms and surveys on campus to } \\
\text { maximize the retrieval rate. }\end{array}$ \\
\hline \multirow{3}{*}{$\begin{array}{l}\text { January } 24,2015 \\
\text { January } 26-28\end{array}$} & Data Analysis & 1. Gave the questionnaire to the \\
\hline & & statistician for data analysis \\
\hline & & $\begin{array}{l}\text { 2. Processes the data and received the } \\
\text { analyzed data }\end{array}$ \\
\hline
\end{tabular}

Figure 6. Timeline

\section{Data Collection}


Quantitative methods were used to collect data. A survey was used as the primary method of data collection from a sample of students at selected institutions. A survey is an approach in quantitative research in which the researcher administers a survey or questionnaire to a sample or to the entire population of people to measure the attitudes, opinions, behaviors, or characteristics of the population (Creswell, 2008). The survey was a series of questions aimed at answering the main research questions. The study fundamentally uses a survey instrument with demographic characteristics items (9 questions), socio-economic background items (5 questions), financial incentives items (7 questions) and items on the perceptions of student choice with 12 questions on a 5point Likert scale ranging from strongly disagree (1) to strongly agree (5).

Anonymity of the research respondents was assured due to the sensitivity of the financial information disclosed in the research. As supported by Ong and Weiss (2000), participants are more likely to respond freely to questions on sensitive topics whenever they are guaranteed anonymity. Primarily and precisely, the questionnaire did not collect identifying information of research respondents like name, address, e-mail address or any other information that link specific responses with the respondents identities.

The IRB was provided with information (IRB application forms, research protocol, research instrument, National Institute of Health web-training certificate, participants informed consent forms, and participants recruitment documents like invitation letters, verbal recruitment script and recruit flyers) in order to grant approval for the study in November 2014. The expected duration of the study was four weeks, from the beginning to the end of data collection. I administered the survey to convenient 
selected students who were informed about the nature of the survey and the intent to administer it by January 15, 2015.

The retrieval rate expected was $75 \%$ of the total questionnaires administered to the participants. This is because many researchers believe that the higher response rate assures more accurate survey results (Fitch, 2009). This ensures the reliability and validity of the research. However, the researcher managed to retrieve 341 questionnaires administered to the research participants because the researcher personally administered the survey. In this case, the researcher managed to retrieve $43.7 \%$ of the total questionnaire administered which was $87.4 \%$ of the sample size.

\section{Data Entry and Screening}

The data screening process revealed that several participants did not indicate their choice of major. In addition, some participants did not indicate their annual income and others did not provide a best estimate of their annual income. Since the missing data is less than $1 \%$ of the questionnaire collected, the best approach was to ignore the missing data by analyzing only the available data (Berglund \& Heeringa, 2014).

In relation to the data screening process, there were also missing data from the administered surveys. In order to correct the missing values, Little Missing at Random Test was used to test whether the missing values were missing completely at random (MCAR), which means a variable is missing completely at random if the probability of missingness is the same for all units or Missing at Random (MAR) which means most missingness is not completely random as can be seen from the data itself (Gelman \& Hill, 2006). For this procedure, the null hypothesis was that data are missing completely at random at the $p$-value is significant at 0.05 . 
The Little Missing Completely at Random Test (MCAR) revealed the first relevant category is missing data completely at random. Given these findings, the missing data have no relationship with the research variables modeled. Therefore, survey data were missing separately and are not due to observed or unobserved data. Thus, the missing data was excluded as long as the regression controls at least all the important variables that affect the probability of missingness.

\section{Data Analysis}

The data gathered was analyzed using the Statistical Package for the Social Sciences (SPSS), Version 22.0 for Windows. Specifically, the data analysis involved the following strategies to analyze the data for three major research questions.

The first strategy was to provide descriptive statistics for question 1 (demographic characteristics), question 2 (socio-economic background) and question 3 (financial incentives). In this section, the researcher summarized and tabulated all the demographic characteristics with questions, their descriptions, frequencies, and percentages. These also help summarize the overall trends or tendencies in the data, provide an understanding of how varied the scores might be, and provide insight into where one score stands in comparison with other scores.

The second strategy was to establish the relationship between demographic characteristics and the perceptions of student choice in selected private Michigan universities. The researcher used ANOVA to predict a single dependent variable based on one or more variables, and to establish whether those predictors are good predictors (Cardinal \& Aitken, 2006). In particular, the researcher arranged the data with subtitles for each survey questions in terms of independent variables (demographic characteristics) 
and dependent variables (perceptions of expected and actual student choice). Once data was assigned subtitles, the researcher compared the means. The researcher took a step further to compare main effects by conducting a post hoc test. For the post hoc test, a Student-New-Keuls (SNK) was used as strategy to identify sample means which are significantly different from each other and Games Howell designed for unequal variances, which also takes into account unequal group sizes.

The third strategy was to establish the relationship between personal income and family income and perceptions of student choice in higher education institutions among students at selected private Michigan universities. In order to implement this strategy, categorical regression analysis was used. Categorical regression analysis was the best method for this question for the following reasons: (a) in determining whether a particular effect of financial incentives is present in student choice, (b) in measuring the magnitude of a particular effect of financial incentives, and (c) in forecasting what a particular effect of financial incentives would be on student choice in higher education (Rubinfeld, 1994).

Furthermore, the same categorical regression analysis was used to establish the relationship between financial incentives (student loans, tuition and fees, scholarships or other financial aid, grants, and tax breaks) and Perceptions of Student Choice of higher education institutions among students in selected private Michigan universities.

\section{Chapter Summary}

In summary, the study used a quantitative research approach. Specifically, the study adopted the correlational method. The study by Vossensteyn (2005) provided a strong theoretical and conceptual background for this study by developing an empirical 
model that captured information on student background characteristics (independent variables), students' perceptions of financial incentives (independent variables), and students' observed study-related choices (dependent variables). The participants were students in selected private universities in Michigan. In connection to this, simple random sampling was used to choose the universities for the research. A total of 780 questionnaires were conveniently administered to participants. The questionnaire was adapted from Felton (2012) and Mullins (2010); however, the questionnaire was modified to capture all the necessary information relating to the research questions. In addition, the adapted research instrument was pilot tested, reliability tested, and evaluated for content and construct validity. Furthermore, the data gathered were analyzed using the ANOVA and Categorical Regression Analysis. The data were tabulated and findings summarized in relevant descriptions. All these steps were crucial for the research methodology. 


\section{CHAPTER 4}

\section{RESEARCH FINDINGS}

\section{Introduction}

The purpose of this study is to investigate the role that financial incentives play in students' selection process for their choice of an undergraduate degree granting higher education institution.

Initially and primarily, this chapter presents the empirical findings that address the three questions posed in the study. Additionally, each hypothesis to be tested summarized the influence of an independent variable on a dependent variable. Finally, this chapter provides a summary of the findings and an extensive synopsis of the study and is organized around the following research questions:

1. What is the relationship between student demographic characteristics and perceptions of student choice of higher education institutions among students at selected private Michigan universities?

2. What is the relationship between personal/family incomes and perceptions of student choice in higher education institutions among students at selected private Michigan universities?

3. Which financial incentives (student loans, tuition and fees, scholarships, financial aid, and grants) are the best predictors of perceptions of student choice of higher education institutions among students at selected private Michigan universities? 


\section{General Findings}

\section{Demographic Characteristics of the Participants}

This section summarizes the background characteristics of the participants of the study including age, gender, enrollment status, degree pursued, race, and university attended. Table 5 provides a summary of the demographic characteristics of the participants.

The data shown illustrates the following age distribution of the participants: under 19 years $(13.2 \%), 19$ to 24 years $(79.8 \%), 25$ to 35 years $(5.6 \%), 35$ to 50 years $(0.6 \%)$, over 50 years $(0.3 \%)$ and missing data $(0.6 \%)$. A total of 341 surveys were retrieved from participants, $41.6 \%$ of whom were female, $57.2 \%$ male, and $1.2 \%$ missing data.

Furthermore, the most common year of study among respondents was the second year (42.2\%), followed by third year (28.2\%), fourth year (19.6\%), first year (7.3\%), students who have been attending their institutions for more than five years (1.5\%) and missing data (1.2\%). Closely connected to this, the enrollment status indicated that $14.7 \%$ of the students were part- time, $84.5 \%$ full-time, and $0.9 \%$ missing data.

Table 5 also shows the majority (54\%) of respondents were out-of-state students with $26.7 \%$ in-state, $17 \%$ international students, and $2.3 \%$ missing data. The large majority of students (94.4\%) were working toward a bachelor's degree, with $2.3 \%$ pursuing associate degrees, $0.6 \%$ working on certificates, and $2.6 \%$ missing data. Moreover, the major areas of study pursued by the participants were: $10.9 \%$ art and humanities, $63 \%$ science, $12.3 \%$ business, $4.7 \%$ education, $8.2 \%$ were pursuing other majors, and $0.9 \%$ missing data. 
Table 5

Demographic Characteristics of Participants

\begin{tabular}{|c|c|c|c|}
\hline Questions & Description & Number & Percentage \\
\hline \multirow[t]{6}{*}{ 1. Age } & Under 19 & 45 & 13.2 \\
\hline & 19-24 & 272 & 79.8 \\
\hline & $25-35$ & 19 & 5.6 \\
\hline & $35-50$ & 2 & 0.6 \\
\hline & Over 50 & 1 & 0.3 \\
\hline & Missing Data & 2 & 0.6 \\
\hline \multirow[t]{3}{*}{ 2. Gender } & Female & 142 & 41.6 \\
\hline & Male & 195 & 57.2 \\
\hline & Missing Data & 4 & 1.2 \\
\hline \multirow[t]{6}{*}{ 3. Year of Study } & First & 25 & 7.3 \\
\hline & Second & 144 & 42.2 \\
\hline & Third & 96 & 28.2 \\
\hline & Fourth & 67 & 19.6 \\
\hline & Other & 5 & 1.5 \\
\hline & Missing Data & 4 & 1.2 \\
\hline \multirow[t]{3}{*}{ 4. Enrollment Status } & Part Time & 50 & 14.7 \\
\hline & Full Time & 288 & 84.5 \\
\hline & Missing Data & 3 & 0.9 \\
\hline \multirow[t]{4}{*}{ 5. Student Origin } & In-State & 91 & 26.7 \\
\hline & Out-of-State & 184 & 54.0 \\
\hline & International & 58 & 17.0 \\
\hline & Missing Data & 8 & 2.3 \\
\hline \multirow[t]{4}{*}{ 6. Degree Program } & Certificate & 2 & 0.6 \\
\hline & Associate & 8 & 2.3 \\
\hline & Bachelor & 322 & 94.4 \\
\hline & Missing Data & 9 & 2.6 \\
\hline \multirow[t]{6}{*}{ 7. Major } & Arts and Humanities & 37 & 10.9 \\
\hline & Sciences & 215 & 63.0 \\
\hline & Business & 42 & 12.3 \\
\hline & Education & 16 & 4.7 \\
\hline & Other majors & 28 & 8.2 \\
\hline & Missing Data & 3 & 0.9 \\
\hline \multirow[t]{5}{*}{ 8. Institution } & Andrews University & 91 & 26.7 \\
\hline & Concordia University & 18 & 5.3 \\
\hline & Spring Arbor University & 63 & 18.5 \\
\hline & University of Detroit-Mercy & 166 & 48.7 \\
\hline & Missing Data & 3 & 0.9 \\
\hline
\end{tabular}


Table 5-Continued.

\begin{tabular}{clcr}
\hline Questions & Description & Number & Percentage \\
\hline 9. Ethnicity & African American & 103 & 30.2 \\
& Caucasian & 152 & 44.6 \\
& Asians & 34 & 9.9 \\
& Latino & 15 & 4.4 \\
& Other & 33 & 9.7 \\
& Missing Data & 4 & 1.2 \\
\hline
\end{tabular}

The participating students came from four educational institutions. The most commonly represented institution was the University of Detroit-Mercy (48.7\%), followed by Andrews University (26.7\%), Spring Arbor University (18.5\%), Concordia University $(5.3 \%)$, and $0.9 \%$ missing data. In addition to their institution, the students reported their ethnic group as follows: 30.2\% African American, 44.6\% Caucasian, 9.9\% Asians, 4.4\% Latino, $9.7 \%$ other, and $1.2 \%$ missing data.

\section{Research Question 1}

What is the relationship between student demographic characteristics and perceptions of student choice of higher education institutions among students at selected private Michigan universities?

ANOVA was used to test the hypothesis that there is no significant relationship between student demographic characteristics and perceptions of student choice of higher education institutions among students at selected private Michigan universities. ANOVA tests the hypothesis by evaluating the means for all the groups; therefore, if the observed p-value is equal to or less than the chosen alpha level, then the null hypothesis (of no differences among the population mean) is rejected; if the observed p-value is greater than the chosen alpha-level then the test fails to reject the null hypothesis (Leach, 2004). 
In connection with this, the significance level was set at $\alpha=0.05$.

However, to avoid possible inflated alpha levels, the Bonferroni correction formula Alpha/ $\mathrm{N}$ was applied whereby the alpha is the chosen alpha level (typically 0.05) and $\mathrm{N}$ is the number of tests conducted (for this study $\mathrm{N}=9$; Meyers, Gamst, \& Guarino, 2013). This formula provides the new corrected alpha level to determine statistical significance. Specifically, the corrected alpha level was 0.005. Despite these alpha level adjustments, due to the fact that Bonferroni correction formula was very conservative and leads to inflated rejections of models and real association (Hall, Friedmann, Dunlap, \& Heyningen, 2008), the researcher used an adjusted alpha level at 0.01 .

Table 6 shows the relationship between age and the perceptions of student choice in private Michigan universities. The mean score and standard deviation for each age group for perceptions of expected student choice were as follows: under $19(M=3.24$, $S D=1.03), 19-24(M=3.09, S D=1.18)$, and 25 and over $(M=3.43, S D=1.01)$ indicating that all participant age groups tended to be neutral regarding whether financial incentives influence their choice of college. In connection to this, the mean score and standard deviation for each age group for perceptions of actual student choice were as follows: under $19(M=3.24, S D=0.89), 19-24(M=3.18, S D=0.87)$, and 25 and over $(M=3.64, S D=0.88)$ showing that respondents tended to be neutral as to whether financial incentives influence student choice in selected private Michigan universities.

In addition, the one-way ANOVA, $F(2,335)=1.13, p=0.32$, indicated no significant relationship between age and the perceptions of expected student choice in selected private Michigan universities. At the same time, the one-way ANOVA, $F$ $(2,335)=2.53, p=0.08$ suggests that there may not be any significant relationship 
between age and the perceptions of actual student choice in selected private Michigan universities.

To add to these findings, the effect size of age on the perceptions of expected student choice (0.006) indicates age accounts for $0.6 \%$ of variance of the perceptions of expected student choice in selected private Michigan universities. In this case, the effect size is small. On the other side, the effect size of age toward perceptions of actual student choice (0.001) reveals age accounts for $0.1 \%$ of variance of the perceptions of actual student choice in selected private Michigan universities. Therefore, the effect size of age toward the perceptions of actual student choice is relatively smaller than the effect size of age toward the perceptions of expected student choice. In general, it can be suggested that age was not statistically significant for both the perceptions of expected and actual student choice in selected private Michigan universities.

Table 6

Relationship Between Age and the Perceptions of Student Choice

\begin{tabular}{llrrrrrrr}
\hline Variable & Group & $N$ & Mean & $S D$ & $F$ & $d f$ & $p$ & $n^{2}$ \\
\hline Expected Choice & Under 19 & 45 & 3.24 & 1.03 & 1.13 & 2,335 & 0.32 & 0.006 \\
& $19-24$ & 271 & 3.09 & 1.18 & & & & \\
& 25 and over & 22 & 3.43 & 1.01 & & & & \\
Actual Choice & Under 19 & 45 & 3.24 & 0.89 & & & & \\
& 19-24 & 271 & 3.18 & 0.87 & 2,53 & 2,335 & 0.08 & 0.001 \\
& 25 and over & 22 & 3.62 & 0.88 & & & & \\
\hline
\end{tabular}


Table 7 establishes the relationship between gender and the perceptions of student choice in selected private Michigan universities. The mean score and standard deviation for each age group for perceptions of expected student choice were as follows: male $(M=2.92, S D=1.15)$, female $(M=3.29, S D=1.11)$ indicate participants tend to somewhat neutral that financial incentives influence their choice of college. Moreover, the mean score and standard deviation for each age group for perceptions of actual student choice were as follows: male $(M=3.12, S D=0.89)$, female $(M=3.29, S D=$ 0.86 ) tend to be neutral regarding whether financial incentives influenced student choice.

In Table 7 the one-way ANOVA, $F(1,334)=8.65, p=0.003$, indicates there may be a relationship between gender and the perceptions of expected student choice in selected private Michigan universities. Post hoc test indicates that female students with mean of 3.29 were more likely influenced by financial incentives compared to male students with a mean of 3.12. In addition, the one-way ANOVA, $F(1,334)=3.11$, $p=0.079$ indicates there likely is no relationship between gender and the perceptions of actual student choice in selected private Michigan universities.

Further findings regarding the effect size of gender on the perceptions of expected student choice $(0.025)$ reveal that gender accounts for $2.5 \%$ of the variance in the perceptions of expected student choice in selected Michigan universities. The effect size is small. At the same time, the effect size of gender on the perceptions of actual student choice (0.009) indicate that gender accounts for $0.9 \%$ of the variance on the perceptions of actual student choice in selected private Michigan universities. The effect size of gender on the perceptions of actual student choice is relatively smaller than the effect size of gender on the perceptions of expected student choice. 
In summary, these findings may imply that gender was statistically significant and contributed to a small variance in perceptions of expected student choice, although gender was not statistically significant to the perceptions of actual student choice in selected private Michigan universities.

Table 7

Relationship Between Gender and the Perceptions of Student Choice

\begin{tabular}{llccccccc}
\hline Variable & Group & $N$ & Mean & $S D$ & $F$ & $d f$ & $p$ & $n^{2}$ \\
\hline Expected Choice & Male & 142 & 2.92 & 1.15 & 8.65 & 1,334 & 0.003 & 0.025 \\
& Female & 194 & 3.29 & 1.11 & & & & \\
Actual Choice & Male & 142 & 3.12 & 0.89 & 3.11 & 1,334 & 0.079 & 0.009 \\
& Female & 194 & 3.29 & 0.86 & & & & \\
\hline
\end{tabular}

Note. Level of significance is 0.01 .

Table 8 shows the relationship between year of study and the perceptions of student choice in selected private Michigan universities. The means for 1 st, 2 nd, 3rd, and 4th year students were $3.42,3.20,3.28$, and 2.68 respectively for the perceptions of expected student choice in higher education. These mean scores indicate students tended to be somewhat neutral about the impact of financial incentives toward the perceptions of expected student choice except for the 4th year students who somewhat disagree. At the same time, the means for 1st, 2nd, 3rd and 4th year students were 3.16, 3.29, 3.27, and 3.02, respectively, for the perceptions of actual student choice. These averages indicate that students tend to be neutral about whether financial incentives influence the perceptions of actual student choice in selected private Michigan universities.

Furthermore, the one-way ANOVA, $F(3,327)=4.88, p=0.002$, suggest there 
may be a relationship between year of study and the perceptions of expected student choice in selected private Michigan universities. In addition to these findings, post hoc test using Student-Newman- Keuls (SNK) indicates 1st, 2nd, 3rd, and 4th year students were statistically different from each other. Specifically, the highest statistical difference was between 1 st year and 4th year students.

At the same time, the one-way ANOVA, $F(3,327)=1.58, p=0.193$, revealed that there may not be any relationship between year of study and the perceptions of actual choice of college among students in selected private Michigan universities.

Table 8 also reveals the effect size for year of study on the perceptions of expected student choice (0.042), indicating year of study accounts for $4.2 \%$ of the variance in the perceptions of expected student choice. The effect size is small. Moreover, the effect size for year of study on the perceptions of actual student choice (0.014) reveals year of study accounts for $1.4 \%$ of variance in the perceptions of actual student choice. In this scenario, the effect size for year of study on the perceptions of actual student choice is relatively smaller than the effect size for year of study on the perceptions of expected student choice.

Therefore, it is appropriate to tentatively infer that year of study was statistically significant and influenced the perceptions of expected student choice, although the year of study was not statistically significant to the perceptions of actual student choice. 
Table 8

Relationship Between Year of Study and the Perceptions of Student Choice

\begin{tabular}{lcccccccc}
\hline Variable & Group & $N$ & Mean & SD & $F$ & $d f$ & $p$ & $n^{2}$ \\
\hline Expected & $1^{\text {st }}$ Year & 25 & 3.42 & 1.10 & 4.88 & 3,327 & 0.002 & 0.042 \\
Choice & $2^{\text {nd }}$ Year & 144 & 3.20 & 1.12 & & & & \\
& $3^{\text {rd }}$ Year & 95 & 3.28 & 1.13 & & & & \\
& $4^{\text {th }}$ Year & 67 & 2.67 & 1.16 & & & & \\
& & & & & & & & \\
Actual & $1^{\text {st }}$ Year & 25 & 3.16 & 1.11 & 1.58 & 3,327 & 0.193 & 0.014 \\
Choice & $2^{\text {nd }}$ Year & 144 & 3.29 & 0.80 & & & & \\
& $3^{\text {rd }}$ Year & 95 & 3.27 & 0.93 & & & & \\
& $4^{\text {th }}$ Year & 67 & 3.07 & 0.82 & & & & \\
& & & & & & & & \\
\end{tabular}

Table 9 shows the relationship between enrollment status and the perceptions of student choice in selected private Michigan universities. Various important aspects need to be understood in this table. The mean for part-time and full time students were 3.43 and 3.07 respectively indicating that students are neutral about the impact of the financial incentives toward the perceptions of expected student choice. On the other hand, the mean for part-time and full-time students were 3.58 and 3.14 respectively, which reveal those students are neutral about the impact of financial incentives toward the perceptions of actual student choice.

Moreover, the one-way ANOVA, $F(1,335)=4.066, p=0.045$, indicate there may not be any relationship between enrollment status and the perceptions of expected student choice in selected private Michigan Universities. In addition, the one-way ANOVA, $F$ $(1,335)=10.702, p=0.001$, indicated that there was a relationship between enrollment 
status and the perceptions of actual student choice in selected private Michigan universities. Further analysis revealed that part-time students were in agreement that financial incentives influenced their perceptions of actual college choice compared to full-time students.

Additional findings indicate that the effect size of enrollment status on the perceptions of expected student choice (0.011) reveals enrollment status explains $1.1 \%$ of the variance in the perceptions of expected student choice. The effect size is small. Furthermore, the effect size of enrollment status toward the perceptions of actual student choice (0.03) shows enrollment status explains $3 \%$ of the variance in the perceptions of actual student choice. The effect size of enrollment status toward the perceptions of actual student choice is relatively larger than the effect size of enrollment status in the perceptions of expected student choice.

To summarize, the pattern of these results imply that enrollment status was statistically significant and contributed a small variance in perceptions of actual student choice while enrollment status was not statistically significant to perceptions of expected student choice.

Table 9

Relationship Between Enrollment Status and the Perceptions of Student Choice

\begin{tabular}{llrrrrrrc}
\hline Variable & \multicolumn{1}{c}{ Group } & $N$ & Mean & $S D$ & $F$ & $d f$ & $p$ & $n^{2}$ \\
\hline Expected Choice & Part-time & 50 & 3.43 & 1.10 & 4.066 & 1,335 & 0.045 & 0.011 \\
& Full-time & 287 & 3.07 & 1.15 & & & & \\
Actual Choice & & & & & & & & \\
& Part-time & 50 & 3.58 & 0.85 & 10.70 & 1,335 & 0.001 & 0.030 \\
& Full-time & 287 & 3.14 & 0.86 & & & & \\
\hline
\end{tabular}


Table 10 shows the relationship between Student Origin and the perceptions of student choice in private Michigan universities. As far as the perceptions of expected student choice are concerned, the mean for in-state, out-of-state, and international student were $2.80,3.27$, and 3.20 respectively. In connection to this, the mean response of the total sample to the statement "financial incentives affect student choice in selected private Michigan universities" was greater than 3 on a 5-point scale which indicate that student are neutral toward the argument. However, the mean response of in-state participants for the perceptions for expected student choice was 2.80, which reveal those students somewhat disagree about the influence of financial incentive toward student choice in higher education. On the other hand, the perceptions of actual student choice have the following mean: $3.12,3.28$, and 3.14 which show students are neutral about the impact of financial incentive toward the perceptions of actual student choice.

Moreover, the one-way ANOVA, $F(2,329)=5.248, p=0.006$, revealed there is a relationship between student origin and the perceptions of expected student choice in selected private Michigan universities. In connection to these findings, the SNK post hoc test revealed the mean score of international students and out of state students was not statistically different from each other. However, the mean score of in-state students was statistically significant different from the mean score of international students and out-ofstate students; although the means also indicated that international students and out-ofstate students were more likely influenced by financial incentives while in-state students tended to disagree on the same notion. In relation to these findings, the one-way ANOVA, $F(2,329)=1.222, p=0.296$, shows there may not be relationship between 
student origin and the perceptions of student choice in selected private Michigan universities.

Further analysis of Table 10 reveals the effect size of student origin on the perceptions of expected student choice was 0.03 . This effect size indicates that student origin explains $3 \%$ of the variance in the perceptions of expected student choice. The effect size is small. In spite these findings, the effect size of student origin toward the perceptions of actual student choice was 0.007 which implies student origin explains $0.7 \%$ of the variance in the perceptions of actual student choice. The effect size of student origin on perceptions of actual student choice is relatively smaller than the effect size of enrollment toward the perceptions of expected student choice.

In essence, the student origin was statistically significant and contributed a small variance to perceptions of expected student choice while student origin was not statistically significant to perceptions of actual student choice.

Table 10

Relationship Between Student Origin and the Perceptions of Student Choice

\begin{tabular}{llrcccccc}
\hline Variable & \multicolumn{1}{c}{ Group } & $N$ & Mean & SD & $F$ & $d f$ & $p$ & $n^{2}$ \\
\hline \multirow{2}{*}{ Desired Choice } & In-state & 91 & 2.80 & 1.25 & 5.24 & 2,329 & 0.006 & 0.030 \\
& Out-of-state & 183 & 3.27 & 1.09 & & & & \\
& International & 58 & 3.20 & 1.01 & & & & \\
& & & & & & & & \\
Actual Choice & In-state & 91 & 3.12 & 0.92 & 1.22 & 2,329 & 0.296 & 0.007 \\
& Out-of-state & 183 & 3.28 & 0.85 & & & & \\
& International & 58 & 3.14 & 0.89 & & & & \\
\hline
\end{tabular}


Table 11 describes the relationship between undergraduate major and the perceptions of student choice in selected private Michigan universities. In the table representation, the mean score for students who majored in Arts and Humanities, Sciences, Business, Education, and Other majors were 3.20, 3.20, 3.24, 2.54, and 2.71 respectively for perceptions of expected student choice. These results indicate students who major in arts and humanities, sciences, and business were somewhat neutral about the impact of financial incentives toward perceptions of expected student choice in selected private Michigan universities. However, the same results revealed students in education and other majors tend to disagree about the impact of financial incentives on the perceptions of expected student choice.

Nevertheless, the mean score for students in Arts and Humanities, Sciences, Business, Education and Other majors were 3.18, 3.23, 3.28, 3.23 and 3.18 respectively for the perceptions of actual student choice. These results indicate students were neutral about the impact of financial incentives toward perceptions of expected student choice in selected private Michigan universities.

To further support these findings, the one-way ANOVA, $F(4,325)=2.07, p=$ 0.08 , revealed there may not be any relationship between degree major and the perceptions of expected student choice in selected private Michigan universities. To this similar results, the one-way ANOVA, $F(4,325)=0.08, p=0.98$ indicate there may not be any relationship between the degree majors and the perceptions of actual student choice in selected private Michigan universities.

In order to gain perspective of these findings, effect size of degree majors toward the perceptions of expected student choice was 0.02 . In this case, degree majors account 
for $2 \%$ of the variance in the perceptions of expected student choice. The effect size is small. Apart from these findings, effect size of degree majors on the perceptions of actual student choice was 0.001 . Consequently, the degree majors account for $0.1 \%$ of the variance in the perceptions of actual student choice. As a result, the effect size of degree majors toward perceptions of actual student choice is relatively smaller than the effect size of the degree majors toward perceptions of expected student choice.

Succinctly, these findings suggest degree majors may not be statistically significant for both the perceptions of expected and actual student choice.

Table 11

Relationship Between Degree Major and the Perceptions of Student Choice

\begin{tabular}{llrrrrrrr}
\hline Variable & \multicolumn{1}{c}{ Group } & $N$ & Mean & SD & $F$ & $d f$ & $p$ & $n^{2}$ \\
\hline Expected & Arts \& Humanities & 37 & 3.20 & 1.16 & 2.07 & 4,325 & 0.08 & 0.020 \\
Choice & Sciences & 215 & 3.20 & 1.13 & & & & \\
& Business & 42 & 3.24 & 1.04 & & & & \\
& Education & 16 & 2.54 & 1.09 & & & & \\
& Other majors & 21 & 2.71 & 1.34 & & & & \\
Actual & Arts \& Humanities & 37 & 3.18 & 0.85 & 0.08 & 4,325 & 0.98 & 0.001 \\
Choice & Sciences & 215 & 3.23 & 0.83 & & & & \\
& Business & 42 & 3.28 & 0.86 & & & & \\
& Education & 16 & 3.23 & 1.08 & & & & \\
& Other majors & 21 & 3.18 & 1.14 & & & & \\
& & & & & & & & \\
\hline
\end{tabular}

Table 12 describes the relationship between participants' educational institution and perceptions of student choice in selected private Michigan universities. The mean score on each institution for perceptions of expected student choice were as follows: Andrews University $(M=3.52)$, Concordia University $(M=3.30)$, and University of Detroit Mercy $(M=3.25)$ indicate that students were neutral about the impact of financial 
incentives toward perceptions of expected student choice. However, Spring Arbor University $(M=2.18)$ reveals that students disagree that financial incentives had an impact on the perceptions of expected student choice.

Furthermore, the mean score on each institution for perceptions of actual student choice was as follows: Andrews University $(M=3.11)$, Concordia University $(M=2.84)$, Spring Arbor University $(M=2.78)$, and University of Detroit Mercy (3.21). These results indicate Andrews University and University of Detroit Mercy were neutral while Concordia University and Spring Arbor University disagreed about the impact of financial incentives toward perceptions of actual student choice in selected private Michigan universities.

Table 12

\section{Relationship Between Educational Institution and the Perceptions of Student Choice}

\begin{tabular}{llrrrrrrr}
\hline Variable & \multicolumn{1}{c}{ Group } & $N$ & Mean & SD & $F$ & $d f$ & $p$ & $n^{2}$ \\
\hline Expected & Andrews university & 87 & 3.52 & 0.95 & 20.89 & 3,326 & $<0.01$ & 0.16 \\
Choice & Concordia university & 18 & 3.30 & 0.65 & & & & \\
& Spring Arbor university & 60 & 2.18 & 1.10 & & & & \\
& Univ. of Detroit Mercy & 165 & 3.25 & 1.13 & & & & \\
& & & & & & & & \\
Actual & Andrews university & 87 & 3.11 & 0.79 & 12.21 & 3.326 & $<0.01$ & 0.10 \\
Choice & Concordia university & 18 & 2.84 & 0.64 & & & & \\
& Spring Arbor university & 60 & 2.78 & 0.87 & & & & \\
& Univ. of Detroit Mercy & 165 & 3.21 & 0.85 & & & & \\
& & & & & & & & \\
\hline
\end{tabular}

Continuing with Table 12, the one-way ANOVA, $F(3,326)=20.89, p<0.01$ indicate there is a relationship between educational institution and the perceptions of expected student choice. In addition to these findings, post hoc analysis using Student Newman-Keuls test revealed Andrews university, Concordia university, and University 
of Detroit-Mercy indicated mean differences which were not significant (because $\mathrm{p}=$ 0.53 which is greater 0.01$)$. However, Spring Arbor university had a mean $(M=2.18)$ which was statistically significantly different from the rest of the institutions, and thus their students tend to disagree that financial incentives influence the perceptions of expected student choice. Concurrently, Andrews university student were more influenced by financial incentives followed by Concordia University and University of DetroitMercy.

Likewise, the one-way ANOVA, $F(3,326)=12.21, p<0.01$ reveal there may be a relationship between educational institution and the perceptions of actual student choice in higher education. In particular, Post hoc analysis using Student Newman-Keuls test indicated Spring Arbor University, Concordia University, and Andrews University were not statistically different from each other; however, University of Detroit-Mercy was statistically significantly different from Spring Arbor University, Concordia University, and Andrews University. Consequently, financial incentives were more likely to influence students from Andrews University and University of Detroit-Mercy than students from Spring Arbor University and Concordia University.

Besides these findings, the effect size of educational institutions toward the perceptions of expected student choice was 0.16 . The results imply educational institutions explain $16 \%$ of the variance in the perceptions of expected student choice. The effect size is small. Additional findings suggest the effect size of education institutions on the perceptions of actual student choice was 0.1. In this case, educational institutions accounts for $10 \%$ of the variance in the perceptions of actual student choice. For that reason, the effect size of educational institutions on the perceptions of actual 
student choice is relatively smaller to the effect size of educational institutions on the perceptions of expected student choice.

In summation, these results suggest education institution was statistically significant for both the perceptions of expected and actual student choice in selected private Michigan universities. Specifically, educational institution contributed to relatively higher perceptions of expected student choice and concurrently contributed to relatively lower perceptions of actual student choice.

Table 13 presents the relationship between ethnicity and the perceptions of student choice in selected private Michigan universities. Following are the mean scores for the perceptions of expected student choice: African Americans $(M=3.32)$, Asians ( $M$ =3.61), Latino/Hispanics $(M=3.19)$, and others $(M=3.73)$ indicating students are neutral about the impact of financial incentive toward perceptions of expected student choice. However, Caucasians $(M=2.79)$ tend to disagree about the impact of financial incentives toward the perceptions of expected student choice.

At the same time, the following results are the mean score for the perceptions of actual student choice: African Americans $(M=3.37)$, Caucasians $(M=3.01)$, Asians $(M$ =3.33), Latino/Hispanics $(M=3.36)$, and others $(M=3.42)$ revealing students are neutral about the influence of financial incentives on the perceptions of actual student choice in selected private Michigan universities.

The one-way ANOVA, $F(4,313)=6.81, p<0.01$ indicate there may be a relationship between ethnicity and the perceptions of expected student choice. Based on the means of every variable, results indicate that other ethnic students were more likely to be influenced by financial incentives followed by African American, Latino, and Asians. 
Given these findings on other ethnicities, financial incentives were less likely to influence Caucasian students.

Despite these results, the one-way ANOVA, $F(4,313)=6.81, p=0.1$ reveals there may not be any relationship between ethnicity and the perceptions of actual student choice in selected private Michigan universities.

To further analyze these findings, the effect size of ethnicity on the perceptions of expected student choice was 0.08 . These results indicate that ethnicity accounts for $8 \%$ of the variance in perceptions of expected student choice. The effect size is small.

Concurrently, the effect size of ethnicity on the perceptions of actual student choice was 0.04 showing ethnicity explains $4 \%$ of the variance on the perceptions of actual student choice. Given these findings, the effects size of ethnicity on the perceptions of actual student choice is relatively smaller than the effect size of ethnicity toward perceptions of expected student choice.

Table 13

Relationship Between Ethnicity and the Perceptions of Student Choice

\begin{tabular}{llccccccc}
\hline Variable & \multicolumn{1}{c}{ Group } & $N$ & Mean & $S D$ & $F$ & $d f$ & $p$ & $n^{2}$ \\
\hline \multirow{2}{*}{ Expected } & African & & 3.32 & 1.05 & 6.81 & 4,313 & $<0.01$ & \multirow{2}{*}{0.08} \\
Amoice & American & 103 & & & & & & \\
& Caucasian & 152 & 2.79 & 1.19 & & & & \\
& Asian & & & & & & & \\
& Latino/Hispanic & 15 & 3.61 & 0.92 & & & & \\
& Other & 14 & 3.19 & 1.19 & & & & \\
& & & & & & & & \\
Actual & African & 103 & 3.37 & 0.79 & 3.39 & 4,313 & 0.10 & 0.04 \\
Choice & American & & & & & \\
& Caucasian & 152 & 3.01 & 0.90 & & & & \\
& Asian & 34 & 3.33 & 0.76 & & & & \\
& Latino/Hispanic & 15 & 3.36 & 1.03 & & & & \\
& Other & 14 & 3.42 & 0.87 & & & & \\
\hline
\end{tabular}


In order to summarize this section, ethnicity was statistically significant and contributed a small variance to perceptions of expected student choice in private Michigan universities meanwhile ethnicity was not statistically significant to perceptions of actual student choice in selected private Michigan universities.

Finally, the degree pursued as demographic characteristic was excluded in this section of data analysis. The degree pursued indicated the large majority of students (94.4\%) were pursuing toward a bachelor degree, with $2.3 \%$ pursuing associate degrees, $0.6 \%$ working on certificates, and $2.6 \%$ missing data. Due to the fact that most of the students were pursuing bachelor degrees and the researcher could not derive a theoretical reason to combine two or more other groups for pertinent comparison, therefore the analysis of variance (ANOVA) was not reported or discussed. Furthermore, the statistical tests or corresponding tables or data summaries were not included.

\section{Research Question 2}

What is the relationship between personal income and family income and perceptions of student choice in higher education institutions among students at selected private Michigan universities?

This section comprises the descriptive statistics of participants' personal income and family income. In addition, this section also examines the relationship between personal income, family income, percentage students pay, and percentage parents pay toward the perceptions of student choice in selected private Michigan universities. In this case, categorical regression analysis was used to test the hypothesis that there is no 
significant relationship between personal income and family income and the perceptions of student choice in higher education institutions among students at selected private Michigan universities. Categorical regression analysis is a method to examine which factor among the categorical variables (personal and family income) has more influence on the dependent variable (perceptions of student choice) by optimal scaling of the categorical variables (Heshmati, Sohn, \& Kim, 2007). In categorical regression analysis, optimal scaling means of data analysis in which the measurement of characteristics of data are reflected but observed categories are granted numerical values so that the relation between observations and data analysis models can be optimized (Heshmati et al., 2007).

Table 14 provides the descriptive statistics of participants' personal income and family income. The survey also inquired about the estimated family annual household income. The responses were as follows: $13.3 \%$ earned below $\$ 30,000$ per year; $27.1 \%$ earned between $\$ 31,000$ and $\$ 60,000 ; 35.8 \%$ earned between $\$ 61,000$ and $\$ 90,000$; and $23.5 \%$ earned $\$ 91,000$ or more.

The personal income data gave the following results: Students with personal income less than $\$ 10,000$ were $92.4 \%$ of the sample, and students with personal income greater than $\$ 10,000$ were $7.5 \%$ of the sample.

The results show the proportion students paid out of pocket for tuition costs at their universities were: None out-of-pocket college cost (78.6\%), out-of-pocket costs of between $1 \%$ and $20 \%$ of the college cost (15.7\% of the sample) and $5.7 \%$ paid more than $21 \%$ of college costs. 
Table 14

Descriptive Statistics of Participants' Personal Income and Family Income

\begin{tabular}{llcr}
\hline Questions & Description & Number & Percentage \\
\hline Family Annual Income & Under $\$ 30000$ & 45 & 13.3 \\
& $\$ 31000-60000$ & 90 & 27.1 \\
& $\$ 61000-90000$ & 119 & 35.8 \\
& $\$ 91000$ or more & 78 & 23.5 \\
Personal Annual Income & Less than $\$ 10000$ & 307 & \\
& $\$ 10000$ or more & 25 & 92.4 \\
& & & 7.5 \\
Percentage Student Pay & None & 261 & 78.6 \\
& $1 \%-20 \%$ & 52 & 15.7 \\
Percentage Parents Pay & $21 \%$ or more & 19 & 5.7 \\
& None & 162 & 48.8 \\
& $1 \%-20 \%$ & 57 & 17.2 \\
& $21 \%-40 \%$ & 54 & 16.3 \\
& $41 \%$ or more & 59 & 17.7 \\
\hline
\end{tabular}

Table 14 also shows the percentage parents pay directly of their children's tuition costs at various institutions as follows: $48.8 \%$ pay nothing for the children's tuition and fees, $17.2 \%$ pay between $1 \%$ and $20 \%$ of the total tuition cost at different institutions, $16.3 \%$ pay between $21 \%$ and $40 \%$, while $17.7 \%$ pay between $41 \%$ or more for their children's education cost.

\section{Personal and Family Income on the Perceptions of Expected Student Choice}

This section examines the relationship between personal and family income toward the perceptions of student choice in private Michigan universities. The following are the results of the survey administered to students in those institutions. 
Table 15 explains the relationship between family income, personal income, percentage students pay, and percentage parents pay toward the perceptions of expected student choice. According to the results, the highest correlation $(r=0.38)$ was between personal income and the percentage students pay for tuition fees. The second highest correlation $(\mathrm{r}=0.26)$ was between family income and the percentage the parents pay for tuition. Other correlation coefficients were relatively lower compared to the two highest correlation coefficients.

Table 15

Relationship Between Family Income, Personal Income, Percentage

Students, Percentage Parents Pay, and Perceptions of Expected

Student Choice

\begin{tabular}{lcccc}
\hline Variable & 1 & 2 & 3 & 4 \\
\hline 1. Family Income & 1.00 & -0.17 & 0.1 & 0.26 \\
& & & 0 & \\
2. Personal Income & & 1.00 & 0.3 & 0.14 \\
3. Percentage Students & & 8 & \\
Pay & & 1.0 & 0.15 \\
4. Percentage Parents Pay & & 0 & 1.00 \\
\hline
\end{tabular}

Note. Correlation is significant at the 0.01 level.

Table 16 presents the correlation, coefficients, $\mathrm{p}$-values and importance of family income, personal income, percentage students pay, percentage parents pay, and the perceptions of expected student choice in private Michigan universities. A significant regression equation was found $\left(F_{(7,324)}=5.933 ; p<0.00\right)$ with $R^{2}$ of 0.114 and adjusted $R^{2}$ of 0.094 . In connection to these findings, the personal income, family income, percentage student pay and percentage parents pay accounts for $11.4 \%$ of the variance in the 
perceptions of expected student choice in selected private Michigan universities.

In addition, a measure of relative importance indicate percentage student pay and parents pay with an importance of 0.51 and 0.41 respectively, were statistically significant and contributed relatively higher to the variance of the perceptions of expected student choice. This implies that the percentage students pay is the best predictor of expected choice of college and the percentage parents pay is the second best predictor of the expected choice of college. In connection to these results, family income with an importance of 0.11 was statistically significant and contributed to the variance of the perceptions of expected student choice in selected private Michigan universities.

Despite these findings, personal income with importance of -0.03 was not statistically significant and contributed to relatively lower variance of the perceptions of expected student choice in selected private Michigan universities.

Table 16

Correlation, Coefficients, P-Values and Importance of Family Income, Personal Income, Percentage Students Pay, Percentage Parents Pay, and the Perceptions of Expected Student Choice

\begin{tabular}{|c|c|c|c|c|c|c|c|c|}
\hline \multirow{3}{*}{ Variable } & \multicolumn{2}{|c|}{$\begin{array}{l}\text { Standardized } \\
\text { Coefficients }\end{array}$} & \multicolumn{5}{|c|}{ Correlations } & \\
\hline & $B$ & $\overline{S E}$ & $F$ & Sig & Zero-Order & Partial & Part & \\
\hline & & & Import & ince & & & & \\
\hline Family Income & 0.15 & 0.06 & 6.45 & 0.00 & 0.09 & 0.15 & 0.14 & 0.11 \\
\hline Personal Income & 0.12 & 0.07 & 3.22 & 0.07 & -0.31 & 0.11 & 0.10 & -0.03 \\
\hline Percentage Student Pay & -0.24 & 0.06 & 17.5 & 0.00 & -0.24 & -0.21 & -0.20 & 0.51 \\
\hline Percentage Parents Pay & -0.22 & 0.06 & 15.9 & 0.00 & -0.22 & -0.21 & -0.21 & 0.41 \\
\hline
\end{tabular}

Note. Dependent Variable: Perceptions of Expected Student Choice; Multiple $R=0.337 ; R^{2}=0.114 ;$ Adjusted $R^{2}=0.094 ; F=5.933 ;$ Sig. $=0.00$

Personal and Family Income on the Perceptions of Actual Student Choice 
Table 17 provides correlation coefficients between family income, personal income, percentage students pay and the percentage parents pay. In particular, the highest correlation $(r=0.49)$ was between personal income and the percentage students pay for tuition fees. The second highest correlation $(r=0.20)$ was between family income with the percentage the parents pay for tuition and family income with the percentage students pay. The third highest correlation $(\mathrm{r}=0.16)$ between personal income and percentage parents pay for tuition. Finally, other correlation coefficients were relatively lower compared to the three highest correlation coefficients.

Table 17

Relationship Between Family Income, Personal Income, Percentage Students Pay, and Percentage Parents Pay

\begin{tabular}{lcccc}
\hline Variable & 1 & 2 & 3 & \multicolumn{1}{c}{4} \\
\hline 1. Family Income & 1.00 & -0.06 & - & 0.20 \\
2. Personal Income & & 1.00 & 0.08 & 0.16 \\
3. Percentage Student & & & 1.00 & 0.20 \\
Pay & & & & \\
$\begin{array}{l}\text { 4. Percentage Parents } \\
\text { Pay }\end{array}$ & & & & 1.00 \\
\hline
\end{tabular}

Table 18 presents the correlation, coefficients, p-values and importance of family income, personal income, percentage student pay, and percentage parents pay toward the perceptions of actual student choice in selected private Michigan universities. According to the results, a significant regression equation was found $\left(F_{(7,324)}=5.275 ; p<0.00\right)$ with $R^{2}$ of 0.102 and adjusted $R^{2}$ of 0.083 . In addition, family income, personal income, 
percentage student pay and percentage parents pay explains $10.2 \%$ in the variance of the perceptions of actual student choice in selected private Michigan universities.

To further explain these findings, the measure of relative importance reveal percentage student pay and percentage family pay with importance of 0.34 and 0.66 respectively, were statistically significant and thus contributed relatively higher to the variance of the perceptions of actual student choice in selected private Michigan universities. In this case, the percentage parents pay was the best predictor of the actual college choice. Furthermore, the percentage student pay was the second best predictor of the actual college choice.

On the other side, family and personal income with importance of 0.01 and -0.02 respectively, were not statistically significant and contributed to relatively lower variance on the perceptions of actual student choice in selected private Michigan universities.

Table 18

Correlation, Coefficients, P-values and Importance of Family Income, Personal Income, Percentage Student Pay, Percentage Parents Pay and Perceptions of Actual Student Choice

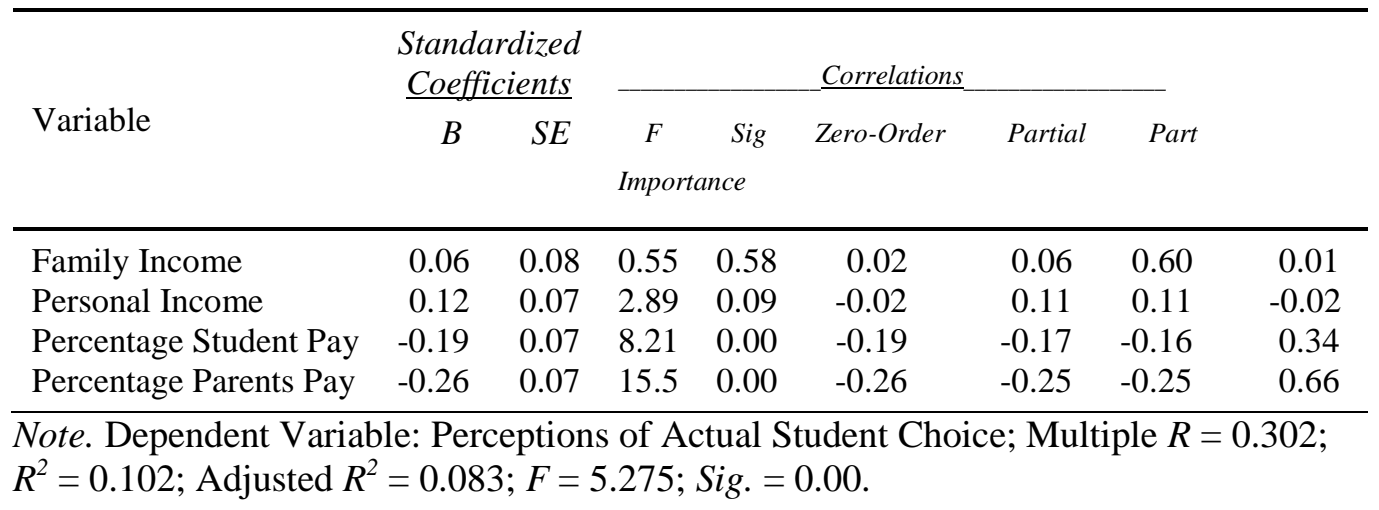

\section{Research Question 3}


Which financial incentives (student loans, tuition and fees, scholarships or financial aid, and grants) are the best predictors of perceptions of student choice of higher educational institutions among students at selected private Michigan universities?

\section{Descriptive Statistics of Financial Incentives}

Table 19 provides the descriptive statistics of financial incentives in selected private Michigan universities. The following was the total debt that students expect to accumulate by the time they graduate: No debt or 0 (16.2\%), Less than $\$ 10,000$ (20.9\%), $\$ 10,000-19,999$ (19.8\%), $\$ 20,000-34,999$ (18.9\%), and $\$ 35,000$ or more (24.2).

Table 19

Descriptive Statistics of Financial Incentives

\begin{tabular}{|c|c|c|c|}
\hline Questions & Description & $\begin{array}{r}\text { Frequenc } \\
\mathbf{y}\end{array}$ & Percentage \\
\hline Total Student Loan & $\begin{array}{l}0 \\
\text { Less than } \$ 10,000 \\
\$ 10,000-19,999 \\
\$ 20,000-34,999 \\
\$ 35,000 \text { or more }\end{array}$ & $\begin{array}{l}55 \\
71 \\
67 \\
64 \\
82\end{array}$ & $\begin{array}{l}16.2 \\
20.9 \\
19.8 \\
18.9 \\
24.2\end{array}$ \\
\hline Annual Tuition and Fees & $\begin{array}{l}\$ 0-14,999 \\
\$ 15,000-24,999 \\
\$ 25,000 \text { or more }\end{array}$ & $\begin{array}{r}93 \\
122 \\
124\end{array}$ & $\begin{array}{l}27.4 \\
36.0 \\
36.6\end{array}$ \\
\hline Total Tuition and Fees & $\begin{array}{l}\text { Less than } \$ 20,000 \\
\$ 20,000-39,999 \\
\$ 40,000-59,999 \\
\$ 60,000-79,999 \\
\$ 80,000 \text { or more } \\
\text { Missing data }\end{array}$ & $\begin{array}{r}56 \\
70 \\
80 \\
65 \\
67 \\
1\end{array}$ & $\begin{array}{r}16.5 \\
20.6 \\
23.6 \\
19.2 \\
19.8 \\
0.3\end{array}$ \\
\hline Annual Financial Aid & $\begin{array}{l}\text { Less than } \$ 10,000 \\
\$ 10,000-14,999 \\
\$ 15,000 \text { or more }\end{array}$ & $\begin{array}{l}106 \\
107 \\
126\end{array}$ & $\begin{array}{l}31.3 \\
31.6 \\
37.2\end{array}$ \\
\hline Total Financial Aid & $\begin{array}{l}\text { Less than } \$ 20,000 \\
\$ 20,000-29,999 \\
\$ 30,000-39,999 \\
\$ 40,000-49,999\end{array}$ & $\begin{array}{l}59 \\
71 \\
75 \\
62\end{array}$ & $\begin{array}{l}17.4 \\
20.9 \\
22.1 \\
18.3\end{array}$ \\
\hline
\end{tabular}




\begin{tabular}{llrr}
\hline & $\$ 50,000$ or more & 72 & 21.2 \\
Annual Grants & 0 & 40 & 11.8 \\
& Less than $\$ 10,000$ & 195 & 57.5 \\
& $\$ 10,000-14,999$ & 51 & 15.0 \\
& $\$ 15,000$ or more & 53 & 15.6 \\
Total Grants & 0 & 36 & 10.6 \\
& Less than $\$ 10,000$ & 87 & 25.7 \\
& $\$ 10,000-14,999$ & 74 & 21.8 \\
& $\$ 15,000-34,999$ & 91 & 26.8 \\
& M35,000 or more & 50 & 14.7 \\
& Missing Data & 1 & 0.3 \\
\hline
\end{tabular}

In connection to this, the percentage distribution of the annual tuition and fees that students expect to pay were: $\$ 0-14,999$ (27.4\%), $\$ 15,000-24,999$ (36.0), and $\$ 25,000$ or more $(24.2 \%)$. At the same time, the total tuition and fees students expected to pay by the time they graduate were: Less than $\$ 20,000$ (16.5\%), $\$ 20,000$ to $\$ 39,999(20.7 \%)$, $\$ 40,000$ to $\$ 59,999(23.7 \%), \$ 60,000$ to $\$ 79,999(19.2 \%), \$ 80,000$ or more $(19.8 \%)$, and missing data $(0.3 \%)$.

In Table 19 the percentage distributions of participants who expect to receive annual financial aid were: less than $\$ 10,000$ (31.3\%), \$10,000 to $\$ 14,999(31.6 \%)$, $\$ 15,000$ or more $(37.2 \%)$. In addition to this, the following expected total financial aid that students expect to receive by the time they graduate was: less than $\$ 20,000(17.4 \%)$, $\$ 20,000$ to $\$ 29,999$ (20.9\%), $\$ 30,000$ to $\$ 39,999$ (22.1\%), $\$ 40,000$ to $\$ 49,999$ (18.3\%), and $\$ 50,000$ or more $(21.2 \%)$.

Furthermore, the percentages distributions of the annual grants that students expect to receive were: $\$ 0(11.8 \%)$, less than $\$ 10,000(57.5 \%), \$ 10,000$ to $\$ 14,999$ 
$(15 \%)$, and $\$ 15,000$ or more $(15.6 \%)$. On the other hand, the total grants that students expect to receive by the time they graduate were: $\$ 0$ (10.6\%), less than $\$ 10,000(25.7 \%)$, $\$ 10,000$ to $\$ 14,999$ (21.8\%), $\$ 15,000$ to $\$ 34,999$ (26.8\%), $\$ 35,000$ or more $(14.7 \%)$, and missing data (0.3).

Financial Incentives and the Perceptions of Actual Student Choice

In order to assess the relationship between financial incentives (student loans, financial aid, tuition and fees, and grants) and the perceptions of actual student choice in selected private Michigan universities, categorical regression analysis was used and the correlation computed. The statistics displayed in Table 20 provide a correlation matrix of each of financial incentives (independent variables) and the perceptions (dependent variable) of actual student choice of higher educational institutions among students at selected private Michigan universities. In particular, the highest correlation $(r=0.47)$ was between annual financial aid and the total financial aid. The second highest correlation $(r$ $=0.38$ ) was between annual financial aid and annual grants offered to students. Finally, other correlation coefficients vary among themselves.

Table 20

Correlation Matrix of Financial Incentives Toward the Perceptions of Actual Student Choice

\begin{tabular}{lcrrrrrr}
\hline Variable & $\mathbf{1}$ & $\mathbf{2}$ & $\mathbf{3}$ & $\mathbf{4}$ & $\mathbf{5}$ & $\mathbf{6}$ & $\mathbf{7}$ \\
\hline 1. Total loans & 1.00 & -0.03 & - & 0.17 & 0.09 & 0.10 & 0.26 \\
& & & 0.05 & & & & \\
2. Annual Tuition & & 1.00 & 0.17 & - & 0.23 & 0.08 & - \\
& & & 1.00 & - & -0.01 & - & - \\
3. Total Tuition & & & 0.25 & & 0.24 & 0.14 \\
4. Annual Financial Aid & & & 1.00 & 0.47 & 0.38 & 0.14 \\
5. Total Financial Aid & & & & 1.00 & 0.22 & - \\
& & & & & & & 0.07
\end{tabular}


Note. Correlation at significant level of 0.01 .

To further analyze the results, Table 21 provides the correlations, coefficients, $p$ values and importance of the financial incentives (student loans, tuition and fees, financial aid, and grants) and the perceptions of actual student choice in selected private Michigan universities. As far as Table 21 is concerned, a significant regression equation was found $\left(F_{(13,323)}=8.466 ; p<0.00\right)$ with an $R^{2}$ of 0.254 and adjusted $R^{2}$ of 0.224 . Together, the changes in financial incentives explain $25.4 \%$ of the variance on the perceptions of actual student choice in selected private Michigan universities.

Table 21

Correlations, Coefficients, $P$ Values and Importance of the Financial Incentive Variables and the Perceptions of Actual Student Choice (CATREG)

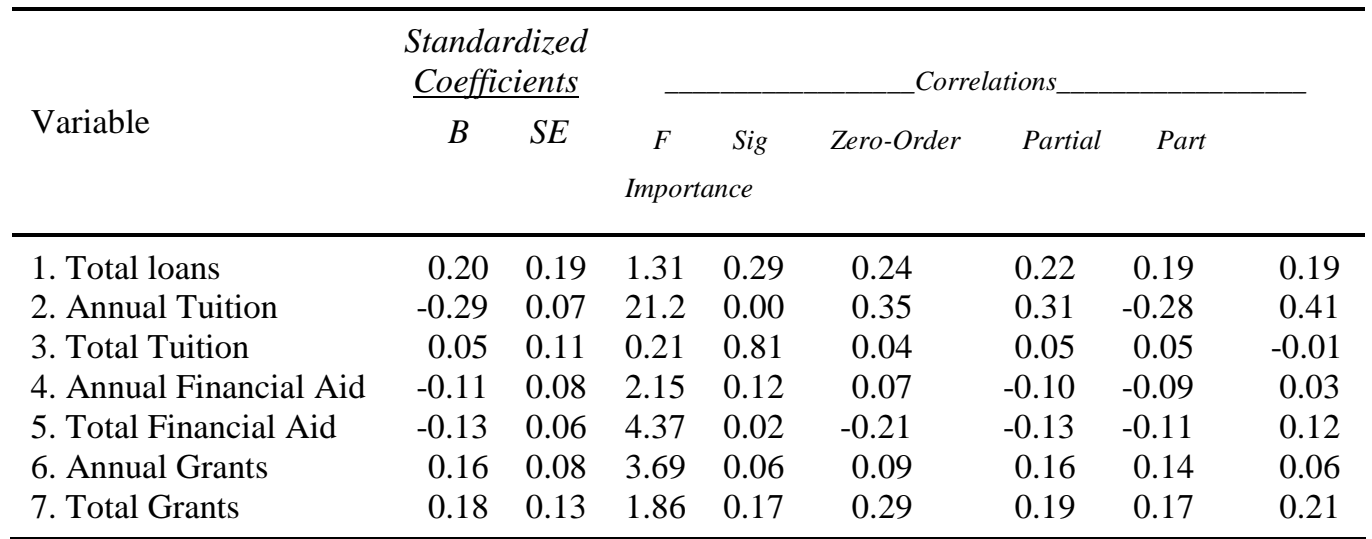

Note. Dependent Variable: Perceptions of Actual Student Choice; Multiple $R=0.504 ; R^{2}=0.254$; Adjusted $R^{2}=0.224 ; F=8.466 ;$ Sig. $=0.00$.

In connection to these findings, the measure of relative importance revealed annual tuition fees (importance $=0.41$ ) was statistically significant and thus contributed to relatively higher variance of the perceptions of actual student choice in selected private 
Michigan universities. In this case, the annual tuition was the best predictor of the perceptions of actual student choice.

At the same time, total grants (importance $=0.21$, total loans (importance $=0.19$ ) and total financial aid (importance $=0.12$ ) were not statistically significant and therefore not as important as annual tuition. In addition, annual grants (importance $=0.06$ ), annual financial aid (importance $=0.03$ ), and total tuition (importance $=0.01$ ) were not statistically significant and contributed relatively lower variance in the perceptions of actual student choice in selected private Michigan universities.

Financial Incentives and the Perceptions of Expected Student Choice

Table 22 reveals the correlation matrix of financial incentives toward the perceptions of expected student choice of higher educational institutions among students at selected private Michigan universities. Specifically, the table provides the correlations, coefficients, $p$ values and the importance of the financial incentive variables and the perceptions of expected student choice (CATREG).

Table 22

Correlation Matrix of Financial Incentives Toward Perceptions of Expected Student Choice

\begin{tabular}{lrrrrrrr}
\hline Variable & $\mathbf{1}$ & $\mathbf{2}$ & $\mathbf{3}$ & $\mathbf{4}$ & $\mathbf{5}$ & $\mathbf{6}$ & $\mathbf{7}$ \\
\hline 1. Total loans & 1.00 & & 0.00 & 0.07 & 0.26 & 0.04 & 0.07 \\
2. Annual Tuition & & 0.31 & & & & & -0.09 \\
3. Total Tuition & & 1.00 & 0.16 & 0.02 & 0.21 & -0.09 & -0.14 \\
\hline
\end{tabular}




\begin{tabular}{lllll} 
4. Annual Financial Aid & 1.00 & 0.39 & 0.24 & 0.18 \\
5. Total Financial Aid & & 1.00 & 0.06 & 0.02 \\
6. Annual Grants & & & 1.00 & 0.71 \\
7. Total Grants & & & & \\
\hline
\end{tabular}

The table indicates the highest correlation $(r=0.71)$ was between annual grants and the total grants. The second highest correlation $(r=0.26)$ was between total loans and total financial aid offered to students. Finally, other correlation coefficients were relatively lower than the two highest results and vary among themselves.

On the other hand, Table 23 provides the results about the correlations, coefficients, p-values and the importance of the financial incentives and the perceptions of expected student choice. According to the table a significant regression equation was found $\left(F_{(14,322)}=7.351 ; p<0.00\right)$ with an $R^{2}$ of 0.305 and an adjusted $R^{2}$ of 0.275 . In general, the financial incentives (student loans, tuition and fees, financial aid, and grants) explain $30.5 \%$ of the perceptions of expected student choice in selected private Michigan universities.

Furthermore, a measure of relative importance reveal total financial aid (importance $=0.30$ ) was statistically significant and contributed relatively higher to the variance of the perceptions of expected student choice. In this scenario, the total program of financial aid was the best predictor of the expected student choice. In connection to this, annual tuition and total grants (both with importance $=0.21$ ) were statistically significant and also contributed significantly to the variance of the perceptions of expected student choice. Therefore, the annual tuition and total program grants were the second best predictor of expected student choice. Finally and with less impact, total tuition and fees (importance $=0.09$ ) were statistically significant and contributed 
relatively lower to the variance of the perceptions of expected student choice. Thus, total program tuition was the least predictor of the expected student choice.

Contrary to these findings, the results indicated that financial incentives such as total loans and annual grants with $p$-value of 0.69 and 0.42 respectively were not statistical significant to the perceptions of expected student choice in selected private Michigan universities. At the same time, the results indicate total loans and annual grants with importance of 0.06 and 0.09 respectively and contributed to relatively lower variance of the perceptions of expected student choice in selected private Michigan universities.

Table 23

Correlations, Coefficients, $P$ Values and Importance of the Financial Incentives and the Perceptions of Expected Student Choice (CATREG)

\begin{tabular}{|c|c|c|c|c|c|c|c|c|}
\hline \multirow[b]{2}{*}{ Variable } & \multicolumn{2}{|c|}{$\begin{array}{c}\text { Standardized } \\
\text { Coefficients }\end{array}$} & & \multicolumn{5}{|c|}{ _Correlations_ } \\
\hline & $B$ & $S E$ & & $F$ & Sig & $\begin{array}{l}\text { der } \\
\text { tance }\end{array}$ & Partial & Part \\
\hline 1. Total loans & -0.08 & 0.13 & 0.49 & 0.69 & -0.20 & -0.09 & -0.08 & 0.06 \\
\hline 2. Annual Tuition & -0.21 & 0.06 & 13.5 & 0.00 & -0.29 & -0.23 & -0.19 & 0.21 \\
\hline 3. Total Tuition & 0.19 & 0.06 & 11.3 & 0.00 & 0.13 & 0.22 & 0.19 & 0.09 \\
\hline 4. Annual Financial Aid & -0.09 & 0.09 & 0.77 & 0.38 & -0.15 & -0.09 & -0.08 & 0.04 \\
\hline 5. Total Financial Aid & -0.26 & 0.06 & 17.5 & 0.00 & -0.36 & -0.26 & -0.23 & 0.30 \\
\hline 6. Annual Grants & 0.13 & 0.14 & 0.88 & 0.42 & 0.24 & 0.11 & 0.08 & 0.09 \\
\hline 7. Total Grants & 0.22 & 0.09 & 6.50 & 0.00 & 0.28 & 0.18 & 0.16 & 0.21 \\
\hline
\end{tabular}

Note. Dependent Variable: Perceptions of Expected Student Choice; Multiple $R=0.553 ; R^{2}=0.305$; Adjusted $R^{2}=0.275 ; F=7.351 ;$ Sig. $=0.00$.

Summary of Chapter 
This quantitative, non-experimental study has as its main purpose an examination of the relationship between financial incentives and the perceptions of student choice in selected private Michigan universities. The research findings and data analysis of the total sample of 390 participants have been presented here in Chapter 4. Discussion of these findings was organized around three research questions and three null hypotheses.

The following comprises a summary of the results about relationship between student demographic characteristics and the perceptions of student choice of higher education institutions among students at selected private Michigan universities.

1. Age appeared not to have a statistically significant relationship with either perceptions of expected or actual student choice.

2. Gender was statistically related to perceptions of expected student choice and made a small contribution to the variance in perceptions of expected student choice, although gender was not statistically related to perceptions of actual student choice.

3. Year of study was statistically related to perceptions of expected student choice and made a small contribution to the variance in perceptions of expected student choice. However, year of study was not statistically related to perceptions of actual student choice.

4. Enrollment status was statistically related to perceptions of actual student choice and made a small contribution to the variance in perceptions of actual student choice while enrollment status was not statistically related to perceptions of expected student choice.

5. Student origin was statistically related to perceptions of expected student choice and made a small contribution to the variance in perceptions of expected student 
choice; meanwhile, student origin was not statistically related to perceptions of actual student choice.

6. Degree majors were not statistically related with either perceptions of expected or actual student choice.

7. Education institutions were statistically related with either perceptions of expected or actual student choice. Specifically, education institutions made a relatively higher contribution to the variance in perceptions of expected student choice compared to the variance in perceptions of actual student choice.

8. Ethnicity was statistically related to perceptions of expected student choice and made a small contribution to the variance in perceptions of expected student choice; meanwhile ethnicity was not statistically related to perceptions of actual student choice.

9. Degree pursued was not reported or included in any data summaries due to the fact that most of the students were pursuing bachelor degrees, and the researcher could not derive a theoretical reason to combine two or more other groups for pertinent comparisons.

The following summarizes results about the relationship between the students' economic status (personal income, family incomes, percentage student pays, and percentage parents pay) and the perceptions of student choice in selected private Michigan universities.

1. Family income, percentage students pay and percentage parents pay were statistically related to perceptions of expected student choice and made a small contribution to the variance in perceptions of expected student choice. However, personal 
income was not statistically significantly related to the perceptions of expected student choice.

2. Percentage student pay and percentage parents pay were statistically related to perceptions of actual student choice and made a small contribution to the variance in perceptions of actual student choice. However, personal income and family income were not statistically related to perceptions of actual student choice.

The following is the summary results about the relationship between financial incentives and the perceptions of student choice in selected private Michigan universities.

1. Annual tuition and fees was statistically related to perceptions of actual student choice and made a small contribution to the variance in perceptions of actual student choice. However, other variables (Total loans, total tuition and fees, annual financial aid, total financial aid, annual grants and total grants) were not statistically related to perceptions of actual student choice.

2. Annual tuition and fees, total financial aid, and total grants were statistically related to perceptions of expected student choice and made a small contribution to the variance in perceptions of expected student choice. However, total loans, annual financial aid and annual grants were not statistically related to perceptions of expected student choice.

Given these results, the analysis revealed that there are mixed perceptions of financial incentives and their influence on student choice in private Michigan universities. 


\section{CHAPTER 5}

\section{SUMMARY, DISCUSSION, CONCLUSIONS, AND RECOMMENDATIONS}

\section{Introduction}

The first section of this chapter provides a summary of the purpose and

methodology of the study, which includes the research questions. The second section 
offers a summary of the research findings and discusses the implications of the study. Finally, the third section outlines possible recommendations for the students, educational institutions, and further research.

\section{Purpose of the Study}

The purpose of this study was to investigate the role of financial incentives in students' choice of an undergraduate degree granting higher education institution. In particular, the research investigated the relationship between financial incentives and student choices in selected private universities in Michigan. Suitably narrow questions were formulated; adequate and relevant instruments to collect the data necessary to address those questions were either located or developed and then the data from those instruments were statistically analyzed. In addition to this, the data were summarized and interpreted to provide a formal report of the findings with possible recommendations.

\section{Review of Literature}

To summarize the literature discussed in Chapter 2, the literature reviews examined prominent college choice models of student choice in higher education. These prominent models included Jackson (1978, 1982), Hanson and Litton (1982), Chapman (1982,1984), Hossler and Gallagher (1987), Cebrara and La Nasa (2000), and DesJardins, Ahlburg, and McCall (2006). Furthermore, the literature discussed other models like economic models, status attainment models, and information models. In addition, the literature review explored other traditional economic theories of student choice like general price theory and human capital theory. Ultimately, the literature 
provided a comprehensive and thorough explanation of the role of financial incentives play in student choices in higher education. These financial incentives such as financial aid, tuition costs, loans, and government grants have an influence on student choice in higher education. In other words, financial incentives represent a concern, and the topic can be beneficial to prospective students, university or college administrators, and higher learning institutions.

Based on thorough and extensive investigation, the literature review highlighted a need to examine the impact of demographic characteristic, economic status, and financial incentives on student choice. The study by Vossensteyn (2005) provided a strong theoretical and conceptual background for this research by examining a behavioral economic exploration of the relationship between socio-economic status, perceptions of financial incentives, and student choice. Vossensteyn developed an empirical model that captures information on student background characteristics (independent variables), students' perceptions of financial incentives (intermediary variables) and students' observed study-related choices (dependent variables).

\section{Research Questions}

The research questions for this study are listed below.

1. What is the relationship between student demographic characteristics and perceptions of student choice of higher education institutions among students at selected private Michigan universities?

2. What is the relationship between personal/family incomes and perceptions of student choice in higher education institutions among students at selected private Michigan universities? 
3. Which financial incentives (student loans, tuition and fees, scholarships or financial aid, and grants) are the best predictors of perceptions of student choice of higher education institutions among students at selected private Michigan universities?

\section{Summary of Methodology}

Specifically, the study adopted the correlational, non-experimental method that describes the relationship between two measured variables (S. Jackson, 2011). The participants were students selected from private universities in Michigan. Simple random sampling was used to choose the universities for the study. Five universities were chosen randomly for the study and the selected institutions were: Andrews University, Clearly University, Concordia University—Ann Arbor, Spring Arbor University, and University of Detroit-Mercy. The sample was 389 students generated from the total number of students in those selected institutions. The number of surveys administered to participants was doubled to 780 students to ensure an adequate sample size for estimating population parameters pertinent to the statistical analysis.

The participant recruitment process involved contacting the administrator, especially the IRB of the five institutions at the beginning of November 2014. Four out of five institutions granted IRB approval. These institutions were Andrews University, Spring Arbor University, University of Detroit—Mercy, and Concordia University—Ann Arbor. A questionnaire, the main method of data collection, was distributed to the student sample population. The questionnaire consisted of three parts. The first part collected the demographic information of the participants (students). The second part was the studentselection questionnaire. Furthermore, the questions in the third part provided information about the independent variables investigated in the study. 
The data gathered were analyzed using the SPSS statistics software. The data were tabulated and findings summarized using elaborative descriptions. Data analysis consisted of two major research areas. The first area, descriptive statistics, indicated general tendencies in the data (mean and frequency), the spread of scores (variance, standard deviation, and range), or a comparison of how one score related to another such as $z$-scores and percentiles (Creswell, 2008). The second area established the relationship between financial incentives and student choices using appropriate inferential tests.

\section{Rationale of Perceptions of Expected and Actual Student Choice}

Because the distinction between perceptions of expected and actual student choice is a critical manipulation in this study, it is crucial to state the rationale for comparing perceptions regarding expected and actual student choice. An extensive literature reveals that expectation determines perceptions. In this case, the anticipated financial incentives will determine the perceptions of expected student choice in private Michigan universities. In other words, the perceptions of expected student choice refers to anticipated financial incentives that students believe will influence their selection of a university, although perceptions of actual student choice involves the confirmed financial incentives that students believe influenced their college decision. In this case, the question motivating the present research is to what extent expected financial incentives influence the perspective of student choice. At the same time, to what extent do actual financial incentives influence the perspective of student choice. It was crucial to differentiate perceptions of expected and actual student choice due to the following reasons 
1. Perceptions of expected and actual student choice are normally different and in this case mismatches between expectations and reality are dysfunctional (McInnis, James, \& McNaught, 1995). These mismatches and dysfunctions can result in confusion of purpose or unrealistic and inappropriate expectations among prospective students (Lowe \& Cook, 2003). Thus, it seems important to examine the perceptions of expected and actual student choice.

2. The gap between prior expectations and experiences is particularly wide regarding students' predictions (Lowe \& Cook, 2003). Therefore, for this reason as well, it appears necessary to examine the perceptions of expected and actual student choice.

3. Perceptions of college choice change with time and therefore it remains appropriate to examine the change in the perceptions of expected and actual student choice in private Michigan universities. As argued by Heppner, Wampold, Owen, Thompson, and Wang (2015) survey research offers an excellent strategy to address student needs and track the changes in their perceptions over time.

\section{General Findings}

This section discusses the general findings for each of the three research questions outlined in this study.

\section{Key Findings on Question 1}

The findings show age appeared not to have a statistically significant association with perceptions of either expected or actual student choice. The results also indicated that gender was statistically related to perceptions of expected student choice and made a small contribution to the variance in perceptions of expected student choice. However, gender did not appear to be statistically related to perceptions of actual student choice. 
Meanwhile, year of study reached statistical significance and thus seemed to influence perceptions of expected student choice, although year of study did not reach significance for the perceptions of actual student choice. For perceptions of expected student choice, year of study seemed to make a small contribution to the variance in perceptions of expected student choice.

Further results indicate enrollment status appears to be statistically related to perceptions of actual student choice and made a small contribution to the variance in perceptions of actual student choice. However, enrollment status did not appear to be statistically related to perceptions of actual student choice.

To add to these results, student origin was statistically related to perceptions of expected student choice and made a small contribution to the variance in perceptions of expected student choice. Nevertheless, student origin was not statistically related to perceptions of actual student choice. At the same time, degree majors appeared not to have a statistically significant relationship with perceptions of either expected or student choice.

In the meanwhile, education institutions indicated a statistically significant relationship with perceptions of either expected or actual student choice. Concurrently, education institutions made a relatively higher contribution to the variance in perceptions of expected student choice compared to the variance in perceptions of actual student choice.

Additional results also revealed ethnicity was statistically related to perceptions of expected student choice and made a small contribution to the variance in perceptions of 
expected student choice. Nonetheless, ethnicity was not statistically related to perceptions of actual student choice.

Despite these results, degree pursued was not reported or any data summaries included due to the fact that most of the students were pursuing bachelor degrees and there was no theoretical reason to combine two or more other groups for pertinent comparison.

\section{Key Findings on Question 2}

The result analysis revealed that family income, percentage student pay, and percentage parents pay appeared to be statistically significant and therefore there may be a relationship between these factors (family income, percentage student pay, and percentage parents pay) and the perceptions of expected student choice. However, there may not be any relationship between student income and the perceptions of expected student choice.

Percentage students pay and percentage parents pay appeared to be statistically significant and consequently indicating there may be a relationship between these factors (percentage students pay and percentage parents pay) and the perceptions of actual student choice. However, the results also indicate personal income and family income appeared not to be statistically significant and therefore, there may not be any relationship between these factors (personal income and family income) and the perceptions of actual student choice.

\section{Key Findings on Question 3}

To provide a summary of the findings on the perceptions of actual student choice, annual tuition appeared to be statistically significant and therefore there may be a 
relationship between annual tuition paid by the student and the perceptions of actual student choice. At the same time, other variables (total loans, total tuition, annual financial aid, total financial aid, annual grants and total grants) appeared not to be statistically significant and subsequently there may not be any relationship between these factors and the perceptions of actual student choice.

As far as the expected perception is concerned, these financial incentives (annual tuition, total financial aid and total grants) appeared to be statistically significant and therefore there may be a relationship between these financial incentives and the perceptions of expected student choice. However, other variables like total loans, annual financial aid, annual grants appeared not to be statistically significant and therefore there may not be any relationship between these financial incentives and the perceptions of expected student choice.

\section{Discussion}

Research Question 1: What is the relationship between student demographic characteristics and perceptions of student choice of higher education institutions among students at selected private Michigan universities?

The results indicate that there is no relationship between age and the perceptions of expected or actual student choice in selected private Michigan universities. To add to these findings, the mean score of the age groups indicated that all students were neutral on the impact of financial incentives on student choice. In other words, the results indicate that students from various age groups did not make their expected or actual choice of college based on financial incentives provided. 
Likewise, the results indicate there is no relationship between degree major and the perceptions of expected and actual student choice in higher education. To substantiate these findings, the mean score of all majors indicated students were neutral about the impact of financial incentives on perceptions of actual student choice. Meanwhile, the mean score of all majors indicated students were neutral about the impact of financial incentives on perceptions of expected student choice except for education and other majors who disagreed.

These findings are contrary to the predictions for this study derived from the Vossenteyn (2005) financial perception model on student choice whereby there should be significant relationship between student demographic characteristics and perceptions of student choice of higher education institution among students at selected private Michigan universities.

However, these findings based on possible relationships between some demographic characteristics and student perceptions yield mixed results. In particular, the results indicated there is a relationship between gender and the perceptions of financial incentives toward expected student choice. According to the results, female students were more susceptible to financial incentive than their male counterparts. In other words, if financial incentives were not offered, female students would have been expected to choose another university. On the other side, male students were expected to choose a college based on other factors.

The findings are consistent with a 2007 National Research Report about the factors influencing college choice. As reported in the Research Report, female students' ranked tuition cost, financial aid, and academic reputation with higher importance than 
male students even though they also tended to value the same factors as male students. Specifically, the National Research Report statistics indicate female students (74.4\%) and male $(69.7 \%)$ ranked tuition cost with highest importance in four-year private universities. Moreover, $82.3 \%$ and $75.2 \%$ of female and male students respectively, identified financial aid as primary motivator to choose a four-year private university. Despite these finding on perceptions of expected student choice, the results revealed there was no relationship between gender and the perceptions of financial incentives toward actual student choice. These results imply, when it come to the actual choice of college, financial incentives did not influence the decision of female or male students.

Mixed results occur in other areas as well. The results indicate there is a relationship between year of study and the perceptions of expected student choice. Further analysis revealed 1 st year students were liable to be influenced by financial incentives and as time progressed to the 2nd, 3rd and 4th year, students were less likely to be influenced by financial incentives toward expected choice of college. The implications of these findings might be that financial incentives attract students at first. As cited by Zernike (2010) students were more likely to be influenced by financial incentives in choosing a college or as other studies suggest that financial incentives are initial motivators toward college choice (Sahin, 2004; Slavin, 2009; Vossensteyn, 2005). However, as time goes by, financial incentives had less impact on expected choice of college. Students then believe there are other reasons: psychosocial factors like perceived safety, positive social climate, and friends on campus (Cho, Lee, Hudley, Barry, \& Kelly, 2008), or other major factors such as (a) student characteristics like SES, level of education, aptitude, and high school performance; (b) significant persons like friends, 
parents, and high school personnel; (c) fixed college characteristics like cost, location, and availability of programs; and (d) college efforts to communicate with students (Chapman, 1981) which influence their expected choice of college.

Meanwhile there is no relationship between year of study and the perceptions of actual student choice in selected private Michigan universities. These findings might simply imply that the perceptions of actual student choice for 1 st, 2 nd, $3 \mathrm{rd}$, and 4 th year students was rather influenced by other factors (Holland and Richard reasons) such as (a) intellectual emphasis of the prospective campus, (b) practical concerns like closeness to home, (c) advice from others like high school counselors and parents, and (d) perceived social climate of the campus (as cited in Cho et al., 2008).

In similarity with the previous findings, the results indicate there is a relationship between ethnicity and the perceptions of expected student choice while there is no relationship between ethnicity and the perceptions of actual student choice in selected private Michigan universities. For the perceptions of expected student choice, additional analysis revealed Asians, African Americans, Latino or Hispanics, and other racial groups were more likely to be influenced by financial incentives while Caucasian were less likely to be affected by financial incentives. These findings are consistent with St. John, Paulsen and Carter (2005) which suggests a larger percentage of African Americans and other minorities selected higher learning institutions based on financial incentives while a lower percentage of white students chose their college based on financial incentives. In addition, the 2007 National Research Report suggested that African American and Hispanics students ranked tuition cost as important or very important in greater number than white students. The research report statistics reveal 
African American (79.2\%), Hispanics (76.2\%), and Caucasians (68.4\%) rank tuition costs as the main factor to choose a four year private university.

While findings from this research question indicated mixed results of the relationship between demographic characteristics (gender, year of study, and ethnicity) and the perceptions of student choice, these findings are somehow consistent with the literature. The literature found differences in student responsiveness due to gender, race, ethnicity, socio-economic, family background, and other demographic characteristics (Felton, 2012; Kim et al., 2009).

As far as the establishing the relationship between demographic characteristics and the perceptions of student choice, the findings reveal there is a relationship between enrollment status and the perceptions of expected and actual student choice in selected private Michigan universities. For both the perceptions of expected and actual student choice, the results analysis revealed that part-time students are more likely influenced by financial incentives than full-time students. This might be due to the fact that part-time students may have a low income compared to most full-time students whose parents' income counts (King, 2008). Consequently, part-time student make the college choices based on financial incentives while most of the full time students consider other facts as well.

In connection to these findings, the results indicate there is a relationship between educational institutions and the perceptions of expected and actual student choice in higher education. In context of this study, these selected private Michigan universities are expensive and therefore resolve to offer financial incentives which subsidize the cost of college and as a result attract students to attend their institutions. In light of the 
availability of financial incentives, the perceptions of expected and actual student choice are in favor of the private selected Michigan universities. These results are consistent with a doctoral dissertation by Schumacher (2015) entitled "What Attracts Students to a Small, Private University?" Schumacher's results suggest the aspect of affordability and scholarships were important for attending a private university.

As far as the perceptions of expected student choice, students from Andrews University were more likely influenced by financial incentives, followed by Concordia University and University of Detroit-Mercy. Despite influence of financial incentives to these institutions, Spring Arbor was less likely to be influenced by financial incentives. Concurrently for the perceptions of actual student choice, students from the University of Detroit-Mercy were presumably influenced by financial incentives, and subsequently followed by students from Andrews University and Concordia University. However, again students from Spring Arbor University did not make their college choice based on financial incentives. In this case, students from Spring Arbor University based their choice on Christian religious principles and values. As the published by the Spring Arbor University Journal that the institution continues to be completely and total committed to providing Christian education to every student (Ellis, 2015).

Moreover, the research findings and literature support the notion that demographic characteristics of the students influence the choice of college they plan to attend. At the same time, these finding were consistent with Vossenteyn (2005) who argues that there is significant relationship between student demographic characteristics and the perceptions of student choice of higher education institution.

Research Question 2: What is the relationship between personal/family incomes 
and perceptions of student choice in higher education institutions among students at selected private Michigan universities?

This section discusses the relationship between personal income and the perceptions of student choice in selected private Michigan universities. The result analysis revealed that family income, percentage student pay, and percentage parents pay were statistically significant and therefore there is relationship between these factors (family income, percentage student pay, and percentage parents pay) and the perceptions of expected student choice. Additionally, percentage student pay (importance $=0.51$ ) was the best predictor of perceptions on expected student choice. Percentage parents pay (importance $=0.51)$ was the second best predictor of the perceptions of expected student choice. Finally, family income (importance $=0.11$ ) was the third best predictor of the perceptions of expected student choice. However, there was no relationship between student income and the perceptions of expected student choice.

These findings on family income were consistent to the study presented by Delaney (1998) entitled “Parental Income and Student College Choice Process: Research Findings To Guide Recruitment Strategies.” In this study, Delaney (1998) draws comparative analysis about the impact of parent income and the student choice process. The results from this study indicate students from higher income families made college choice based on the life style, college experience, and college surroundings. Meanwhile, student from the lower income families attributed the choice of college based on cost of attendance and the opportunities for internships. In summary, the Delaney suggests there is a strong relationship between family income and the perceptions of student choice. 
In connection to these findings, percentage students pay and percentage parents pay were statistically significant and consequently indicating a relationship between these factors (percentage students pay, percentage parents pay) and the perceptions of actual student choice. Percentage parents pay (importance $=0.66$ ) is the best predictor of the perceptions of actual student choice. Percentage parents pay (importance $=0.34$ ) is the second best predictor of the perceptions of actual student choice. However, the results also indicate personal income and family income were not statistically significant and therefore, there is no relationship between these factors (personal income, family income) and the perceptions of actual student choice.

Generally, these findings contradict the literature review in this study. Previous research indicates student choice is based on socioeconomic background. For instance, a study by Heller (1997) on student price response in U.S. higher education revealed lowincome students are sensitive to changes in tuition, while higher income students are price inelastic. Heller implies that personal and family incomes have a significant influence on student choice. In close connection to this, these findings are contrary to one of the three specific predictions for this study which was derived from Vossensteyn (2005) in his writing that there should be a significant relationship between incomes (personal and family incomes) and the perceptions of student choice.

Research Question 3: Which financial incentives (student loans, tuition and fees, scholarships or financial aid, and grants) are the best predictors of perceptions of student choice of higher educational institutions among students at selected private Michigan universities?

This section provides a comprehensive discussion about the results of financial 
incentives on the perceptions of student choice in contrast with the literature review on the same subject. Initially, annual tuition was statistically significant and therefore there was a relationship between annual tuition paid by the student and the perceptions of actual student choice. Further analysis reveal annual tuition (importance $=0.41$ ) contributed relatively higher to the perceptions of actual student choice. Annual tuition paid was the best predictor of actual choice of college. These findings are consistent with a study by Hemelt and Marcotte (2011), using data gathered between 1991 and 2006 from all U.S. public 4-year colleges and universities, illustrates that tuition increased dramatically beginning in the early part of this decade. The study found that a $\$ 100$ increase in tuition and fees could cause a decline in enrollment of about $0.25 \%$ with possibly larger effects at research universities.

At the same time, other variables (total loans, total tuition, annual financial aid, total financial aid, annual grants and total grants) were not statistically significant and subsequently there was no relationship between these factors and the perceptions of actual student choice. Furthermore, total grants (importance $=0.21$ ), total loans (importance $=0.19)$ and total financial aid (importance $=0.12)$ were not statistically significant and therefore not as important as annual tuition. In general, the results are inconsistent with existing literature about the impact of financial incentives on perceptions of student choice. According to survey by CIRP published in 2009,

Students were more probable to weigh financial factors in choosing a college: 41.6 percent of students reported that the cost of their school was a very important reason for choosing it, the highest number since the survey asked the question. And 44.7 percent said that an offer of financial aid from the school had been a very important reason for attending, up from 39.4 percent in 2007. (Zernike, 2010 p.A25) 
Despite the inconsistency of literature and some findings, other specific results are consistent with the literature provided about the impact of financial incentives on perceptions of actual student choice. For instance, the results indicate there may not be any relationship between loans toward perceptions of expected and actual student choice in selected private Michigan universities. These results are consistent with some studies which have argued, with concern, the large debts students accumulate impact negatively on potential student choice in pursuing a college education (Baum \& O'Malley, 2003; Cunningham \& Santiago, 2008; King \& Bannon, 2002; King \& Frishberg, 2001; Price, 2004).

For the perceptions of expected student choice, these financial incentives (annual tuition, total financial aid, and total grants) were statistically significant and therefore there was a relationship between these financial incentives and the perceptions of expected student choice. Further analysis on annual tuition (importance $=0.21$ ), total tuition (importance $=0.09$ ), total financial aid (importance $=0.30$ ), and total grants (importance $=0.21)$ contributed a small variance toward the perceptions of expected student choice. These results are consistent with the study conducted by Gunnes, Kirkebøen, and Rønning (2011) entitled "Financial Incentives and the Study Duration in Higher Education." Gunnes et al. suggests students respond strongly to financial incentives. Furthermore, they provide an explanation that students in general are quite constrained financially and as results financial incentives is a motivation factor of student choice.

Specifically, and as results of this study, annual tuition and total tuition paid by students is one predictor of the perceptions of expected student choice. These findings are 
consistent with literature on the impact of tuition cost on the perceptions of expected student choice. Leslie and Brinkman (1987) found that students were price responsive and that, ceteris paribus, a $\$ 100$ increase in tuition and fees reduced students' participation rate (in higher education) by $0.7 \%$. Another study by Heller (1997) found an inverse but moderate relationship between tuition and enrollment rates across most studies, ranging from $-0.5 \%$ to $-120 \%$ for each $\$ 100$ tuition increase (Vossensteyn, 2005).

At the same time, and in particular, total financial aid offered to students was a significant predictor of the perceptions of expected student choice. Most of these findings were consistent with the Hurwitz (2012) which used admission and financial aid data from 30 anonymous post-secondary institutions on students planning to attend college in fall 2009 and showed a strong correlation between student choice and financial aid. In particular, the study revealed revealing that an additional $\$ 1,000$ in financial aid awarded by an institution to a prospective student, increased the probability by $1.66 \%$ that the student would choose that institution.

However, other variables like total loans, annual financial aid, annual grants were not statistically significant and therefore there was no relationship between these financial incentives and the perceptions of expected student choice. Meanwhile, these findings are contradicting the results suggested by Felton (2012) in his study of students at New York College between the ages of 19 and 24, as research revealed financial factors played a significant role in student choice.

On the specific issue of student loans, the results reveal that total loans were not a significant predictor of the perceptions of expected student choice. In this regard, some studies differ in their perceptions of the impact of loans on student choice. For instance, a 
study conducted by Long (2007) suggested that the expansion of students loans did positively impact college enrollment. In this case, Long is consistent with the results of this study; however, other studies are inconsistent with this study. For example, a doctoral dissertation by Ordu (2014) entitled "The Perception of Increased Student Loan Debt on the College Choice and Enrollment on Rural Low-Income Students, suggests that the availability of student loans was not a motivating factor toward choice of college. As a matter of fact, some students investigated in the study expressed their disdain about using student loans for their college education.

The findings also suggested that annual financial aid had no relationship with the perceptions of expected student choice and therefore the results were inconsistent with some literature. According to Avery and Hoxby (2003) typical high aptitude student chooses his college and responds to aid in a manner that is broadly consistent with rational investment. This is due to the fact that financial aid is a motivating factor for students to choose a university. However in this study, there is a possibility that students made their choice based on other factors like psychosocial factors. Psychosocial factors include safety, positive social climate, and friends on campus (Cho et al., 2008). Additionally, there is a possibility student made decisions based on Holland and Richard factors like (a) intellectual emphasis of the prospective campus, (b) practical concerns like closeness to home, (c) advice from others like high school counselors and parents, and (d) perceived social climate of the campus (as cited in Cho et al., 2008).

The results also indicated that annual grants did not influence the perceptions of expected student choice. These findings are inconsistent with the literature review. According to McDonough et al. (2007) they examined the impact of 11 selected state 
financial aid programs on students' choices. McDonough et al. (2007) concluded that there is compelling evidence to suggest that financial aid in large part mediates the final destination choices of students from lower-income and working-class families and that those choices are often made in response to pricing and financial grant availability. At the same time, studies such as Long (2008) suggest that grants have a stronger impact on student choice than loans. The implications might be those students choose their institutions based on other factors rather than financial incentives.

\section{Conclusions}

Generally, the participants' responses provided mixed results regarding the relationship between financial incentive and their perceptions of student choice in selected private Michigan universities. These responses varied based on age, gender, year of study, major of study, enrollment status, student origin, ethnicity, and institution attended. Additionally, the results indicated differences based on personal and family income as well as the amount paid out-of-pocket by students and parents for tuition. Based on the research findings of this study as substantiated by empirical data, the following conclusions emerged from the study on the demographic characteristics of the participants.

1. Age group did not influence the expected or actual choice of college.

2. Female students were more likely to expect to choose an institution based on financial incentives while male students were less likely to expect to choose an institution based on financial incentives. 
3. First-year students expected to choose a college based on financial incentives, although students were less motivated by financial incentives as they progressed to their 2nd, 3rd and 4th year.

4. Part-time students were more likely than full-time students to make their expected and actual college choice based on financial incentives.

5. International and out-of-state students were more likely to make their expected college choice based on financial incentives compared to in-state students.

6. The student major apparently had no influence on student choice.

7. Students from Andrews University, University of Detroit-Mercy, and Concordia University made their decision about the expected and actual choice of college based on financial incentives while students attending Spring Arbor did not.

8. African Americans, Asians, and Latino or Hispanics seemed to choose their expected college based on the availability of financial incentives while Caucasians seemed less likely to do so.

Based on the research findings of this study as supported by empirical data, the following conclusions were suggested concerning the role of student economic status (personal income, family income, percentage students pay, and the percentage parents pay) in the perceptions of student choices in selected private Michigan universities.

1. The family income, the percentage students pay, and the percentage parents pay for tuition will most likely determine the expected choice of college.

2. The percentage students and parents pay for tuition seems to determine the actual choice of college. 
The following were conclusions drawn about the relationship between financial incentives and the perceptions of student choice in selected private Michigan universities.

1. The annual tuition cost assumed to be paid influenced students' expected choice of college.

2. The annual tuition cost, total program cost, and total grants offered by federal and state sources influenced the actual choice of college.

\section{Recommendations for Practice}

As extensively discussed in Chapter 1, the reason for this study was derived from the specter of escalating tuition and diminishing college affordability, which pose financial barriers or hardship particularly for underprivileged student populations (Ellwood \& Kane, 2000; Kim et al., 2009); therefore, this study examined the role of financial incentives in students' matriculation choices in selected private Michigan universities. The following summarizes a few recommendations derived from these results for students, parents, institutions, governments, and all student-funding agencies.

The findings suggest that there were mixed results about the relationship between demographic characteristics and perceptions of student choice in selected private Michigan universities. On this notion, it is known that differences in demographic characteristics lead to different perceptions of student choice. Therefore, institutions should look for strategies to improve financial incentives for students from all demographic characteristics. In particular, financial incentives should be based on student variance in demographic characteristics. The following are the specific recommendations for private Michigan universities. 
1. Institutions should offer a number of financial incentives to female students, part-time students, out-of-state and international students. These financial incentives can attract potential students with those demographic characteristics.

2. Institutions should focus their financial incentives efforts on ethnic minorities such as African Americans, Asians, and Latino or Hispanics in order to attract and encourage those students and contribute to diversity goals.

3. Institutions such as Andrews University, Concordia University, and University of Detroit-Mercy should offer financial incentives, because these represent the one best and proven way to attract prospective students.

Because family income, percentage parents and students pay were important determinants for the perceptions of student choice in selected private Michigan universities, higher education institutions should devote more resources to assist students from different socioeconomic backgrounds. The following specific strategies can be implemented to attract students from different socio-economic backgrounds:

1. Institutions should ask students about their family income and determine the percentage students and parents will pay in order to offer financial incentives based on those socio-economic factors and subsequently attract prospective students.

2. Institutions should offer financial incentives that subsidize the percentage parents and students will actually pay as tuition. In turn, students will be attracted to choose those institutions. 
The findings suggest that there are mixed results about the relationship between financial incentives and perceptions of expected and actual student choice in selected private Michigan universities. These findings support the notion that financial incentives influence every student differently. Specific steps can improve the influence of financial incentives toward student choice.

1. Institutions should adjust the annual tuition cost and total tuition cost for entire degree programs in order to attract students.

2. Government agencies offer grants to subsidize the annual tuition cost or total program tuition cost so as to encourage students to choose colleges. These grants and financial aid should be based on the demographic characteristics and socio-economic factors of students.

3. The government should develop strategies to assess the financial need of the prospective student, and then provide financial assistance based on the student's demographic characteristics and socio-economic background.

In summary and based on the mixed results of the study, the most fundamental recommendation is that universities in collaboration with government agencies need to formulate a comprehensive, inclusive, and coordinated financial plan based on current financial theories to promote awareness about financial factors in student choice.

\section{Recommendations for Future Research}

There are always opportunities to improve financial incentive packages for recruiting prospective students planning to join universities. These improvements require extensive research to align institutional strategies with students' need. Recommendations for future research about financial incentives and their impact on student choice include: 
1. More research is required regarding how tuition and fees of private universities can be offset or restricted so as to be affordable for students from lower socioeconomic families.

2. Further research on financial incentive variables is crucial to establish the reasons for differences among student demographic groups and outline steps to align institutional strategies with variances in the perception of student choice. 3. Further studies should be conducted in related areas to solidify and substantiate the findings of this research. In particular, students and institutions may evaluate how these results and other findings from similar studies may be relevant to their recruiting and financial incentives strategies. 
APPENDIX A

RECRUITMENT DOCUMENTS FOR STUDENT PARTICIPANTS 


\section{Verbal Recruitment Script}

Hello - My name is NDALAHWA MASANJA, a PhD student at Andrews University I'm talking to you about my dissertation research titled "An examination of the relationship between financial incentives and perceptions of student choice at private Michigan universities". The purpose of the study is to investigate the role of financial incentives in the student choice of an undergraduate degree granting higher education institution. In particular, the research investigates the relationship between financial incentives and student choices in selected private universities in Michigan. The relevance of the study is to improve the institutional policies seeking to increase higher education enrollment at private institutions. Furthermore, the research will provide data about students from low- and middle-income families. These data will assist institutions in the development of strategies and plans to make higher education more accessible and affordable to all socio-economic classes. Furthermore, the study will provide information for the state and the federal government.

You're eligible to be in this study because you are a student who might have received financial incentives and made college choice decision based on financial factors.

If you decide to participate in this study, you must be 18 years or older. The survey is voluntary. The answers will remain anonymous. The survey will take 10 minutes. Please answer the questions to your comfort level. The survey is expected to be completed in two weeks and returned to the primary investigator by January 24, 2015. The results will be reported for the group of respondents as a whole.

Remember, this is completely voluntary. You can choose to be in the study or not. If you'd like to participate, we can go ahead and schedule a time for me to meet with you to give you more information. If you need more time to decide if you would like to participate, you may also call or email me with your decision.

Do you have any questions for me at this time?

If you have any more questions about this process or if you need to contact me about participation, I may be reached by email at ndalahwa@ andrews.edu or by phone 269944-6660.

Thank you so much.

Ndalahwa Masanja 


\section{Letter of Research Invitation}

\section{Dear Prospective Participant,}

My name is NDALAHWA MASANJA, a PhD student at Andrews University I am conducting an anonymous survey for my dissertation titled "An examination of the relationship between financial incentives and perceptions of student choice at private Michigan universities". The purpose of the study is to investigate the role of financial incentives in the student choice of an undergraduate degree granting higher education institution. In particular, the research investigates the relationship between financial incentives and student choices in selected private universities in Michigan. The relevance of the study is to improve the institutional policies seeking to increase higher education enrollment at private institutions. Furthermore, the research will provide data about students from low- and middle-income families. These data will assist institutions in the development of strategies and plans to make higher education more accessible and affordable to all socio-economic classes. Furthermore, the study will provide information for the state and the federal government.

To participate, you must be 18 years or older. The survey is voluntary and your answers will treated with strict confidentiality.

The survey will take 10 minutes. Please answer the questions to your comfort level. The survey is expected to be completed in two weeks and returned to the primary investigator by January 24, 2014. The results will be reported for the group of respondents as a whole.

If you have any more questions about this process or if you need to contact me about participation, I may be reached by email at ndalahwa@ andrews.edu or by phone 269944-6660.

Thank you for your consideration.

Sincerely,

Ndalahwa Masanja 
Recruitment Flyer

\section{VOLUNTEERS WANTED FOR A RESEARCH STUDY}

\section{Dissertation Topic: \\ An examination of the relationship between financial incentives and perceptions of student choice at private Michigan universities}

The purpose of the study is to investigate the role of financial incentives in the student choice of an undergraduate degree granting higher education institution. In particular, the research investigates the relationship between financial incentives and student choices in selected private universities in Michigan. The relevance of the study is to improve the institutional policies seeking to increase higher education enrollment at private institutions. Furthermore, the research will provide data about students from low- and middle-income families. These data will assist institutions in the development of strategies and plans to make higher education more accessible and affordable to all socioeconomic classes. Furthermore, the study will provide information for the state and the federal government.

You're eligible to be in this study because you are a student who might have received financial incentives and made college choice decision based financial factors.

If you decide to participate in this study, you must be 18 years or older. The survey is voluntary. The answers will remain anonymous. The survey will take 10 minutes. Please answer the questions to your comfort level. The survey is expected to be completed in two weeks and returned to the primary investigator by January 24, 2014. The results will be reported for the group of respondents as a whole.

Remember, this is completely voluntary. You can choose to be in the study or not. If you'd like to participate, we can go ahead and schedule a time for me to meet with you to give you more information. If you need more time to decide if you would like to participate, you may also call or email me with your decision. 
If you have any more questions about this process or if you need to contact me about participation, I may be reached by email at ndalahwa@ andrews.edu or by phone 269944-6660.

This research is conducted under the direction of the Institutional Review Board of Andrews University

\begin{tabular}{|c|c|c|c|c|c|c|c|c|c|}
\hline 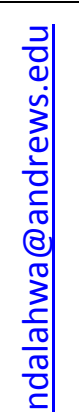 & 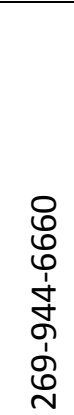 & 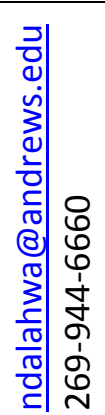 & 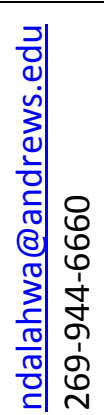 & 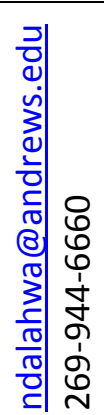 & 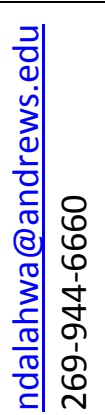 & 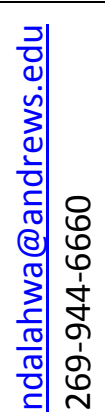 & 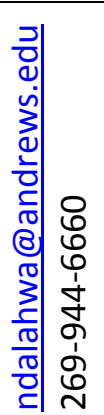 & 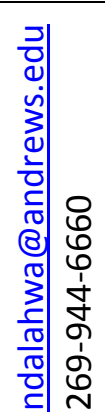 & 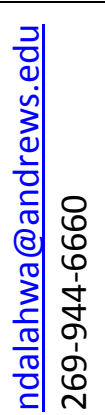 \\
\hline
\end{tabular}


APPENDIX B

SURVEY 


\section{Andrews University}

\section{INFORMED CONSENT FORM}

I am conducting a reseach study as part of my dissertation research, in partial fullment for my $\mathrm{PhD}$ in Higher Education Administration at Andrews University, Berrien Springs, Michigan. Your participation in this study is greatly a appreciated

\section{Reserach Title: AN EXAMINATION OF THE RELATIONSHIP BETWEEN FINANCIAL INCENTIVES AND PERCEPTIONS OF STUDENT CHOICE AT PRIVATE MICHIGAN UNIVERSITIES}

Purpose of Study: The purpose of the study is to investigate the role of financial incentives in the student choice of an undergraduate degree granting higher education institution. In particular, the research investigates the relationship between financial incentives and student choices in selected private universities in Michigan.

Duration of participation in study: I understand that I will be required to complete a SURVEY which will take appriximately 10 minutes of my time and the survey is expected to be completed in two weeks and returned to the the primary investigator by December 6, 2014.

Benefits: the study will improve the institutional policies seeking to increase higher education enrollment at private institutions. Furthermore, the research will provide data about students from low- and middle-income families. These data will assist institutions in the development of strategies and plans to make higher education more accessible and affordable to all socio-economic classes. Furthermore, the study will provide information for the state and the federal government.

Risks: The participants might disclose financial incentives which affected their college choice.

Data Usage and Accessibility: The data will be analyzed and interpreted in the findings of the study. The data will be accessed by the researcher, advisor, research methodologist, and the research statistician.

Voluntary Participation: I have been informed that my participation in this study is completely voluntary. I am aware that there will be no penalty or loss of benefits I'm entitled to if I decide to cancel my participation in this study. And that there will be no cost to me for particpating in this study

Confidentiality: The participant responses will be treated with strict confidentiality, I understand that my identity in this study will not be disclosed in any published document.

Contact: I am aware that I can contact the supervisor of the researcher (Jay Brand by email at brand@ andrews.edu or by phone at 269-471-3784) or Ndalahwa Masanja by 
email at ndalahwa@andrews.edu or by phone at 269-944-6660 for answers to questions related to this study.

I have read the contents of this Consent and received verbal explanations to questions I had. My questions concerning this study have been answered satisfactorily. I hereby give my voluntary consent to participate in this study. I am fully aware that if I have any additional questions I can contact Ndalahwa Masanja by email at ndalahwa@andrews.edu or by phone at 269-944-6660 or advisor Jay Brand by email at brand@andrews.edu or by phone at 269-471-3784.

$\overline{\text { Signature } \quad \text { (Subject) }} \overline{\text { Date }}$

$\overline{\text { Researcher Signature }} \overline{\text { Phone }} \overline{\text { Date }}$

Note: The next two pages (148 and 149) are copies of the Research Instrument used. 


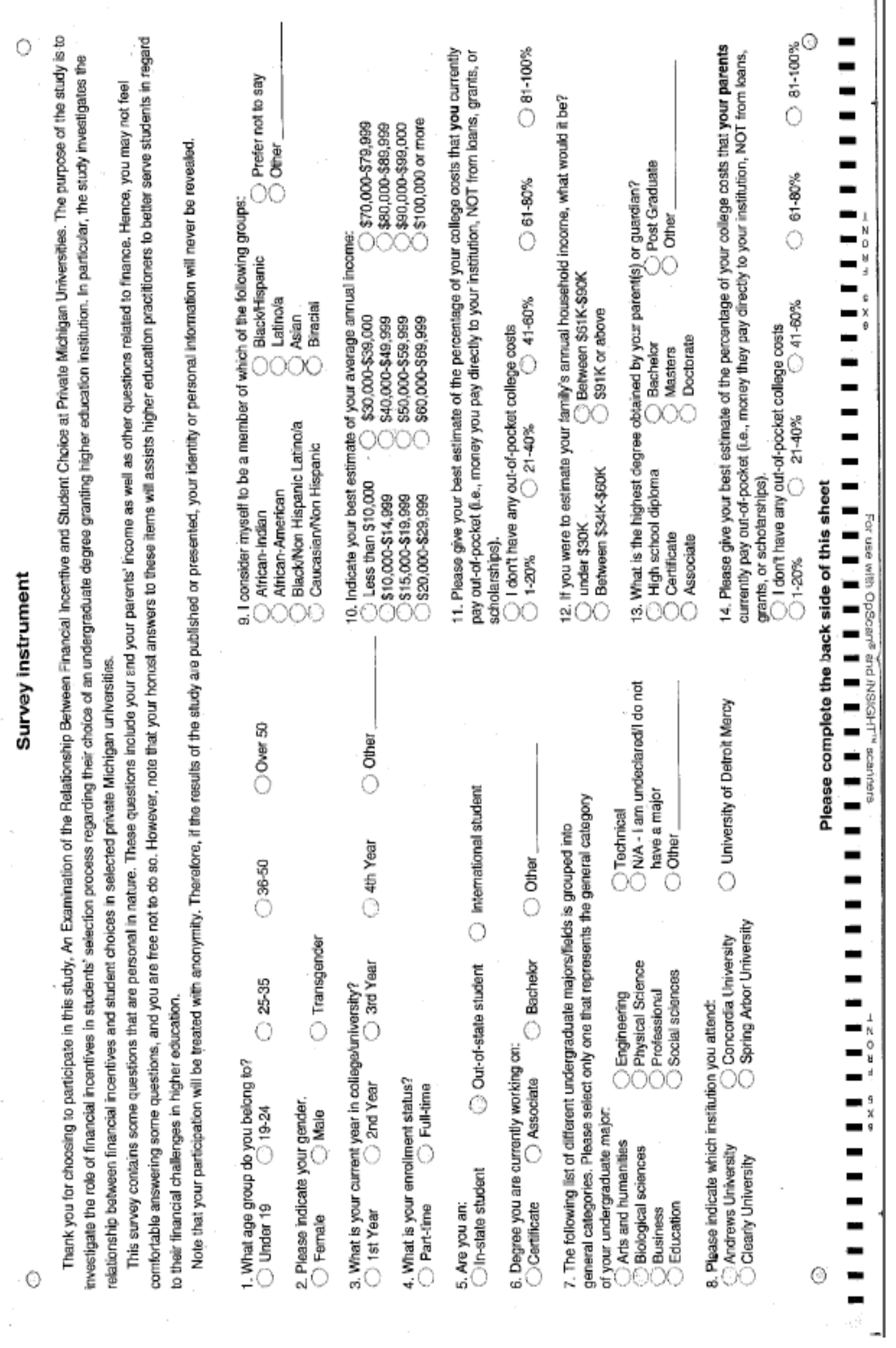




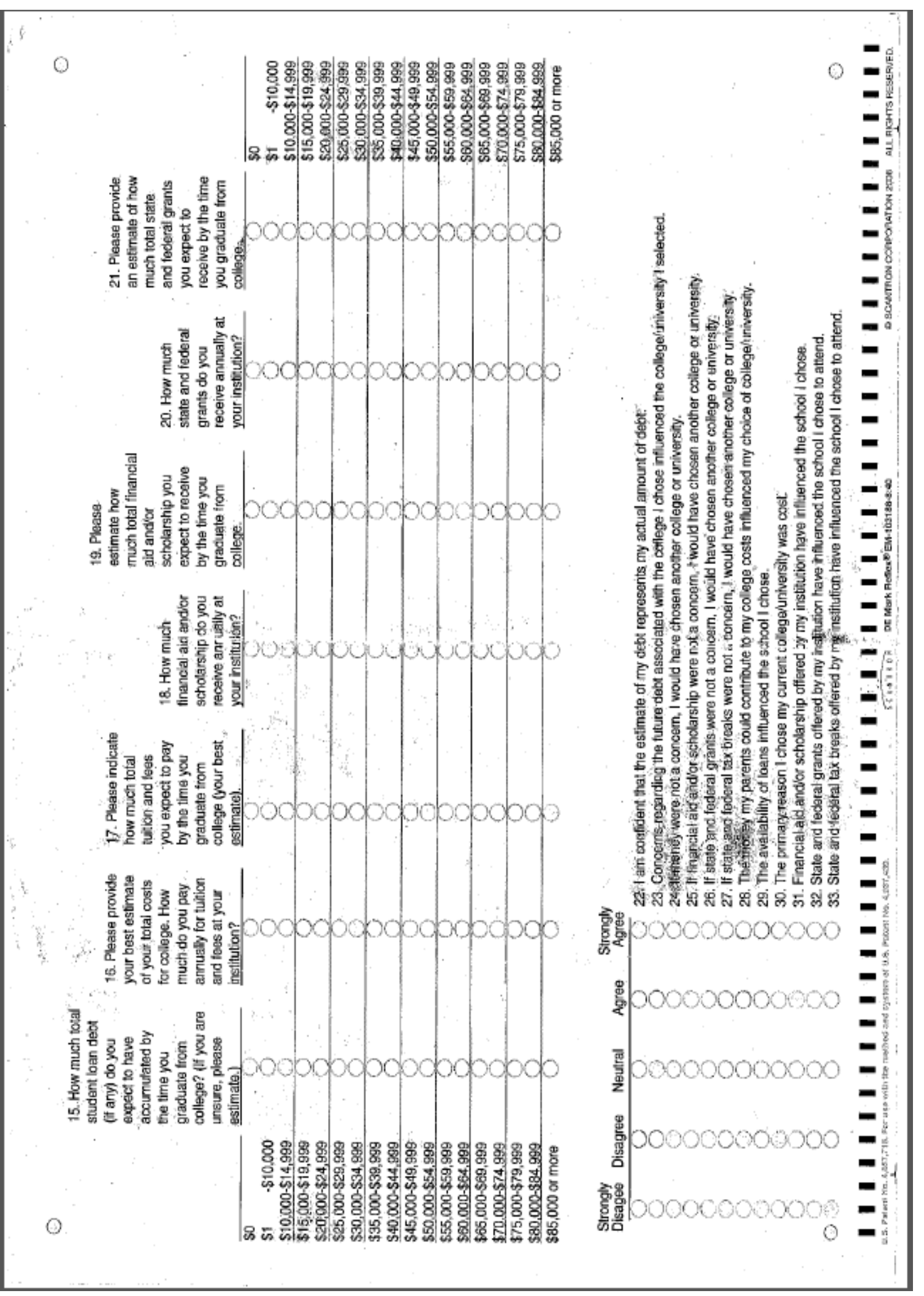


APPENDIX C

IRB APPROVAL FORMS 


\title{
Andrews University
}

\author{
Office of Research and Creative Scholarship
}

November 24, 2014

Ndalahwa Masanja

Tel: (269) 944-6660

Email: ndalahwa266@yahoo.com

\section{RE: APPLICATION FOR APPROVAL OF RESEARCH INVOLVING HUMAN SUBJECTS \\ IRB Protocol \#: 14-116 pplication Type: Original Dept.: Leadership \\ Review Category: Expedited Action Taken: Approved Advisor: Jay Brand}

Title: An examination of the relationship between financial incentives and perceptions of student choice at private Michigan universities.

This letter is to advise you that the Institutional Review Board (IRB) has reviewed and approved the pre-trial phase of your IRB application of research involving human subjects entitled: "An examination of the relationship between financial incentives and perceptions of student choice at private Michigan Universities" IRB protocol number 14-116 under Expedited category. This approval is valid until November 24, 2015. If your research is not completed by the end of this period you must apply for an extension at least four weeks prior to the expiration date. You must submit a new application for approval for the experimental (clinical) phase of the project with the 12 churches. We ask that you inform IRB whenever you complete your research. Please reference the protocol number in future correspondence regarding this study.

Any future changes made to the study design and/or consent form require prior approval from the IRB before such changes can be implemented. Please use the attached report form to request for modifications, extension and completion of your study.

While there appears to be no more than minimum risk with your study, should an incidence occur that results in a research-related adverse reaction and/or physical injury, this must be reported immediately in writing to the IRB. Any project-related physical injury must also be reported immediately to the University physician, Dr. Reichert, by calling (269) 473-2222. Please feel free to contact our office if you have questions.

Best wishes in your research.

Sincerely

$\mathrm{X}$

Mordekai Ongo

Research Integrity \& Compliance Officer

Institutional Review Board - 4150 Administration Dr Room 322 - Berrien Springs, MI 49104-0355 Tel: (269) 471-6361 Fax: (269) 471-6543 E-mail: irb@andrews.edu 


\section{IRB APPROVAL FROM CONCORDIA UNIVERSITY}

Please note that Concordia University Wisconsin/Ann Arbor IRB has taken the following action on IRBNet:

Project Title: [673470-1] AN EXAMINATION OF THE RELATIONSHIP BETWEEN FINANCIAL INCENTIVES AND PERCEPTIONS OF STUDENT CHOICE AT PRIVATE MICHIGAN UNIVERSITIES Principal Investigator: NDALAHWA MASANJA, PHD

Submission Type: New Project

Date Submitted: November 26, 2014

Action: APPROVED

Effective Date: November 30, 2014

Review Type: Administrative Review

Should you have any questions you may contact Tamara Ferry at tamara.ferry@cuw.edu.

Thank you,

The IRBNet Support Team 


\section{IRB APPROVAL FROM SPRING ARBOR UNIVERSITY}

\section{Spring Arbor University Institutional Review Board}

\section{Decision Sheet}

Project Category:

$\begin{array}{ll}\ldots \underline{X} \text { New } & \text { Assigned IRB\#: Masanja 11.18.14 } \\ \text { _ Renewal } & \text { Funding Agency, (if applicable): }\end{array}$

Project Timeline: $\quad$ Start Date: September 30, 2014 End Date:

Committee Decision:

X_ Approved as an exempted review, no further review needed unless protocol changes.

Your study would fall under category \# 2 of the Health and Human Services Code of Federal Regulations, as below. Be certain to comply with the specification given. Code all participants' data for confidentiality purposes.

2. Research will involve the use of educational tests (cognitive, diagnostic, aptitude, achievement), survey procedures, interview procedures or observation of public behavior, unless the subjects can be identified directly or through identifiers linked to the subjects and disclosure of responses could reasonably place the subjects at risk or criminal or civil liability or be damaging to the subjects' financial standing, employability or reputation.

Approved as an expedited review, no further review needed unless protocol
changes.

Approved as a full review, no further review needed unless protocol changes.

Denied due to:

Comments: Be careful about how data is handled. For example, data stored on a laptop or desktop computer must be properly coded for confidentiality. As the lead researcher 
in this project, it is your responsibility to be certain the highest level of confidentiality is maintained.

Date of Committee Decision: 11/18/14

Signature of IRB Designate: Craig D. Hayeward 
APPENDIX D

NIH CERTIFICATE OF COMPLETION 


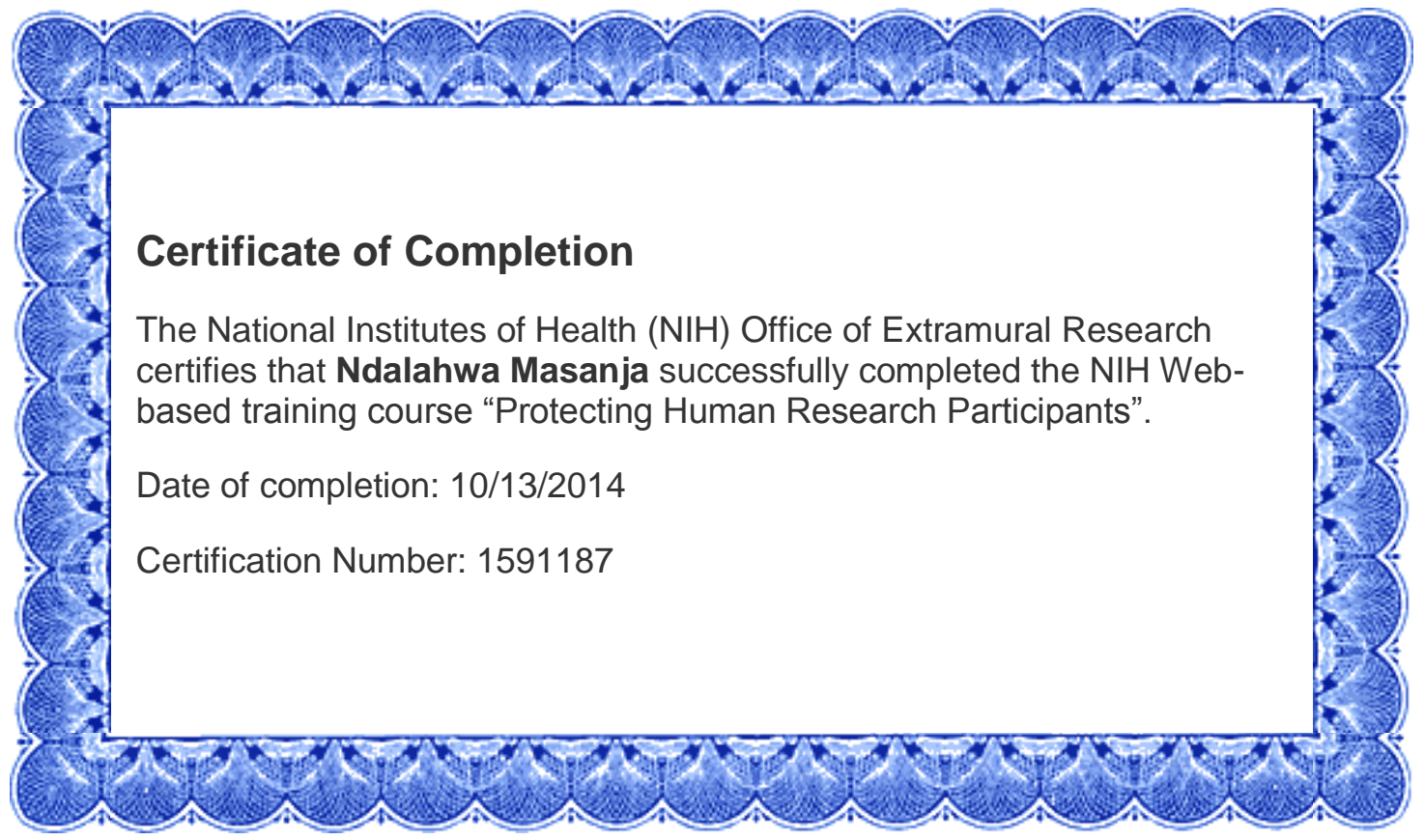




\section{REFERENCE LIST}

AASCU Policy Statement. (2012). State role in college affordability. Retrieved from aascu.org/uploadedFiles/AASCU/Content/Root/PolicyAndAdvocacy/ PublicPolicyAgenda/12ppa_stateafford.pdf

Agresti, A. (2013). Categorical data analysis (3rd ed.). Hoboken, NJ: Wiley.

Avery, C. \& Hoxby, C. M. (2003). Do and should financial aid packages affect students' college choices? (NBER Working Paper No. 9482). Retrieved from http://www .nber.org/papers/w9482.pdf

Baum, S., \& O'Malley, M. (2003). College on credit: How borrowers perceive their education: The 2002 National Student Loan Survey. Boston, MA: Nellie Mae.

Berglund, P. \& Heeringa, S. (2014). Multiple imputation of missing data using SAS. Cary, NC: SAS Institute.

Beri, G. C. (2007). Marketing research. New Delhi, India: Tata McGraw-Hill.

Binder, M., \& Ganderton, P. T. (2004). The New Mexico lottery scholarship: Does it help minority and low-income students? In D. E. Heller \& P. Marin (Eds.), State merit scholarship programs and racial inequality (pp. 103-120). Cambridge, MA: Civil Rights Project, Harvard University.

Blakenship, D. (2009). Applied research and evaluation methods in recreation. Champaign, IL: Human Kinetics.

Bouse, G. A. \& Hossler, D. (1991). Studying college choice: A progress report. Journal of College Admissions, 130, 11-16.

Briggs, S. \& Wilson, A. (2007). Which university? A study of the influence of cost and information factors on Scottish undergraduate choice. Journal of Higher Education Policy \& Management, 29(1), 57-72.

Brown, R. C., Hernandez, M. Y., Mitchell, T. D., \& Turner, C. R. (1999). Factors influencing student college choice between in-state and out-of-state students. Journal of the Indiana Student Personnel Association. Retrieved from portal.education.indiana.edu/Portals/32/FactorsInfluencing.pdf 
Burdman, P. (2005). The student debt dilemma: Debt aversion as a barrier to college access. Berkeley, CA: Project on Student Debt, Institute for College Access \& Success.

Burdman, P. (2006). Fear of borrowing: Debt aversion is a barrier to college access, especially for low-income students. National Crosstalk, 14(2), 11-12.

Burns, M. J. (2006). Factors influencing the college choice of African-American students admitted to the College of Agriculture, Food, and Natural Resources (Unpublished master's thesis). University of Missouri, Columbia.

Cabrera, A. F. \& La Nasa, S. M. (2000). Understanding the college-choice process. New Directions for Institutional Research, 107, 5-22.

Callender, C. \& Jackson, J. (2005). Does the fear of debt deter student from higher education? Journal of Social Policy, 34(4), 509-540.

Callender, C. \& Jackson, J. (2008). Does the fear of debt constrain choice of university and subject of study? Studies in Higher Education, 33(4), 405-429.

Campaigne, D. A. \& Hossler, D. (1998). How do loans affect the educational decisions of students? Access, aspirations, college choice, and persistence. In R. Fossey \& M. Bateman (Eds.), Condemning students to debt: College loans and public policy (pp. 224-226). New York, NY: Teachers College Press.

Cardinal, R. N. \& Aitken, M. R. F. (2006). ANOVA for the behavior sciences research. Mahwah, NJ: Lawrence Erlbaum Associates.

Chapman, D. W. (1981). A model of student college choice. Journal of Higher Education, 52(5), 490-505.

Chapman, R. G. (1984). Toward a theory of college choice: A model of college search and choice behavior. Edmonton, AB: University of Alberta.

Chatfield, H. K., Lee, S. J., \& Chatfield, R. E. (2012). The analysis of factors affecting choice of college: A case study of University of Nevada Las Vegas Hotel college students. Journal of Hospitality \& Tourism Education, 24(1), 26-33.

Cho, S. J., Lee, S., Hudley, C., Barry, L., \& Kelly, M. (2008). Roles of gender, race and SES in the college process among first-generation and non-first-generation students. Journal of Diversity in Higher Education, 1(2), 95-107.

Cokgezen, M. (2012). Determinants of university choice: A study on economics department in Turkey. Retrieved from papers.ssrn.com/sol3/papers.cfm? abstract_id $=2035327$ 
Cornwell, C., Mustard, D. B., \& Sridhar, D. J. (2006). The enrollment effects of meritbased financial aid: Evidence from Georgia's HOPE program. Journal of Labor Economics, 24(4), 761-786.

Creswell, J. W. (2008). Educational research: Planning, conducting, and evaluating quantitative and qualitative research. Upper Saddle River, NJ: Pearson Education.

Creswell, J. W. (2009). Research design: Qualitative, quantitative, and mixed methods approaches. Thousand Oaks, CA: Sage.

Cummingham, A. F., Wellman, J. V., Clinedinst, M. E., Merisotis, J. P. \& Carroll, C. D. (2001). Study of college costs and prices, 1988-89 to 1997-98. (Vol. 1). Washington DC: U.S. Department of Education, National Center for Education Statistics.

Cunningham, A. P. \& Santiago, D. A. (2008). Student aversion to borrowing: Who borrows and who doesn't. Retrieved from ihep.org/assets/files/publications/s-z/ studentaversiontoborrowing.pdf

Curtis, R. (2012). Factors influencing the college choice of music majors attending a four-year institution: A comparative study (Unpublished doctoral dissertation). Lindenwood University, St. Charles, MO.

Delaney, A. M. (1998). Parental income and students' college choice process: Research findings to guide recruitment strategies. Retrieved from http://cms-content .bates.edu/prebuilt/delaney.pdf

DesJardins, S. L., Ahlburg, D. A., \& McCall, B. P. (1999). An event history model of student departure. Economics of Education Review, 18, 375-390.

DesJardins, S. L., Ahlburg, D. A., \& McCall, B. P. (2006). An integrated model of applications, admissions, enrollment, and financial aid. Journal of Higher Education, 77(3), 381-429.

Dixon, P. N. \& Martin, N. K. (1991). Measuring factors that influence college choice. NASPA Journal, 29(1), 31-36.

Doolan, K. (2009). Weight of costs: The financial aspect of student course choices and study: Experiences in a Croatian higher education settling. Institute for Social Research, 17(2), 239-256.

Doyle, W. R. (2009). Playing the numbers: Hard choices. Change, 41(6), 50-54.

Doyle, W. R. (2012). The politics of public college tuition and state financial aid. Journal of Higher Education, 83(3), 617-647. 
Dynarski, S. (2002). The behavioral and distributional implications of subsidies for college. American Economic Review, 92(2), 279-285.

Dynarski, S. M. (2003). Does aid matter? Measuring the effects of student aid on college attendance and completion. American Economic Review, 93(1), 279-288.

Dynarski, S. M. (2004). The new merit aid. In C. M. Hoxby (Ed.), College choices: The economics of where to go, when to go, and how to pay for it (pp. 63-97). Chicago, IL: University of Chicago Press.

ECMC Group Foundation. (2003). Cultural barriers to incurring debt: An exploration of borrowing and impact on access to postsecondary education. Santa Fe, NM: Caliber Associates.

Ellis, B. (2015). Rooted in tradition. Spring Arbor University publication journal, 39(1), 2.

Ellwood, D. \& Kane, T. J. (2000). Who is getting a college education: Family background and the growing gaps in enrollment. In S. Danziger \& J. Waldfogel (Eds.), Securing the future: Investing in children from birth to college (pp. 283307). New York, NY: Russell Sage Foundation.

Features, B. (2014). An A to Z list of Michigan colleges and universities. Retrieved from mlive.com/education/index.ssf/2011/09/an_a_to_z_list_of_michigan_col.html

Felton, J. D. (2012). College choice: An examination of projected student indebtedness (Unpublished doctoral dissertation). Johnson \& Wales University, North Miami, FL.

Field, A. P. (2005). Discovering statistics using SPSS. London, England: Sage.

Field, E. (2007). Educational debt burden and career choice: Evidence from a financial aid experiment at NYU Law School. Working Paper, No. 469. Cambridge, MA: Harvard University.

Fiorini, M. (2012). Fostering educational enrollment through subsidies: The issue of timing. Journal of Applied Econometrics, 27(5), 741-772.

Fitch, W. L. (2009). A study of relationship between ethical decision-making, leadership style, and demographics in Pennsylvania superintendents (Doctoral dissertation). Available from ProQuest Dissertations and Theses database. (UMI No. 3369974)

Galotti, K. M. \& Mark, M. C. (1994). How do high school students structure an important life decision? A short-term longitudinal study of the college decision-making process. Research in Higher Education, 35(5), 589-607.

Gelman, A. \& Hill, J. (2006). Data analysis using regression and multilevel/hierarchical models. New York, NY: Cambridge University Press. 
Gertner, J. (2006). Forgive us our student debts. New York Times. Retrieved from nytimes.com/2006/06/11/magazine/11loans.html?pagewanted $=1 \& \_r=1$

Gravetter, F. \& Forzano, L. A. (2012). Research methods for the behavioral sciences. Stamford, CT: Cengage Learning.

Gunnes, T., Kirkebøen, L. J., \& Rønning, M. (2011). Financial incentives and study duration in higher education. Retrieved from ntnu.edu/documents/140152/ 38281869/6_fininc.pdf/81d72afc-fa31-4fc1-9417-b3b3e82d5b67

Hall, J. C., Dunlap, J. C., Friedmann, T., \& Heyningen, V. V. (2008). Advances in genetics. San Diego, CA: Elsevier.

Hanson, K., \& Litten, L. (1982). Mapping the road to academia: A review of research on women, men, and the college selection process. In P. Perum (Ed.), The undergraduate woman: Issues in educational equity (pp. 413-414). Lexington, MA: Heath.

Hearn, J. (1984). The relative roles of academic ascribed and socioeconomic characteristics in college destinations. Sociology of Education, 57, 22-30.

Heller, D. E. (1997). Student price response in higher education. Journal of Higher Education, 68(6), 624-659.

Heller, D. E. (2001). Debt and decisions: Student loans and their relationship to graduate school and career choice. Retrieved from luminafoundation.org/ publications/debtsdecisions.pdf

Heller, D. E. (2013). Does federal financial aid drive up college prices? American council on education. Retrieved from http://www.acenet.edu/news-room/Documents/ Heller-Monograph.pdf

Hemelt, S. W. \& Marcotte, D. E. (2011). The impact of tuition increases on enrollment at public colleges and universities. Educational Evaluation \& Policy Analysis, 33(4), 435-457.

Heppner, P. P., Wampold, B. E., Owen, J., Thompson, M. N., \& Wang, K. T. (2015). Research design counseling. (4th ed.). Boston, MA: Cengage learning.

Heshmati, A., Sohn, Y. B., \& Kim, Y. R. (2007). Commercialization and transfer of techonology:major country case studies. New York, NY: Nova Science Publishers.

Hicks, B. C. (2013). The effect of tuition subsidies on student choices. Retrieved from: stanford.edu/ bcardiff/tuition_college_choice.pdf 
Hossler, D., Braxton, J. M., \& Coopersmith, G. (1989). Understanding student college choice. In J. C. Smart (Ed.), Higher education: Handbook of theory and research, Vol. 5 (pp. 231-288). New York, NY: Agathon Press.

Hossler, D. \& Gallagher, K. S. (1987). Student college choice: A three-phase model and the implications for policymakers. College \& University, 62(3), 207-221.

Hossler, D. \& Palmer, D. (2008). Why understand research on college choice? Retrieved from nacacnet.org/research/PublicationsResources/Marketplace/ Documents/chap3forcd.pdf

Hossler, D., Schmit, J., \& Vesper, N. (1999). Going to college: How social, economic, and educational factors influence the decisions students make. Baltimore, MD: Johns Hopkins University Press.

Hurwitz, M. (2012). How does institutional grant aid impact college choice? Retrieved from advocacy.collegeboard.org/sites/default/files/11b_4821_GrantAid_ ResearchBrief_WEB_120607.pdf

Jackson, G. (1978). Financial aid and student enrollment. Journal of Higher Education, $49,548-574$.

Jackson, G. (1982). Public efficiency and private choice in higher education. Educational Evaluation \& Policy Analysis, 4, 237-247.

Jackson, S. L. (2011). Research methods and statistics: A critical thinking approach. Belmont, CA: Wadsworth.

Jaschik, S. (2008). In the dark on aid changes. Inside Higher Ed. Retrieved from insidehighered.com/news/2008/01/31/poll

Kaba, A. J. (2013). Profile of contributors to the American economic review, 2010 : Human capital theory, gender and race. Irvine, CA: Scientific Research Publishing.

Kaltenbaugh, L. S., St. John, E. P., \& Starkey, J. B. (1999). What difference does tuition make? Analysis of ethnic differences in persistence. Journal of Student Financial Aid, 29(2), 21-31.

Kane, T. (2004). Evaluating the impact of the DC Tuition Assistance Grant Program. NBER Working Paper, No. 10658. Washington, DC: National Bureau of Economic Research.

Kim, J. (2012). Exploring the relationship between state financial aid policy and postsecondary enrollment choices: A focus on income and race differences. Research in Higher Education, 53, 123-151. 
Kim, J., DesJardins, S. L., \& McCall, B. P. (2009). Exploring the effect of student expectations about financial aid on postsecondary choice: A focus on income and racial/ethnic differences. Research in Higher Education, 50, 741-774.

King, J. E. (2002). Crucial choices: How students' financial decisions affect their academic success. Retrieved from armasineducation.com/documents/ crucialchoices.pdf

King, J. E. (2008). Financing college education: How it works, how it's changing. Westport, CT: American Council on Education and the Oryx Press.

King, T. \& Bannon, E. (2002). The burden of borrowing: A report on the rising rates of student loan debt. Washington, DC: State PIRG's Higher Education Project.

King, T. \& Frishberg, I. (2001). Big loans, bigger problems: A report on the sticker shock of student loans. Washington, DC: State PIRG's Higher Education Project.

Kinzie, J., Palmer, M., Hayek, J., Hossler, D., Jacob, S. A., \& Cummings, H. (2004). Fifty years of college choice: Social, political, and institutional influences on the decision-making process. New Agenda Series, 5(3), 1-63.

Krishnaswamy, K. N., Sivakumar, A. I., \& Mathirajan, M. (2006). Management research methodology: Integration of principles. Methods and techniques. Delhi, India: Dorling Kindersley (India) Pvt.

Leach, R. A. (2004). The chiropractic theories: A textbook of scientific research (4th ed.). Philadelphia, PA: Lippincott, Williams, \& Wilkins.

Lee, S. J. \& Chatfield, H. K. (2011). The analysis of factors affecting choice of college: A case study of UNLV Hotel college students. Retrieved from scholarworks .umass.edu/cgi/viewcontent.cgi?article=1288\&context=gradconf_hospitality

Leon, A. C., Davis, L. L., \& Kraemer, H. C. (2011). The role and interpretation of pilot studies in clinical research. Journal of Psychiatric Research, 45(5), 626-629.

Leslie, L. L. \& Brinkman, P. T. (1987). The economic value of higher education. Journal of Higher Education, 58(2), 181-204.

Liberto, J. (2012). Obama's college tuition plans face tough fight. Retrieved from money.cnn.com/2012/09/17/pf/college/college-costs-bama/index.html? $\mathrm{iid}=$ H_PF_News

Lillis, M. P. \& Tian, R. G. (2008, Summer). The impact of cost on college choice: Beyond the means of the economically disadvantaged. Journal of College Admission, 200, 4-14. 
Long, B. T. (2007). Do loans increase college access and choice? Examing the introduction of universal student loans. Retrieved from http://files.eric.ed.gov/ fulltext/ED505608.pdf

Long, B. T. (2008). What is known about the impact of financial aid? Implications for policy. Retrieved from postsecondaryresearch.org/i/a/document/6963 _LongFinAid.pdf

Lowe, H. \& Cook, A. (2003). Mind the gap: Are students prepared for higher education? Journal of Further and Higher Education, 27(1), 53-76.

Marshall, A. (1920), Principles of economics. London, England: Macmillan.

McDonough, P. M., Calderone, S. M., \& Purdy, W. C. (2007). State grant aid and its effects on student college choices. Retrieved from wiche.edu/info/publications/ state_grant_aid_choice.pdf

McInnis, C., James, R., \& McNaught, C. (1995). First year on campus: Diversity in the initial experiences of Australian undergraduates. Melbourne, Australia: University of Melbourne Centre for the Study of Higher Education.

McPherson, M. S. \& Schapiro, M. O. (1991). Keeping college affordable: Government and educational opportunity. Washington, DC: Brookings.

Mehboob, F., Shah, S. M. M., \& Bhutto, N. A. (2012). Factors influencing student's enrollment decisions in selections of higher education. Interdisciplinary Journal of Contemporary Research in Business, 4(5), 558-568.

Menon, M. E. (2004). Information search as an indication of rationality in student choice of higher education. Education Economics, 12(3), 267-283.

Meyers, L. S., Gamst, G., \& Guarino, A. J. (2013). Applied multivariate research: Design and interpretation. Thousand Oaks, CA: Sage Publications.

Millett, C. M. (2003). How undergraduate loan debt affects application and enrollment in graduate or first professional school. Journal of Higher Education, 74(4), 386427. Retrieved from muse.jhu.edu/journals/journal_of_higher_education/ v074/74.4millett.html

Monaghan, P. (2001). Researchers note correlation between students' race and willingness to take on college loans. Chronicle of Higher Education. Retrieved from chronicle.com/daily/2001/04/ 2001041303n.htm

Moore, J., McNeill, J., \& Halliday, S. (2011). Worth the price? Some findings from young people on attitudes to increases in university tuition fees. Widening Participation \& Lifelong Learning, 13(1), 57-70. 
Muijs, D. (2010). Doing quantitative research in education with SPSS. Thousand Oaks, CA: Sage.

Mullins, E. E. (2010). Debt and decision-making: The impact of student loan debt on undergraduates' choice of major, vocation, and post-college plans (Unpublished doctoral dissertation). University of South Carolina, Columbia.

National Center for Education Statistics. (2011). IPEDS data feedback report: Anonymous northeastern public college. Retrieved from nces.ed.gov/ipeds/ DataCenter/DfrFiles/IPEDSDFR2011_114433.pdf

National Research Report (2007). Why did they enroll? The factors influencing college choice. Retrieved from https://www.ruffalonl.com/documents/shared/Papers_and _Research/2007/Why\%20Did\%20They\%20Enroll.pdf

Pallant, J. (2013). SPSS survival manual. Berkshire, UK: Open University Press.

Paulsen, M. B. \& St. John, E. P. (1997). The financial nexus between college choice and persistence. New Directions for Institutional Research, 1997(95), 65-82.

Perna, L. (2008). Understanding high school students' willingness to borrow to pay college prices. Research in High Education, 49, 589-606.

Price, D. V. (2004). Education debt burden among student borrowers: An analysis of the baccalaureate and beyond panel: 1997 follow-up. Research in Higher Education, 45(7), 701-737.

Ong, A. D. \& Weiss, D. J. (2000). The impact of anonymity of responses to sensitive questions. Journal of Applied Social Psychology, 30(8), 1691-1708.

Ordu, C. (2014). The perceptions of increased student loan debt on the college choice and enrollment of rural low-income students. (Unpublished doctoral dissertation), Clemson University, South Carolina.

Robinson, J. A. \& Cheston, D. (2012). Pell grant: Where does all the money go? Retrieved from johnlocke.org/acrobat/pope_articles/pell_report_final.pdf

Rubinfeld, D. L. (1994). Reference guide on multiple regression. Retrieved from fjc.gov/public/pdf.nsf/lookup/sciman03.pdf/\$file/sciman03.pdf

Sahin, A. (2004). The incentive effects of higher education subsidies on student effort. Staff report No. 192. New York, NY: Federal Research Bank. Retrieved from newyorkfed.org/research/staff_reports/sr192.pdf

Samuelson, P. A. (1976). Economics (10th ed.). New York, NY: The McGraw-Hill Book Companies.

Samuelson, P. A. (1980). Economics. New York, NY: McGraw-Hill. 
Sanford, N. (1966). Self and society: Social change and individual development. New York, NY: Atherton Press.

Sauder, V. (2008). Marketing Seventh-day Adventist higher education: College-choice motivators and barriers (Unpublished doctoral dissertation). Andrews University, Berrien Springs, MI.

Schumacher, R. M. (2015). What attracts students to a small, private university? (Unpublished doctoral dissertation). Bowling Green State University. Bowling Green, $\mathrm{OH}$.

Schwester, R. W. (2015). Teaching research methods in public administration. Hershey, PA: IGI Global.

Slavin, R. E. (2009). Can financial incentives enhance educational outcomes? Evidence from intentional experiments. Retrieved from bestevidence.org/word/finan_inc _feb_4_2009.pdf

Smith, A. (1776). The Wealth of Nations. Retrieved from https://books.google.com/ books?id=N11oAwAAQBAJ\&pg=PT25\&dq=adam+smith+wealth+of+nations\&h $\mathrm{l}=\mathrm{en} \& \mathrm{sa}=\mathrm{X} \& \mathrm{ved}=0 \mathrm{ahUKEwj750-Tp \_ XLAhXr74MKHYQYBegQ6AEIOjAD}$ $\# \mathrm{v}=$ onepage \&q=adam\%20smith $\% 20$ wealth\%20of\%20nations\&f=false

Somers, P., Bauer, J., Haines, K., Keene, B., Pfeiffer, M., . . \& Sparks, B. (2006). Toward a theory of choice for community college students. College Journal of Research \& Practice, 30, 53-67.

Srivastava, U. K., Shenoy, G. V., \& Sharma, S. C. (1989). Quantitative techniques for decision making. New Delhi, India: New Age.

St. John, E. P. (1991). What really influences minority attendance? Sequential analyses of the high school and beyond: Sophomore cohort. Research in Higher Education, $32,141-158$.

St. John, E. P. \& Asker, E. H. (2003). Refinancing the college dream: Access, equal opportunity, and justice. Baltimore, MD: John Hopkins University Press.

St. John, E. P., Paulsen, M., \& Carter, D. (2005). Diversity, college costs, and postsecondary opportunity: An examination of the financial nexus between college choice and persistence for African Americans and Whites. Journal of Higher Education, 76(5), 545-569.

St. John, E. P. \& Starkey, J. B. (1995). An alternative to net price: Assessing the influence of prices and subsidies on within-year persistence. Journal of Higher Education, 66, 156-186. 
Stark, R. \& Scholder, T. (2011). What drives student choices? Applying behavioral economics to higher education. Retrieved from maguireassoc.com/ wp-content/ uploads/2011/07/White-Paper-What-Drives-Student-Choices-June-2011.pdf

Starter, M. (2009). The impact of financial aid on college GPA at three flagship public institutions. American Educational Research Journal, 46(3), 782-815.

Tatar, E. \& Oktay, M. (2006). Search, choice and persistence for higher education: A case study in Turkey. Eurasia Journal of Mathematics, Science, \& Technology Education, 2(2), 115-129.

Taylor, B., Kermode, S., \& Roberts, K. (2006). Research in nursing and health care: Evidence for practice. Australia: Cengage Learning Australia.

Taylor. M. C. (2010). Academic bankruptcy. New York Times. Retrieved from nytimes.com/2010/08/15/opinion/15taylor.html?_r $=0$

Texeira, P. N., Johnstone, D. B., Rose, M. J., \& Vossenteijn, J. J. (2006). Cost-sharing and accessibility in higher education: A fairer deal? Dordrecht, Netherlands: Springer.

Thomas, R. M. (2003). Blending qualitative and quantitative research methods in theses and dissertations. Thousand Oaks, CA: Corwin Press.

Tierney, M. L. (1983). Student college choice sets: Toward an empirical characterization. Research in Higher Education, 18(3), 271-284.

Usher, A. (2006). Grants for students: Canadian education report series. Retrieved from educationalpolicy.org/pdf/GrantsForStudents.pdf

Vossensteyn, J. J. H. (2005). Perceptions of student price responsiveness: A behavioral economics exploration of the relationship between socio-economic status, perceptions of financial incentives, and student choice (Unpublished doctoral dissertation). University of Twente, Enschede, Netherlands.

Wilson, J. (2010). Essentials of business research. Thousand Oaks, CA: Sage.

Wyer, R. S. (2006). The models of information processing: An evaluation and conceptual integration. Psychological Inquiry, 17(3), 185-255.

Yamane, T. (1967). Statistics: An introductory analysis (2nd ed.). New York, NY: Harper \& Row.

Yang, P. (2011). The impact of financial aid on learning, career decisions, and employment. Chinese Education \& Society, 44(1), 27-57. 
Zernike, K. (2010). Annual poll of freshmen shows effect of recession. New York Times. Retrieved from nytimes.com/2010/01/21/education/21college.html? scp=1\&sq=Annual-Poll-of-Freshmen-Shows-Effect-of-Recession-\&st=cse

Zhang, L. (2010). Effects of college educational debt on graduate school attendance and early career and life choices. Working Paper, No. 942793. Shanghai, China: Clemson University.

Zlomek, E. (2012). The wealth effect and college choice. Retrieved from businessweek .com/articles/2012-08-03/the-wealth-effect-and-college-choice 
VITA

NDALAHWA M. MASANJA

ndalahwa@andrews.edu

\section{EDUCATION:}

Andrews University- Berrien Springs, Michigan

$\mathrm{PhD}$ in Higher Education Administration (Aug 2009- May 2016)

Dissertation: The Relationship between Financial Incentives and Perception of Student Choice at Private Michigan Universities.

University of Eastern Africa Baraton- Eldoret, Kenya

MBA in Accounting (July 2007-June 2009)

Thesis: The Determinants of the Performance of Accountants in Educational Institutions in Tanzania.

BBA in Accounting and Management (July 2002-June 2007)

\section{WORK EXPERIENCE:}

Library Attendant- James White Library at Andrews University (Jan 2014November 2014)

Assistant- Meier Hall at Andrews University (August 2009- January 2014)

Customer Service Associate- Andrews University Press (June-August 2010)

Accountant and Assistant Business Manager- Mukidoma School Company Ltd Arusha, Tanzania (June 2007- July 2009).

Teacher of Economics- Mukidoma High School, Arusha, Tanzania (Jan-June 2009)

\section{PROFESSIONAL PRESENTATIONS:}

Curriculum International Perspective Presentation in the Department of Curriculum at Andrews University. (October 2010).

Topic: Internationalization of the University Curricula in Japan.

\section{VOLUNTEER EXPERIENCE:}

Treasurer- Tanzanian Club at Andrews University (February 2011-November 2013)

Treasurer- South Bend All Nation Fellowship, South Bend Indiana (July 2010November 2011). 